\title{
Treatment of Diabetic Retinopathy with Adipose-Derived Stem Cells
}

\author{
Thomas Allan Mendel \\ Woodbridge, VA \\ Bachelor of Science, Duke University, 2006
}

A dissertation presented to the Graduate Faculty of the University of Virginia for the Candidacy for the Degree of

Doctor of Philosophy

Department of Pathology

University of Virginia

April, 2014 
Doctoral Thesis Committee Signatures

\author{
Dennis Templeton, MD PhD \\ Department of Pathology \\ Chair of Thesis Committee
}

Adam Goldfarb, MD

Department of Pathology

Peter Netland, MD PhD

Department of Ophthalmology

Shayn Peirce-Cottler, $\mathrm{PhD}$

Department of Biomedical Engineering

Paul Yates, MD PhD

Department of Ophthalmology

Mentor 


\section{Forward}

Much has been made of the promise of regenerative medicine. Vast funding resources and countless hours of study have been dedicated over decades towards curing some of the most devastating illnesses of the human condition. The prospect of stem cell therapy is enticing: harness the body's own regenerative capacity to cure itself, utilizing the cellular and molecular wound-healing machinery honed by millions of years of evolution. We are just beginning to grasp the potential of stem cell therapeutics. Some of that potential is embodied within these pages. To harness stem cells expertly, richer understanding of the ensemble cast of cells and molecules is mandated. In that effort, I submit this thesis as a humble step towards a regenerative therapeutic treatment for diabetic retinopathy, a devastating disease that robs millions of sight. 


\begin{abstract}
Diabetic retinopathy threatens the vision of over 100 million people in the world. Retinal pericytes are critical cells that enshealth and protect the delicate retinal microvasculature via direct contact and paracrine mechanisms. After diabetes causes pericyte dysfunction over decades with the disease, a cascade of microvascular pathology ensues that results in blindness. Current therapies aid patients with their symptoms, but do not address the fundamental cellular biology of diabetic retinopathy.
\end{abstract}

Mesenchymal stem cells, found throughout the body, are capable of acting as pericytes. This suggests that they may be useful as a protective and regenerative cellular therapy for retinal vascular disease, applied in a way that is mindful of the underlying cellular pathology. Easily harvested from adipose, these stem cells may serve as a regenerative cure for diabetic retinopathy.

Our work demonstrated, for the first time, that adipose-derived stem cells are capable of engraftment into multiple pre-clinical models of diabetic retinopathy, where they appear and function like pericytes to stabilize retinopathy, sometimes dramatically. These models included short experimental times of only a few days as well as longer experiments, which revealed transplanted stem cells adopting pericyte morphology along vessels.

Over the course of our experiments, we came to appreciate the impact that the transplanted stem cells could have via paracrine signaling, even without full engraftment 
and microvascular contact. We also discovered that the diabetic status of the stem cell donor impacted the signaling and disease-modulating efficacy of the cells transplanted into the eye.

While clarity is difficult to find in the field of mesenchymal stem cell research, largely due to its relative youth as a field of study, these experiments confirm the bright promise that stem cell therapy holds for degenerative diseases. Further work should be directed towards understanding the relationship between mesenchymal stem cells and pericytes, as well as investigating precisely how they control their own differentiation and interaction with their surrounding microenvironment. 


\section{Acknowledgements}

My walk through Academia has been a winding one. When I arrived on the Grounds of Mr. Jefferson's University, I had every intention of graduating from medical school in four years and moving on to residency training. But as I moved through the rigorous first three years of medical school, it became ever more clear that I had left something behind. Under the weight of useful and voluminous pre-clinical and clinical study, I was no longer able to ask the fundamental questions behind the science I was learning so rapidly. I knew that I was standing on the shoulders of decades of giants who had constructed an impressive monument of scientific and medical understanding for my intellectual consumption and clinical use. But I missed asking the questions for which we did not yet have answers. I missed my science fair days as a boy inquiring about the nature of waterfalls in Zion National Park, or building wind tunnels for novel airplane wings. I missed the thrill of science, and I knew that I was called to a career pursuing its answers alongside my clinical practice.

Thankfully, Dr. Yates was just getting started here at the University of Virginia. While I did not have well-practiced laboratory hands or any funding of my own at all, he took a chance and invited me to work in his lab. When we had early success, he was first to suggest to me a full doctorate course of study. I do not know of another principle investigator who has hired his lowly graduate student a full time assistant for his laborintensive in vivo experiments. While driven, Dr. Yates has also demonstrated to me deep understanding during very trying times. Words on this page cannot encapsulate how thankful I am for him. 
My conversion to an $\mathrm{MD} / \mathrm{PhD}$ student would not have been possible without the thoughtful and compassionate guidance of Dr. Templeton. Together with Dr. Owens, the Medical Scientist Training Program opened their doors and adopted me, an act not required and outside of the normal workings of the program. I have always felt grateful, if not intimidated, to be grafted into such a talented and driven collection of minds. The program has treated me warmly, embodied in the always-smiling Dori Williams.

Dr. Peirce-Cottler has served as my collaborator and co-mentor and deserves special mention. Her steady hand showed me an example of leadership for laboratories larger than my own when we were just getting started. She is a consummate advocate for her students and their education. Working in her lab, Anthony Bruce has tirelessly assisted our voluminous in vivo work. Her former graduate students, Pete Amos and Alyssa Taylor, taught me a great deal when I was beginning my studies.

I have had the privilege of working with Dr. Netland on both the clinical side of ophthalmology as well as the scientific, through the University of Virginia's Vision Research Group that he founded. I have been very thankful for his service on my Thesis Committee, not to mention his personal and professional advice through the years.

I asked Dr. Goldfarb to serve on my Thesis Committee based upon his thoughtful questions at Pathology Department research presentations and the consistent performance 
of his graduate students. I have valued his rigorous input and have been very grateful for his time and effort.

Dr. Laurie, Mary Hall, and the Biotechnology Training Grant have uniquely prepared me for my career as a clinician scientist. I have been blessed to be a part of such a diverse group of invested scientists. Few graduate students can boast that they were required to spend a summer on a Mediterranean island working in a stem cell clinic and laboratory, which even produced a publication. I also came to work with Jaymes Beech through the training grant, who toiled through chemical engineering problem sets with me and assisted me with in vitro signaling experiments.

To the other members of Dr. Yates' laboratory, I am very grateful. David Kao, in particular deserves mention. My right-hand man in the laboratory for years, often very late and usually each weekend, David was a joy to work with. Ken Tran, Brendan Zotter, and Alex Guendel have also made my graduate experience what it has been in very meaningful ways.

I have been immensely grateful to my friends outside of the walls of the University of Virginia. I am blessed to be a part of a brilliant family of friends from high school, now scattered across the world trying to change it one way or another. Their encouragement has meant a lot to me. 
Especially over the last year of my life, I have been incredibly thankful for the community friends through City Church of Charlottesville, which has walked alongside me through struggles I never would have imagined. They have been so important to me.

Finally, I am keenly aware that I have been blessed with a wonderful family. I did not do anything to merit a father pushing me to ask scientific questions about the world around me as a boy. Few sons get to point to a protein in the pre-clinical medical school textbooks and know their father helped establish its importance in the human brain (calmodulin). Few sons have a mother who stayed up late helping them construct science fair boards year after year and also took them to Space Camp to explore their love of science. My brothers and parents have supported me throughout my entire life, and I would not be the student or man I am without them. 


\section{Table of Contents}

Doctoral Thesis Committee Signatures...................................... I

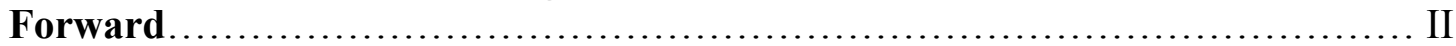

Abstract............................................................ III

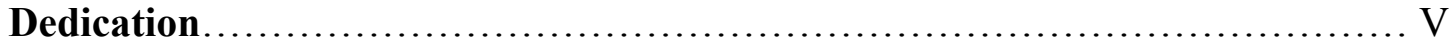

Table of Contents............................................................. IX

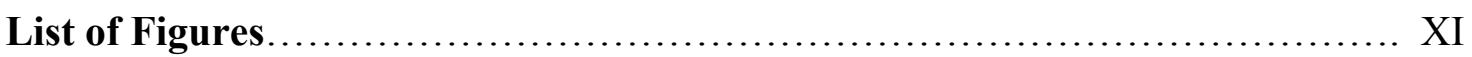

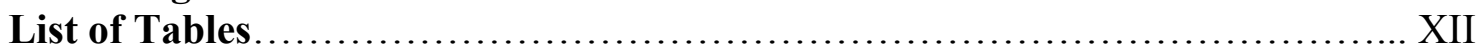

List of Abbreviations..................................................... XII

Chapter 1: Introduction........................................................... 1

Global Problem of Diabetes........................................ 2

Molecular Pathogenesis of Diabetic Retinopathy.......................... 4

Pericytes and the Cellular Pathogenesis of Diabetic Retinopathy............ 7

Treatment Modalities for Diabetic Retinopathy........................... 15

Mesenchymal Stem Cells............................................... 18

Relationship of Pericytes and Mesenchymal Stem Cells..................... 24

Clincial Trials Featuring Mesenchymal Stem Cells........................ 26

Mesenchymal Stem Cell Therapy for Diabetic Retinopathy................. 28

Chapter 2: Materials and Methods.................................................. 33

Chapter 3: Pericytes derived from adipose-derived stem cells

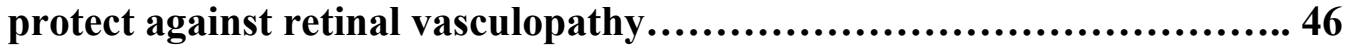

Abstract............................................................. 47

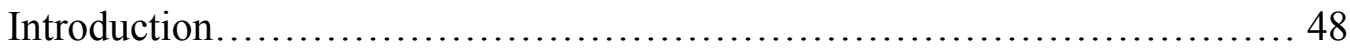

Results...................................................... 50

Discussion...................................................... 71

Chapter 4: Adipose-derived stem cells from diabetic sources show impaired vasoprotection in the treatment of diabetic retinopathy................... 75

Abstract................................................................ 76

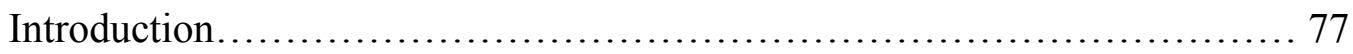

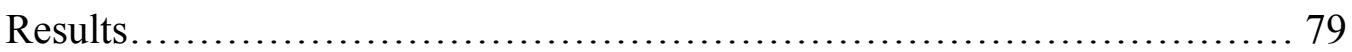

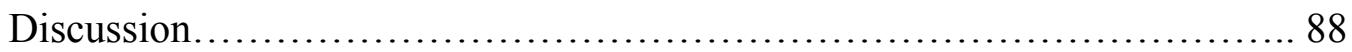

Chapter 5: Discussion and Future Directions.................................... 97

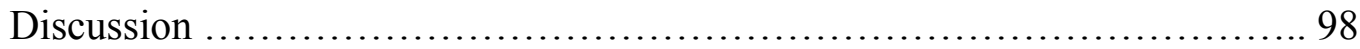

Future Directions............................................... 101

Concluding Remarks.............................................. 110

Chapter 6: Literature Cited....................................................... 112 


\section{List of Figures}

\section{Chapter 1: Introduction}

Figure 1. Schematic diagram of pericyte interactions with cellular effectors

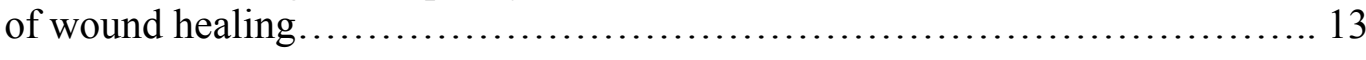

Figure 2. Illustration of the proposed therapeutic approach..................... 31

\section{Chapter 3: Pericytes derived from adipose-derived stem cells protect against retinal vasculopathy}

Figure 3. Human adipose-derived stem cells demonstrate pericyte-like morphology and phenotype markers in vitro and in vivo................... 53

Figure 4. Human adipose-derived stem cells stabilize oxygen-induced retinopathy...................................................... 56

Figure 5. Human bone marrow-derived stem cells fail to accelerate hypoxic revascularization.

Figure 6. Passage 2 human adipose-derived stem cells injections do not impact retinal vascularizaiton prior to hyperoxia.

Figure 7. Human adipose-derived stem cell-pericytes respond to TGF- $\beta 1$ treatment in a manner analogous to native retinal pericytes.

Figure 8. TGF- $\beta 1$ treated murine adipose-derived stem cells prevent long-term retinal capillary dropout in diabetic retinopathic Akimba mice.

\section{Chapter 4: Adipose-derived stem cells from diabetic sources show impaired vasoprotection in the treatment of diabetic retinopathy}

Figure 9. Treatment with healthy and diabetic murine adipose-derived stem cells have differential effects on the retinal microvasculature

Figure 10. Healthy murine adipose-derived stem cells incorporate in the retina in greater numbers and assume perivascular positions more often than diabetic mASCs.

Figure 11. Healthy murine adipose-derived stem cells exhibit higher rates of proliferation and lower rates of apoptosis than diabetic mASCs. 
Figure 12. Healthy and diabetic murine adipose-derived stem cells show

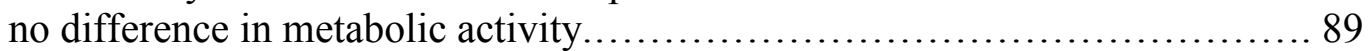

Figure 13. Diabetic murine adipose-derived stem cells secrete decreased levels

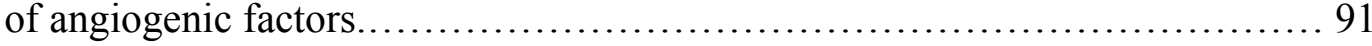




\section{List of Tables}

\section{Chapter 1: Introduction}

Table 1. Pericyte Identification Markers....................................... 9

Table 2: Surface antigens commonly identified during isolation of mesenchymal stem cells.............................................. 20 


\section{List of Abbreviations}

AGEs andvanced glycation end-products

Alk activin receptor like kinase

AMD age-related macular degeneration

ASCs adipose-derived stem cells

BMSCs bone marrow-derived stem cells

BRECs bovine retinal endothelial cells

DiI 1,1'-Dioctadecyl-3,3,3',3'-tetramethylindocarbocyanine perchlorate

DR diabetic retinopathy

DRS Diabetic Retinopathy Study

EdU 5-ethynyl-2'-deoxyuridine

EPCs endothelial progenitor cells

ETDRS Early Treatment of Diabetic Retinopathy Study

FACS fluorescence activated cell sorting

GAPDH glyceradehyde 3-phosphate dehydrogenase

GSH reduced glutathione

hBMSCs human bone marrow-derived stem cells

hASCs human adipose-derived stem cells

IGF-1 insulin-like growth factor 1

mASCs murine adipose-derived stem cells

MSCs mesenchymal stem cells

NADPH nicotinamide adenine dinucleotide phosphate

NG2

NG2 proteoglycan 
NOD SCID non-obese diabetic with severe combined immunodeficiency syndrome

$\begin{array}{ll}\text { OCR } & \text { oxygen consumption rate } \\ \text { OIR } & \text { oxygen-induced retinopathy } \\ \text { P\# } & \text { post-natal day \#, or cell passage \# } \\ \text { PDGF-B } & \text { platelet derived growth factor } \\ \text { PDGFR- } \beta & \text { platelet derived growth factor receptor beta } \\ \text { PKC } & \text { protein kinase C } \\ \text { RAGE } & \text { receptor for AGEs } \\ \text { ROP } & \text { retinopathy of prematurity } \\ \text { ROS } & \text { reactive oxidative species } \\ \text { SMA } & \text { smooth muscle actin } \\ \text { TEM } & \text { transmission electron microscopy } \\ \text { TGF } \beta & \text { transforming growth factor } \beta \\ \text { TUNEL } & \text { terminal deoxynucleotidyl transferase dUTP nick end labeling } \\ \text { VEGF } & \text { vascular endothelial growth factor } \\ & \text { vascular smooth muscle cells } \\ \text { VSM } & \end{array}$




\section{Chapter 1}

Introduction 


\section{Global Problem of Diabetes}

Diabetes now reaches an epidemic scale across our planet. 347 million people in the world are diabetic, ${ }^{1}$ a disease responsible for 4.6 million mortalities per year. ${ }^{2}$ An estimated 429 million people worldwide will be diabetic by $2030 .^{3,4}$ While type 1 and type 2 diabetes feature fundamentally different pathophysiologies, they both result in decades of unregulated blood glucose and common downstream microvascular complications.

A particularly feared complication is diabetic retinopathy (DR), a condition that threatens the vision of 101 million people worldwide, with an estimated prevalence of 155 million people by $2030 .^{5}$ One third of patients with diabetes have signs of DR in the form of macular edema or more severe retinopathy. ${ }^{6,7}$ Sadly, even with intensive glucose control, up to $20 \%$ of diabetic patients will develop proliferative DR after 30 years with the diease..$^{8,9}$

Retinal ganglion cells fire axon potentials nearly constantly, requiring substantial metabolic support and an intricate multi-layered retinal microvasculature. ${ }^{10}$ Indeed the programmed and ordered development of the supporting retinal microvasculature is carefully coordinated with the embryologic maturation of retinal ganglion cells. ${ }^{11,12}$ Disruption of proper oxygenation of the retinal ganglion cells, most concentrated in the central macular area of the retina, results in a cascade of molecular and cellular events that characterize retinopathic inflammation. While the hypoxia associated with any 
retinopathic diagnosis can elicit an inflammatory response, the chronic microvascular inflammation of diabetes produces a unique cellular progression that leads to retinal decline and loss of vision.

This pathophysiologic decent from proper function to DR takes decades to progress. Somewhat similar to other diseases of the retina, such as age-related macular degeneration (AMD), diabetic patients often experience a non-proliferative phase of their disease time course, characterized by cotton-wool spots (retinal nerve fiber layer infarcts) and microvascular anomolies including microanneuryms as well as dilated, tortuous, and occluded vessels. ${ }^{13}$ Patients in this early stage of disease may be asymptomatic or begin to suffer some vision loss from plasma leakage and tissue swelling around the center of the vision, a condition known as macular edema. Of note, patients at this early stage lack the robust angiogenic and fibrotic retinal response to microvascular dysfunction that characterize the later stages of the disease.

The clinical conversion from non-proliferative DR to the more feared proliferative phase of the disease occurs when angiogenesis begins in the retina. Typically, this begins around the optic disk, where retinal ganglion cell axons collect to form the optic nerve. ${ }^{13}$ Angiogenesis can also occur surrounding the larger retinal vessels, and it is possible for acute visual loss in this situation through an acute bleeding event. More commonly, however, visual loss is the final step in the reactionary fibrotic response of the diabetic retina to chronic inflammation, resulting in mechanical traction from fibrotic infiltrates that pull the retina anteriorly into the vitreous, detaching it from the retinal pigment 
epithelium, and opening the potential space posterior to the retina left from embryogenesis. ${ }^{13}$ If untreated, DR produces a well documented cascade of events, from vascular leakage, to macular edema, microanneurysms, venous stasis, bleeding, fibrosis, and ultimately retinal detachment and blindess. ${ }^{14}$

\section{Molecular Pathophysiology of DR}

The endothelial cells that comprise the retinal microvasculature have been noted to undergo accelerated cell death under diabetic conditions. ${ }^{15}$ Among the theories researched as to the biochemical link between hyperglycemia and endothelial decline, four emerge as leading candidates that contribute to the oxidative environment through the generation of reactive oxidative species (ROS). Brownlee elegantly posits that hyperglycemia impacts endothelial cells through the following mechanisms. ${ }^{16}$

\section{(1) Increased polyol pathway flux}

The polyol pathway features the reduction of glucose to sorbitol with the aid of aldose reductase, a reaction that consumes nicotinamide adenine dinucleotide phosphate (NADPH). Production of an intracellular antioxidant, reduced glutathione (GSH), also requires NADPH. With less NADPH available from sorbitol production, less intracellular (GSH) is produced, decreasing the antioxidant armory the cell uses to scavenge ROS.

(2) Production of andvanced glycation end-products (AGEs) 
AGEs form in retinal microvessles by non-enzymatic glycation of both proteins and lipids, which in turn modify intracellular proteins - including transcription factors - and the extracellular matrix. ${ }^{17}$ A receptor for AGEs (RAGE) then acts through the NF-kB pathway to increase inflammatory cytokines and contribute to the oxidative environment. ${ }^{18}$

\section{(3) Activation of protein kinase C (PKC)}

Increased hyperglycemia-ROS production inhibits the glycolitic enzyme glyceradehyde 3-phosphate dehydrogenase (GAPDH), which increases the cytoplasmic concentration of glycolytic reactants, including triose phosphate. Triose phosphate acts through diacylglycerol, known to be one of the most potent activators of PKC, which in turn dramatically increases vascular permeability. ${ }^{19}$

\section{(4) Increased flux through the hexosamine pathway}

The hexosamine pathway is thought to compound oxidative stress inside a hyperglycemic cell. ${ }^{20}$ Excess glycolitic reactants from the inhibition of GAPDH are shunted to the hexosamine pathway, which produces N-acetylglucosamine. N-acetylglucosamine is frequently added to threonine and serine residues on transcription factors, resulting in pathologic changes in gene expression.

Underscoring these different mechanisms by which hyperglycemia impacts endothelial cells is the concept of chronic oxidative damage. Brownlee suggests a synthetic theory, which states that all four of these processes lead to an overproduction of mitochondrial 
superoxide by the electron transport chain. ${ }^{16}$ While much remains to be explored, it is clear that chronic oxidative damage plays a key role in the pathology imparted to endothelial cells by hyperglycemia.

Pericytes, as with endothelial cells, respond to the oxidative inflammatory environment induced by DR through the NF- $\mathrm{KB}$ pathway. ${ }^{21}$ Pericytes ensheath the microvasculature and interact with endothelial cells by direct contact, sharing a basement membrane. ${ }^{22}$ Critically, pericytes also respond to inflammatory stimuli to orchestrate a host of paracrine interactions with neighboring endothelial cells. ${ }^{23}{ }^{24}$ As hyperglycemia erodes endothelial and pericyte integrity, the microvasculature becomes prone to plasma protein leakage. ${ }^{25}$ As in the brain, maintenance of the blood retinal barrier is particularly important. Edema can be devastating to either tissue, as macular edema is to retinal function. Retinal pericytes are critical partners with endothelial cells, functioning in tandem to maintain blood retinal barrier integrity. ${ }^{26}$ Specifically, pericytes help regulate permeability controlling signals angiopoietin-1 and angiopoietin- $2 .{ }^{27}$ Recent work has highlighted the importance of pericyte function in the regulation of transcellular transport across the blood retinal barrier. ${ }^{28}$

Thus, multiple lines of evidence support the notion that pericytes act as both inflammatory responders and blood retinal barrier gatekeepers. These roles make pericytes central actors in microvascular diseases that feature chronic inflammation from oxidative damage and subsequent leakage, two well-understood features of DR. Clearly, further consideration of pericytes is warranted. 


\section{Pericytes and the Cellular Pathophysiology of DR}

\section{Pericyte Identification}

The discovery of pericytes is typically attributed to French scientist Charles-Marie Benjamin Rouget in $1873,{ }^{29}$ although Eberth had described them previously. ${ }^{28,} 30$ Pericytes were called "Rouget cells" until Zimmerlin introduced the term "pericytes" in 1923. ${ }^{31}$ Pericytes have been traditionally accepted to be mural cells on the abluminal side of microvessels, embedded within the basement membrane of endothelial cells, as demonstrated by transmission electron microscopy (TEM) ${ }^{32}$ Since TEM is not always practical, a mixture of location, gene expression studies, and morphology is used in most of the literature to date, as noted in a thorough review by Armulik, Betsholtz, and colleagues. ${ }^{28,33,34}$

Location is critical for in vivo characterization of pericytes. Their investment in the basement membrane of endothelial cells is defining and central to their function. In fact, evidence suggests that the interaction of the pericyte with the endothelial cell is responsible for the formation of proper basement membrane. ${ }^{35,36}$ Direct communication between pericytes and endothelial cells is also suggested by in vitro work that demonstrates gap junctions between pericytes and endothelial cells. ${ }^{37,} 38$ It is hypothesized that transforming growth factor $\beta$ (TGF $\beta$ ) production by pericytes and endothelial cells might require these gap junctions. ${ }^{28}$ 
Pericyte gene expression and marker identification has been used centrally in laboratory investigation as it lends itself to techniques such as immunohistochemistry and fluorescence activated cell sorting (FACS) for cell harvest and culture purification. Pericytes are reported to express smooth muscle actin (SMA), NG2 proteoglycan (NG2), desmin, and platelet derived growth factor receptor beta (PDGFR- $\beta$ )..$^{33,39-41}$ Critically, those marker descriptions depend precisely upon where in the transition from artery to vein a pariticular pericyte resides. ${ }^{38,42}$ Below is a modified table generated by Armulik and colleges that summarizes some of the most commonly used periycte markers, along with other cell types that share expression of those markers. ${ }^{28}$ 


\section{Table 1. Pericyte Identification Markers}

\begin{tabular}{|c|c|c|c|c|}
\hline Pericyte Marker & $\begin{array}{l}\text { Gene } \\
\text { Symbol }\end{array}$ & $\begin{array}{l}\text { Examples of Other Cell Types } \\
\text { Expressing the Marker }\end{array}$ & Comments & References \\
\hline \multicolumn{5}{|l|}{ Validated Markers } \\
\hline $\begin{array}{l}\text { PDGFR- } \beta \text { (platelet- } \\
\text { derived growth factor } \\
\text { receptor-beta) }\end{array}$ & Pdgfrb & $\begin{array}{l}\text { Interstitial mesenchymal cells } \\
\text { during development; } \\
\text { smooth muscle; in the CNS } \\
\text { certain neurons and neuronal } \\
\text { progenitors; myofibroblasts; } \\
\text { mesenchymal stem cells }\end{array}$ & $\begin{array}{l}\text { Receptor tyrosine kinase; } \\
\text { functionally involved in } \\
\text { pericyte recruitment during } \\
\text { angiogenesis; useful } \\
\text { marker for brain pericytes }\end{array}$ & $\begin{array}{l}\text { Lindahl et al., 1997; } \\
\text { Winkler et al., } 2010\end{array}$ \\
\hline $\begin{array}{l}\text { NG2 (chondroitin sulfate } \\
\text { proteoglycan 4) }\end{array}$ & Cspg 4 & $\begin{array}{l}\text { Developing cartilage, bone, } \\
\text { muscle; early postnatal skin; } \\
\text { adult skin stem cells; adipocytes; } \\
\text { vSMCs; neuronal progenitors; } \\
\text { oligodendrocyte progenitors }\end{array}$ & $\begin{array}{l}\text { Integral membrane } \\
\text { chondroitin sulfate } \\
\text { proteoglycan; involved in } \\
\text { pericyte recruitment to } \\
\text { tumor vasculature }\end{array}$ & $\begin{array}{l}\text { Ozerdem et al., 2001; } \\
\text { Ruiter et al., 1993; } \\
\text { Huang et al., } 2010\end{array}$ \\
\hline $\begin{array}{l}\text { aSMA (alpha-smooth } \\
\text { muscle actin) }\end{array}$ & Acta2 & $\begin{array}{l}\text { Smooth muscle; } \\
\text { myofibroblasts; } \\
\text { myoepithlium }\end{array}$ & $\begin{array}{l}\text { Structural protein; } \\
\text { quiescent pericytes do not } \\
\text { express } \alpha \text { SMA (e.g., CNS); } \\
\text { expression in pericytes is } \\
\text { commonly upregulated in } \\
\text { tumors and in inflammation }\end{array}$ & Nehls and Drenckhahn, 1993 \\
\hline Desmin & Des & $\begin{array}{l}\text { Skeletal, cardiac, } \\
\text { smooth muscle }\end{array}$ & $\begin{array}{l}\text { Structural protein; useful } \\
\text { pericyte marker outside } \\
\text { skeletal muscle and heart }\end{array}$ & Nehls et al., 1992 \\
\hline
\end{tabular}


Pericyte morphology and ultrastructural relationship with endothelial cells changes along the vascular continuum from artery to vein as well. ${ }^{28}$ Classically understood pericytes exist primarily on capillaries. Often found clustered around capillary branch points, pericytes feature cytoplasmic extensions along the abluminal side of the capillary network, typically reaching along multiple branches of the microvascular tree. ${ }^{28}$ These primary processes can extend their own perpendicularly oriented secondary processes as well. This cellular sheathing can serve to help seal an endothelial network from leakage. In some tissues where sheathing is particularly functionally important, such as the kidney or central nervous system, pericytes are found in much higher abundance than they are in other tissues. In the retina and central nervous system, pericyte coverage can be as dense as 1:1 with endothelial cells. ${ }^{32,43}$ Far sparser coverage is found in other tissues, such as skeletal muscle where there may be a 100:1 endothelial to pericyte ratio, ${ }^{38,44}$ although there is some variability in the reported pericyte density in muscle. ${ }^{45}$ Functionally, perhaps this more porous capillary network is reflected in the relative ease with which muscles swell upon injury with vascular plasma leakage and cellular extravasation, as muscles do not possess such a tight-knit barrier of wrapped of pericytes as featured in the central nervous system.

\section{Pericyte Ontogeny and Regeneration}

Pericyte ontogeny has been scarcely researched, so we must rely upon investigations about vascular smooth muscle cells (VSMCs), which overlap with periytes in marker expression, morphology, and function in the vasculature. Seeking an intellectually elegant single source model, early work suggested that VSMCs, as terminally 
differentiated and functional cell types, derive from nearby mesenchymal stem cells and localize to the abluminal side of endothelial cells. ${ }^{46,47}$ However, recent work suggests that the origin of VSMCs is rather a heterogeneous patchwork, ${ }^{48,49}$ likely including neural crest derivation toward the cephalic end of the developing embryo. ${ }^{50,51}$ Origins of VSMCs in other organs, like the liver, ${ }^{52}$ lungs, ${ }^{53}$ and gut, ${ }^{54}$ have been shown to be derived from nearby mesothelium. Pericytes depend more heavily upon PDGF signaling for recruitment than do VSMCs. ${ }^{28,55}$ However, our understanding of both VMSCs and pericytes features one critical element in common; the mechanism by which VMSCs and pericytes regenerate themselves remains poorly illuminated. We are unsure if neighboring cells divide and migrate or differentiate from nearby - or distant - stem cell sources.

\section{Pericyte Signalling}

Pericyte signaling, particularly with nearby endothelial cells, has been richly studied. Platelet derived growth factor (PDGF-B) and its receptor, PDGFR- $\beta$, comprise a signaling axis that is central to pericyte recruitment to endothelial cells. ${ }^{34,56}$ Mice with PDGF-B knocked out lack microvascular pericytes, and also demonstrate the expected resultant microanneurysm formation. ${ }^{57}$ Similarly, if the receptor PDGFR- $\beta$ is knocked out, a nearly identical phenotype lacking microvascular pericyte coverage is revealed. ${ }^{28,58}$ Once thought only to play a role in enbryogenesis, we now know that PDGF-B/PDGFR- $\beta$ signaling does influence the mature organism, as mutated constitutively active PDGF-B impedes the differentiation of mural cells. Expressed on endothelial cells and bound to 
their extracellular matrix, ${ }^{56}$ PDGF-B appears not only to aid in pericyte recruitment but also retention of pericytes.

TGF $\beta$ signaling has been heavily implicated in the maturation of pericytes along the abluminal side of endothelial cells. ${ }^{28}$ As both endothelial cells and pericytes express TGF $\beta$ and its receptors, teasing apart the effect of one cell type upon the other has proven difficult experimentally. ${ }^{34}$ An elegant theory supported by Betsholtz and colleagues suggests that the impact of TGF $\beta$ depends upon the balance of TGF $\beta$ receptors, particularly activin receptor like kinase (Alk)-1 and Alk-5, which are expressed on both pericytes and endothelial cells. The receptors may have opposing effects, ${ }^{59,60}$ with activation of Alk-5 acting intracellularly through Smad2/3 to discourage migration and mitosis of pericytes, while activation through Alk-1 transduces through Smad1/5 to target genes that promote pericyte migration and mitosis. What is clear is that TGF $\beta$ does work to increase smooth muscle actin expression ${ }^{61}$ and enhance pericyte contraction. ${ }^{62}$

Like MSCs, discussed in greater detail below, pericytes exchange signals with inflammatory cells, microvasculature endothelial cells, and surrounding parenchymal cells. Herman and colleagues have constructed the following figure to illustrate the network of studied and hypothesized cellular interactions that pericytes maintain. ${ }^{63}$ 
Figure 1. Schematic diagram of pericyte interactions with cellular effectors of wound healing. Pericytes form relationships with vascular, immune, connective tissue, and glial cells during injury repair. This diagram demonstrates that pericytes may regulate multiple points of the wound-healing cascade. Pericyte functions are not confined to the microvasculature, and range from modulations of immune cell infiltration and activation to glial scar formation. Hypothesized interactions are indicated by (?). 


\section{Figure 1.}

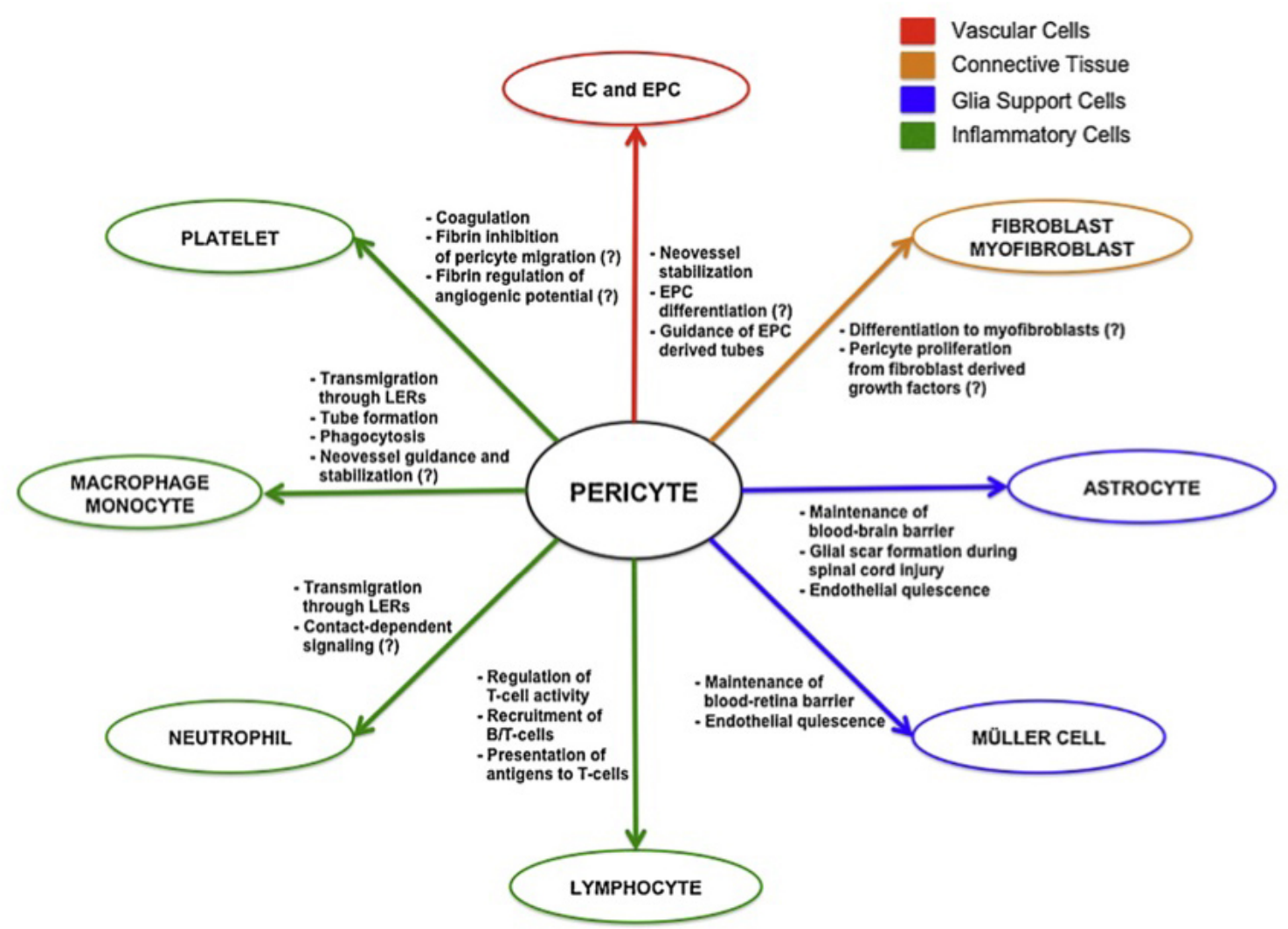

Dulmovits, B.M. and I.M. Herman, Microvascular remodeling and wound healing: a role for pericytes. Int J Biochem Cell Biol, 2012. 44(11): p. 1800-12. 
The wide variety of roles and cellular interactions that pericytes demonstrate in vivo and in vitro both confounds and entices their study. Clearly, we have much to resolve about the basic science of pericytes alongside their possible implementation as translational therapy.

What we have understood since the 1960's is the importance of retinal pericytes that ensheath the crucial retinal microvasculature. Cogan famously published his observations that the typically dense pericyte coverage of endothelial cells in the retina decreases over time with diabetes. ${ }^{64-67}$ When pericyte coverage falls and endothelial dysfunction ensues, the downstream retinal ganglion cells, ${ }^{68}$ and importantly Müeller cells, ${ }^{69}$ secrete vascular endothelial growth factor (VEGF) in what will be a failed attempt to improve perfusion. The diabetic retina responds to inflammation fibrotically, initiating the course of events that leads to blindness, as described above.

\section{Treatment Modalities for DR}

To interrupt and retard the progression of DR, two major approaches are used clinically today: laser photocoagulation of the peripheral retina and anti-VEGF antibody therapy. ${ }^{6}$ Laser photocoagulation, introduced in 1959, utilizes lasers to burn, permanently kill, and scar peripheral retinal tissue, effectively reducing the downstream hypoxic tissue area and resultant VEGF production. ${ }^{70}$ The chief idea behind the therapy is to sacrifice the peripheral retina in order to spare or prolong function in the critical central retina, the macula, on which we rely to recognize faces, read, and use for most of our visual 
interaction with the world. Both the Early Treatment of Diabetic Retinopathy Study $(\text { ETDRS })^{71}$ and the Diabetic Retinopathy Study (DRS) $)^{72}$ strongly validated laser therapy as a therapeutic mainstay for DR. In both studies, each enrolling thousands of patients, disease progression risk was cut in half with the use of laser therapy. However, laser treatment also results in light-dark adaptation problems, visual acuity reduction, and importantly - permanent peripheral field visual defects. ${ }^{73}$

More recently, the anti-VEGF armamentarium has transformed how DR is treated. Bevacizumab (Avastin ${ }^{\circledR}$ ), a monoclonal VEGF antibody designed as an anti-angiogenic cancer therapy, has achieved wide use off-label to treat multiple retinopathies, including DR and AMD. Ranibizumab (Leucentis $\left.{ }^{\circledR}\right)$ is a related molecule that has been optimized to provide stronger binding to VEGF than bevacizumab, and is also used to treat DR. Both therapies have proven to be crucial treatments for DR, as well as AMD, after their off-label use to treat ocular disease was validated in multiple clinical trials. ${ }^{74-76}$

While anti-VEGF therapy represents one of the most clinically significant examples of molecularly directed therapy that advances treatment of a disease with scientific precision, there are some concerns in the scientific and ophthalmic community about the impact of chronic and total removal of VEGF from the retina. ${ }^{77}$ Specifically, we do not yet know the impact of antibody-mediated removal of all VEGF signaling in the retina on retinal ganglion cells, which rely upon constitutive non-pathologic VEGF signaling under normal conditions. ${ }^{78}$ VEGF is also utilized in adult microvascular maintenance. ${ }^{79-81}$ It should be noted that risks of off-target effects of ocular anti-VEGF therapy to other 
organs have been evaluated by retrospective analysis and found to similar to other retinal therapies. ${ }^{82}$ Lastly, ocular anti-VEGF therapies are exceedingly expensive, with a single intravitreal dose of ranibizumab costing $\$ 1,950$ and being prescribed with regularity for a variety of complex factors, in spite of the lower $\$ 30$ cost of the related bevacizumab. ${ }^{83}$ In 2012 alone, Medicare spent $\$ 1.2$ billion on ranibizumab. ${ }^{84}$ As the diabetes epidemic spreads, and more patients are diagnosed with DR earlier in life, they will face the daunting prospect of intra-ocular injections, as often as monthly in some cases, for the remaining decades of their lives in hopes of preserving vision.

Of critical importance, both laser photocoagulation and anti-VEGF therapy only aim to reduce VEGF signaling, rather than repairing the microvasculature that is damaged over time from chronic diabetic inflammation. ${ }^{8,85} 86$ In effect, neither therapy addresses the antecedent molecular and cellular pathophysiology that occurs slowly with chronic diabetes and results in DR. Reducing VEGF signaling that results from hypoxic retinal tissue does not repair the delicate retinal microvasculature or reinstate healthy endothelial networks directly. Moreover, simply reducing VEGF signaling does not adequately remedy the molecular milieu responsible for the initial pericyte dysfunction and loss.

Precisely what occurs to the resident retinal pericytes over the course of decades with diabetes? Cogan noted that pericytes seem to move away from retinal microvessels in animal models of diabetes. ${ }^{65}$ Where do the pericytes go and what were they doing? Why do pericytes fail to return to the microvessles in the context of DR? These questions have stood for decades, despite advances in molecular and surgical therapy to impede 
progression of DR. Only in recent years have some enticing theories emerged concerning the identity, activity, and therapeutic potential of these wandering pericytes, which may contain within their ranks a population of stem cells that masquerade as quiescent pericytes while waiting to respond to local inflammation.

\section{Mesenchymal Stem Cells (MSCs)}

\section{MSC Identification}

In recent years, the promise of MSC regenerative therapy has generated much interest, funding, and high-profile publications. Described originally by Friedenstein and colleagues in $1970,{ }^{87}$ MSCs have been an intriguing area of study for years. ${ }^{88}$ The relationship of MSCs to pericytes, discussed further below, has both confused and potentially offered promise to the study of both cell types.

As they have held different names imparted by different researchers, ${ }^{89}$ MSCs are commonly defined by molecular markers and demonstrated multi-lineage potential, as well as cellular location in vivo. The clarity that molecular surface marker expression confers to cellular study, as is the case in hematopoesis research for example, is unfortunately lacking in MSC research. As is the case for pericytes, there is no singular exclusive marker or set of markers that exclusively identifies an MSC in vivo, ${ }^{88}$ perhaps because of their general distribution around the body. To complicate the issue further, marker expression - including the important primitive hematopoietic stem cell marker CD34 - varies depending upon species studied. ${ }^{90}$ 
To illustrate these differences further, consider the following table provided in the excellent review from Kolf and colleagues. ${ }^{90}$ 
Table 2: Surface antigens commonly identified during isolation of MSCs.

Surface antigens commonly identified during isolation of mesenchymal stem cells (MSCs)

\begin{tabular}{|c|c|c|c|c|c|c|c|}
\hline \multirow[b]{3}{*}{ Marker type } & \multirow[b]{3}{*}{ Surface antigen ${ }^{a}$} & \multicolumn{6}{|c|}{ Number of populations reported with specified antigen levels ${ }^{b}$} \\
\hline & & \multicolumn{3}{|c|}{ Human $\mathrm{MSCs}^{\mathrm{C}}$} & \multicolumn{3}{|c|}{ Murine MSCs ${ }^{c}$} \\
\hline & & + & $+/-$ & - & + & $+/-$ & - \\
\hline \multirow[t]{7}{*}{ Positive } & Stro-1 & 7 & 1 & 2 & 0 & 0 & 0 \\
\hline & CD13 & 5 & 0 & 0 & 1 & 0 & 1 \\
\hline & CD29 & 5 & 0 & 0 & 11 & 0 & 0 \\
\hline & CD44 & 11 & 0 & 1 & 10 & 1 & 0 \\
\hline & CD73 & 5 & 0 & 0 & 0 & 0 & 0 \\
\hline & CD105 & 7 & 0 & 0 & 1 & 0 & 0 \\
\hline & CD106 & 4 & 0 & 2 & 4 & 1 & 0 \\
\hline \multirow[t]{5}{*}{ Negative } & CD11b & 0 & 0 & 3 & 0 & 1 & 5 \\
\hline & CD31 & 0 & 3 & 10 & 0 & 0 & 6 \\
\hline & CD34 & 1 & 1 & 10 & 5 & 6 & 3 \\
\hline & CD45 & 0 & 0 & 11 & 0 & 0 & 6 \\
\hline & CD117 & 0 & 2 & 3 & 1 & 1 & 13 \\
\hline \multirow[t]{4}{*}{ Variable } & Sca-1 & 0 & 0 & 0 & 6 & 5 & 4 \\
\hline & CD10 & 6 & 0 & 5 & 0 & 1 & 0 \\
\hline & CD90 & 11 & 1 & 1 & 2 & 4 & 10 \\
\hline & Flk-1 & 2 & 1 & 1 & 0 & 0 & 5 \\
\hline
\end{tabular}

Aantigen chosen if tested in at least 4 MSC populations from the 19 papers reviewed; ${ }^{b}$ number of MSC populations (isloated from various tissues from human or mouse) reported in these studies to be mostly positie (+), somewhat positive (+/-), or negative (-); ' MSCs isloated primarily from bone marrow but also from fat, skin, thymus, kidney, muscle, liver, lung, and placenta. 
In an effort to clarify the paralyzing confusion generated from marker identification inconsistencies across the field in basic research and clinical trials, The International Society for Stem Cell Research convened and established the following criteria to define MSCs once harvested from a donor: ${ }^{91}$

1. Cells adhere to plastic.

2. Cells are capable of differentiating into chondrocytes, adipocytes, and osteocytes.

3. Cells are $\mathrm{CD} 105+, \mathrm{CD} 73+, \mathrm{CD} 90+$.

4. Cells are CD45-, CD34-, CD11b-, CD14-, CD79a-, HLA-, HLA-DR-

MSCs have been harvested from multiple tissues, including bone, muscle, central nervous system, and - importantly - adipose. $^{42}$ In the adipose, multiple laboratories have independently shown that MSCs can be readily harvested from the stromal vascular fraction of adipose following digestion with collagenase. ${ }^{92-95}$ Lin and colleagues have demonstrated that cells surrounding capillaries can express embryonic stem cell markers Oct4 and telomerase. ${ }^{96}$ Practically, this is of major significance for patient therapy since harvesting adipose is a regularly performed procedure. While there have been some very exciting breakthroughs in the induced pluripotent stem cell field recently, which might make their autologous therapeutic application more attainable, much remains unknown about their function and immunogenicity. ${ }^{97}$ Thus, safely harvesting sufficient MSCs for therapeutic use is a major objective for the field of regenerative medicine in general. ${ }^{98}$ In fact, harvesting MSCs from adipose has proven far more efficient than harvesting them 
from bone marrow (5,000 MSCs per gram of adipose versus 100-1000 MSCs per gram of bone marrow). ${ }^{99}$

Function of MSCs

As stem cells, MSCs have long been understood to differentiate into requisite mesodermal cells for tissue reconstitution. ${ }^{100}$ MSCs from multiple tissues were induced to differentiate into chondrocyte, osteocyte, and adipocyte lineages. ${ }^{42}$ Caplan and colleagues have published extensively on the functions of MSCs, particularly as they pertain to wound healing. They contend convincingly that MSCs from all tissues act, among other capacities, in the following ways during a wound-healing event: ${ }^{101}$

1. Reduce inflammation and shield host molecular epitopes from immune system surveillance and subsequent auto-immunity.

2. Temper apoptosis of neighboring cells and tissues.

3. Promote angiogenesis to revascularize the repaired tissue.

4. Differentiate into required mesenchymal cells to rebuild damaged tissues.

MSCs do respond the local inflammatory environment. ${ }^{102}$ Upon activation, they move away from capillaries, serving to orchestrate a paracrine immunosuppressive, angiogenic, and antifibrotic response. ${ }^{103}$ MSCs have been found specifically to suppress T-cell proliferation as well. ${ }^{104}$ The method by which MSCs reduce inflammation is an area of active research today. Rather than requiring cell-to-cell contact, it may be that MSCs secrete a milieu of signaling molecules capable of influencing the system. The conditioned media of MSCs alone, having previously been activated by TNF $\alpha$ or 
interferon- $\gamma$, is sufficient to reduce the proliferation of T-cells after they are independently stimulated. ${ }^{105-107}$ Interestingly, MSCs also indirectly manipulate the immune environment surrounding a wound by increasing IL-4 and IL-10, shifting the $\mathrm{T}_{\mathrm{H}} 1 / \mathrm{T}_{\mathrm{H}} 2$ helper $\mathrm{T}$-cell balance toward more predominantly $\mathrm{T}_{\mathrm{H}} 2$ position. ${ }^{108,}{ }^{109}$ This attribute is potentially important in the context of DR since, during chronic inflammation, a predominant $\mathrm{T}_{\mathrm{H}} 2$ phenotype has been shown to aid in cartilage and muscle regeneration. ${ }^{101,110,111}$ The increase in IL-4 also promotes a shift from inflammatory M1 macrophages to anti-inflammatory M2 macrophages. ${ }^{112-114}$

MSCs also aid to diminish nearby cellular apoptosis, ${ }^{101}$ protecting neurons for example. ${ }^{115}$ Following an ischemic event, MSCs can also reduce local cardiomyocyte apoptosis. ${ }^{116}$ The mechanism by which MSCs exert this important influence on the surrounding parenchyma is not yet fully known, but it is believed that insulin-like growth factor 1 (IGF-1) and IL-6 are centrally involved, acting through the NF- $\mathrm{KB}$ axis. ${ }^{117}$ Adipose derived stem cells in particular, compared to other MSCs, readily secrete IGF-1. ${ }^{118}$

MSCs have been implicated in the promotion of angiogenesis. March and colleagues reported that MSCs harvested from the adipose secrete VEGF in response to hypoxia, and that conditioned media taken from those hypoxia treated cells is sufficient to decrease endothelial apoptosis and increase endothelial cell growth. ${ }^{119}$ Importantly, in vivo hind limb revascularization experiments using MSCs resulted in functional revascularization rather than pathologic angiogenesis. Other in vitro reports suggest that following resolution of inflammation, MSCs not only work via paracrine methods, but also return to 
ensheath the neovessels they had previously stimulated to revascularize the tissue. ${ }^{120}$ This full resolution is critical for subsequent tissue function. While the entire molecular and cellular mechanism responsible for this angiogenic response remains dimly illuminated, these results are promising for the therapeutic potential of MSCs.

\section{Relationship of Pericytes and MSCs}

To consider and study MSCs effectively, their relationship with pericytes must be established. There is evidence that cells traditionally thought to be MSCs appear and behave as pericytes. A robust literature suggests that MSCs are found surrounding the

abluminal side of capillaries, in a perivascular position, throughout the human body. ${ }^{102}$, 121-123 The perivascular location of MSCs lends itself to a well-studied role in wound healing, a process that requires the orchestration of multiple signaling networks, influx of leukocytes, immunomodulation, angiogeneis, and structural reconstitution, described above.

There is also evidence that cells traditionally thought to be pericytes behave as MSCs. In the renal system, Campanholle and colleagues demonstrated pericyte detachment in response to injury in the kidney, noting prominent "pericyte-to-myofibroblast" differentiation. ${ }^{124}$ Chen and colleagues elicited the importance of PDGF signaling for that transition in the kidney, also citing the central role that detached pericytes play in response to injury. ${ }^{125}$ Stefanska and colleagues, in addition to suggesting that pericytes in the kidney are central to the rennin-angiotensin system in that organ, discussed their role as potential renal progenitor cells. ${ }^{126}$ 
If the term "peri-cyte" is taken to mean "around or enclosing the cell," as its etymological roots imply, then the perivascular location of MSCs implies that they are pericytes. But it may not be the case that all pericytes are MSCs. ${ }^{88}$ Recently, Braun and colleagues published their findings that the human perivascular space is occupied by two distinct cellular identities, namely CD34+ CD146- MSCs and CD34- CD146+ pericytes. ${ }^{127}$ It is important to recognize that some reports have indicated that while murine MSCs are CD34+, those of humans may not be..$^{90}$ The MSCs, harvested from adipose for those studies, were more clonogenic than the pericyte fraction, aligning with data from other publications. $^{123,128,129}$ Independently, Zimmerlin and colleagues have recently published similar results, distinguishing three separate groups of perivascular cells on the basis of CD31, CD34, and CD146. ${ }^{130}$ These results more specifically define the perivascular compartment and actually fall in line with the standard protocol for isolating MSCs from tissues, including adipose. It has long been suspected that the stromal vascular fraction harvested from adipose is a heterogeneous mixture of cells, yet serially passaged cells appeared largely homogenous. By serially passaging before use in vivo, while a crude method, researchers may have given time for the more clonogenic CD34+ CD146- MSCs to expand and numerically dominate the heterogeneous cell culture consisting of slower growing CD34- CD146+ pericytes.

But the in vivo distinction between cells thought to be terminally differentiated pericytes, and those retaining stem cell properties as MSCs, may not be as lucid as a simple heterogeneous perivascular allotment. There may be crossover from one type to another. 
Cellular context, including inflammatory environment and surrounding substrate may actually be capable of "dedifferentiating" terminally differentiated cells into clonogenic cells. $^{88}$ This is known to occur upon isolation and passage in vitro with MSCs from

different tissues, including cartilage. ${ }^{131-133}$ It may well be the case the studies to date that have relied upon marker expression profiles of isolated pericytes in vitro have, by the very nature of their prior isolation and plating on tissue culture plastic, rendered indiscernible what were previously distinct populations of pericytes and MSCs in vivo. Caplan remarked in a high profile review, "It is now clear that isolated pericytes exhibit a panel of cell surface markers that are identical to those expressed by isolated MSCs., ${ }^{22,102}$ These recent observations serve to demonstrate just how difficult it has been for the field to explore the in vivo definition and capability of MSCs and pericytes without obfuscating the molecular reality by the necessary process of cellular harvest and in vitro culture itself.

\section{Clincial Trials Featuring MSCs}

Despite the unrest about the precise identity of and distinction between pericytes and MSCs, the tantalizing regenerative promise these cells hold for clinical medicine is prompting widespread interest and initiation of clinical trials. From 1995 to 2011, 206 separate clinical trials have been listed at clinicaltrials.gov that explore the use allogeneic and autologous MSCs for therapy in a variety of tissues. ${ }^{102}$ Some injected into the bloodstream have localized to sites of injury and inflammation. 
Among the anatomical locations considered for stem cell therapy, the eye is uniquely suited for clinical trials. Often times, patients are already blind in one eye and feel that their risk of a negative outcome, even in a preliminary safety study, is mitigated by the fact that they lack vision already in the one eye and use their other eye exclusively. Further, the vitreous cavity in the eye provides a rare largely acellular gel cavity which can serve to test stem cell suspensions and their impact on retinal biology. The easy accessibility of the eye, retina, and vitreous, relative to other organ systems, as well as physiologic readouts of efficacy, supports even more convincingly the use of the eye as a model system for stem cell therapy. No other window into the in vivo physiology of the central nervous system or well-templated microvasculature provides such a clear picture for evaluation of safety and efficacy.

To date, there are 98 clinical trials registered with the NIH that are exploring the use of stem cells for treatment of disease with ocular manifestations. ${ }^{134}$ Still in the infancy of MSC ocular therapy, these trials aim to establish safety data for future efficacy trials required for FDA approval. The ocular diseases being explored for MSC treatment range from retinopathy of different types, to glaucoma, to auto-immune neuropathies. Much of the ocular stem cell basic science and clinical trial effort to date focuses on cellular replacement of a particular ocular cell, such as a retinal pigment epithelial cell for example, reviewed well by Huang and colleagues. ${ }^{135}$

However, the basic scientists that research MSCs have not yet arrived at consensus understanding of cell function, control, or even MSC exclusive definition. As such, the 
proof of concept provided by such therapeutic clinical trials will lack the nuanced molecular understanding that will be required to refine and control MSC therapeutic potential. Specifically, the molecular mechanisms with which MSCs manipulate retinal microvasculature, alter the immune response, and differentiate themselves are not fully elucidated. Deeper understanding of these processes will greatly enhance and accelerate the development and adaptation of stem cell therapy for ocular disease. Rather than wait for every facet of the molecular biology of MSCs to come to light, it may serve both researchers and clinicians well to select diseases for which known specific cellular pathologies drive clinical progression. DR is just such a disease.

\section{MSC Therapy for DR}

Given that incipient pericyte dysfunction is central to the pathogenesis of DR, and that the eye has proven an attractive site at which to test stem cell therapeutics, it is not unreasonable to explore vigorously the use of MSCs for the treatment of DR. Other groups have endeavored to do so. Most notably, Friedlander and colleagues published the first use of bone marrow-derived MSCs (BMSCs) for treatment of retinopathy. ${ }^{11,136,}$ 137 In those studies, lineage negative stem cells from the bone marrow were isolated rather than using cells that were lineage positive and capable of differentiating into myeloid lineages - and injected into the vitreous. Specifically, BMSCs were used to differentiate into circulating endothelial progenitor cells (EPCs) that could differentiate into endothelial cells. These EPCs were unable to display MSC mutilineage potential for mesenchymal cell types, such as adipocytes, chondrocytes, or osteocytes. Impressively, they found that intravitreally injected BMSCs could stably integrate into the 
microvasculature of a damaged retina. Other myeloid progenitors harvested from the bone marrow have also demonstrated their utility in stabilizing retinopathic microvasculature. ${ }^{138}$ Microglia were also shown to be important cell types in retinal vascularization. Importantly though, especially given the central understanding of pericyte dysfunction in DR, these studies were unable to produce stable differentiation of pericytes from their progenitor populations, the authors even stating so explicitly. ${ }^{138}$

Grant and colleagues have also published extensively, focusing on the application of hematopoetic stem cells ${ }^{139-141}$ as well as harvested circulating EPCs ${ }^{142}$ for treatment of retinopathy and choroidal neovascularization. Again, Grant points out that hematopoetic BMSCs, when applied to the retina, do not readily generate pericytes. ${ }^{140}$ Grant's published studies suggest that, like BMSCs and pericytes, circulating EPCs also work by paracrine modification of the surrounding environment. ${ }^{142}$ Of note, her work and that of others provides a rich description of the deleterious impact that diabetes exerts on the paracrine profile and therapeutic potential of harvested circulating EPCs. ${ }^{142-146}$

These promising data indicate that intravitreally injected stem cells are capable of influencing multiple murine models of retinopathy, doing so by cellular integration into the retina and also paracrine conditioning of the inflammatory microenvironment. However, generating and stably integrating the pericyte - the cell long described as central to the cellular pathophysiology of DR - remained elusive. Given the accessibility and high cellular harvest yield of adipose-derived MSCs (ASCs), as well as their demonstrated likeness to pericytes, ASCs seemed a promising source as a cellularly 
specific stem cell therapy for diabetic retinopathy. Clinically, DR lacks a treatment that addresses the upstream microvascular dysfunction, and is treated only symptomatically by slowing the downstream molecular events that lead to proliferative retinopathy, fibrosis, and blindness. Considering the research advantages of stem cell therapy exploration in the eye, as well as the known pericyte dysfunction featured by DR, we hypothesized that ASCs could be used to stabilize the microvasculature of DR, acting as pericytes to integrate with retinal microvasculature and influence the local inflammatory environment in a paracrine fashion. A schematic for this cellular treatment paradiagm is laid out in Figure 2 below. 
Figure 2. Illustration of the proposed therapeutic approach. Human ASCs (hASCs) will be injected intra-ocularly to supplement the endogenous retinal pericyte population on the retinal microvasculature that has been pathologically reduced by DR. We hypothesize that hASC-pericytes will protect against early non-proliferative retinopathy and late-stage proliferative angiogenesis. 
Figure 2.

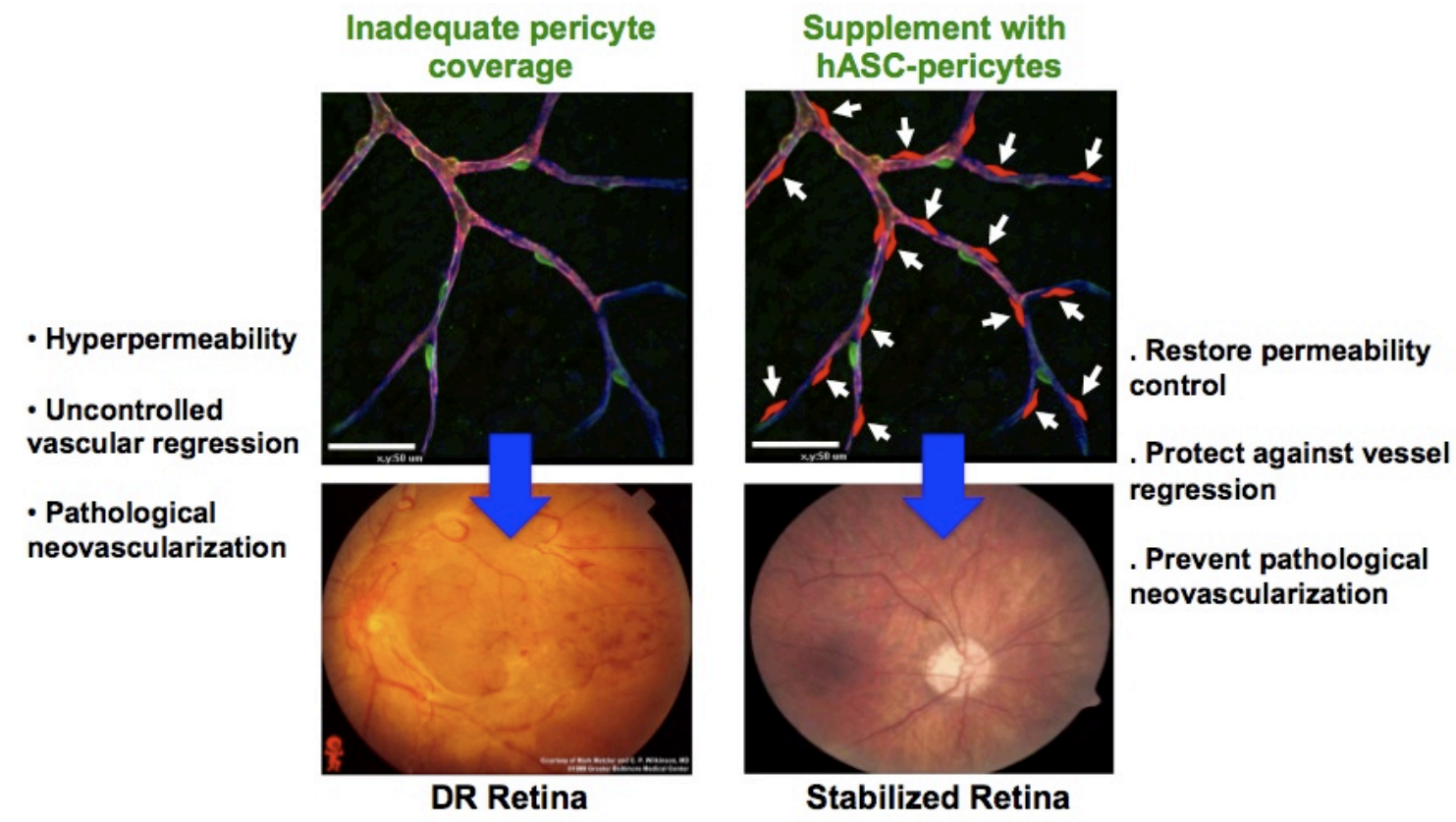




\section{Chapter 2}

Materials and Methods 
Cell Harvest - Human adipose derived stem cells (hASCs) were obtained from patients under full approval of University of Virginia's Institutional Review Board. Adipose tissue was removed surgically from patients during elective plastic surgery by Adam Katz, MD, in the operating room at the University of Virginia, as previously described. ${ }^{147}$ To prepare hASCs for in vitro and in vivo assays, the stromal vascular fraction was isolated from patient-derived lipoaspirate and further purified with serial passaging and sub-culturing, as we and others have previously shown. ${ }^{147}$ Mouse adipose derived stem cells (mASCs) were purchased from Eton Bioscience (280004001G) or isolated from the epididymal fat pad of C57BL/6 mice of the same genetic background as those animals into which these cells were subsequently injected. Human bone marrow derived stem cells (hBMSCs) were purchased from Allcells (\#MSC-001F). Bovine retinas and retinal microvascular endothelial cells and pericytes were isolated and characterized as previously described; no institutional animal use committee approval was required. ${ }^{148-151}$

Isolation of the stromal vascular fraction from the fat pad and culture of mASCs was performed in a manner identical to our processing of human lipoaspirates. Briefly, mASCs were harvested from epididymal fat pads of 21-week old wild type Akita mice, The fat pads were digested in a collagenase digestion buffer for one hour at $37 \mathrm{C}(0.01 \%$ collagenase type I, 2.5\% BSA, $200 \mathrm{nM}$ adenosine, $20 \mathrm{mM}$ HEPES, 1X Solution I, $1 \mathrm{X}$ Solution II). The resulting digest was filtered through $200 \mathrm{uM}$ mesh to exclude any undigested tissue. The filtrate was centrifuged to remove remaining collagenase, and the pellet (containing cells) incubated with red blood cell lysis buffer (15.5 mM NH4Cl, 10 mM KHCO3, $0.1 \mathrm{mM}$ EDTA) for 5 minutes at room temperature to lyse red blood cells. 
The cell suspension was then sterile-filtered through $40 \mathrm{uM}$ mesh and plated on sterile culture plates.

Cell Culture - Isolated hASCs and mASCs were cultured in $10 \mathrm{~cm}$ Nunc culture dishes (Thermoscientific \#12-565-020) using Gibco DMEM/F12 (1:1) (Life Technologies \#11320-033), supplemented with 10\% Gibco fetal bovine serum (Invitrogen \#16000044, Lot \#953873), 1\% antibiotic-antimycotic (Invitrogen \#15240062). hBMSCs were cultured in the same media as hASCs, but augmented to $20 \%$ fetal bovine serum. Media was replaced every three days and passaged at 70\% confluency with Stempro Accutase (Gibco/Life Technologies \#A11105-01). Cells were maintained at $37^{\circ} \mathrm{C}, 5 \% \mathrm{CO}_{2}$, and $75 \%$ humidity. hASCs and mASCs were used from passage 3 to 6 in all studies. hBMSCs were injected at passage 3 . Bovine retinas and retinal microvascular endothelial cells and pericytes were isolated and characterized as previously described. ${ }^{148,151}$

Cellular Contractility Assay - The assay was performed essentially as described. ${ }^{152}$ Briefly, round $12 \mathrm{~mm}$ diameter cover slips were coated with a thin layer of silicone that was then thermally cross-linked. A glow plasma discharge apparatus was used to charge silicone-coated coverslips, which were then coated with Type I collagen suspended in PBS (0.1 mg/ml, BD Biosciences \#354236). Thus prepared cover slips were placed in the wells of 24-well tissue culture plates, sterilized for 3 minutes with UV irradiation and seeded with $2 \times 10^{3}$ hASCs or bovine retinal pericytes. Silicone substrate deformation by cellular contraction can be visualized using brightfield imaging. 24 hour post-plating, hASCs were either left in serum-containing media or treated with this basal media 
containing $10 \mathrm{ng} / \mathrm{ml}$ rhTGF- $\beta 1$ (R\&D Systems \#240B). Following another 24-hour incubation period control or rhTGF- $\beta 1$-treated hASCs were visualized with an Axiovert 200M microscope (Carl Zeiss MicroImaging, Thornwood, NY) using 5x or 10x objective lenses. ${ }^{151,152}$ In order to quantify changes of hASC contractility induced by rhTGF- $\beta 1$ we manually counted the number of wrinkles formed by the cells cultured in the presence or absence of rhTGF $\beta-1$. The values were recorded using Microsoft Excel and are shown as a mean $+/-$ SEM.

Co-Culture Assay - This assay was performed as described previously ${ }^{151}$ with the following modifications. UV sterilized round cover slips were placed into the wells of 24well tissue culture plates and seeded with either bovine retinal pericytes or hASCs $\left(3 \times 10^{3}\right.$ cells/well). After the cells attached overnight, cultures were either incubated with normal $10 \%$ serum-containing growth media or pre-conditioned with $1 \mathrm{ng} / \mathrm{mL}$ rhTGF- $\beta 1$ in $0.5 \%-5 \%$ serum containing media for $24-48 \mathrm{~h}$. Pericyte/hASC cultures were washed with PBS to remove the rhTGF $\beta-1$, and bovine retinal endothelial cells (BRECs) were added to the wells at a density of $5 \times 10^{3}$ cells/well in $5 \%$ serum-containing media. For control experiments, BRECs were plated in monoculture, and allowed to attach overnight. For BREC monoculture, half the wells were treated with $5 \%$ serum media while the remainder was treated with $1 \mathrm{ng} / \mathrm{mL}$ rhTGF- $\beta 1$ in $5 \%$ serum-containing media. Both mono- and co-cultures were incubated for $24 \mathrm{~h}$, then S-phase entry (endothelial proliferation) was assessed using Click-iT® EdU Cell Proliferation Kit (Invitrogen \#C10339) according to the manufacturer's instructions. Following EdU detection, hASC and pericytes were stained using primary antibodies against mouse anti-SMA (Biogenex 
\#MU128-UC) and secondary anti-mouse Alexa-Fluor488 (Invitrogen A-21200). Digital fluorescence and brightfield imaging was performed following fixation and staining as previously described. ${ }^{151}$ Endothelial S-phase entry in control and treated co-cultures both for BRECs that were isolated or contacting either hASCs or bovine retinal pericytes were then quantified and values expressed +/- SEM.

In Vitro Immunohistochemistry - hASCs and mASCs were briefly washed in PBS, fixed using methanol (10 min at $-20 \mathrm{C})$, rinsed with PBS (3 x 5 min), blocked with $1 \%$ BSA, $2 \%$ goat serum, $0.1 \%$ Triton $\mathrm{X}$ in $\mathrm{PBS}$, exposed to primary antibodies in blocking solution (4C overnight), washed with PBS (3 x $10 \mathrm{~min}$ ), and either cover slipped or exposed to secondary antibody (45 min), followed by washing with PBS (3 x 10 min). Antibodies used for hASCs were mouse monoclonal SMA-FITC (Sigma-Aldrich F3777; 1:250), rabbit polyclonal NG2 (Millipore AB5320; 1:100), rabbit polyclonal PDGFR $\beta$ (Santa Cruz sc-432; 1:100), and secondary goat anti rabbit Cy2 (Millipore; 1:250). mASCs were stained with $\alpha$-smooth muscle actin preconjugated to Cy3 (Sigma \#C6198.2ML).

Flow Cytometry - Antibody characterization of hASCs (passage 4) and mASCs (passage 4) was performed on a Becton Dickinson/Cytek FACSCalibur C with CellQuest Pro acquisition software, using FlowJo software for analysis. Cells were lifted using Accutase (20 min), fixed with methanol (10 min; -20C), washed with $1 \%$ BSA in PBS, permeabilized with $1 \%$ BSA, $0.1 \%$ Triton $\mathrm{X}$ in PBS (10 min; 4C). Primary antibody incubation in $1 \%$ BSA in PBS (45 min), washed with $1 \%$ BSA in PBS (2x) and re- 
suspended in $500 \mu \mathrm{l} 1 \% \mathrm{BSA}$ in PBS for analysis. Antibodies used for hASCs were mouse monoclonal $\beta$-actin-FITC (Abcam ab64496), mouse monoclonal SMA-FITC (Sigma-Aldrich F3022; 1:500), rabbit polyclonal PDGFR $\beta$ (Santa Cruz sc-432; 1:200), and secondary goat anti rabbit Cy2 (Millipore; 1:250), and mouse IgG1-FITC isotype control (BD Pharmingen 554679; $0.5 \mathrm{ug} / \mathrm{uL}$ ). mASCs were stained with PDGFR $\beta$ (CD140b) preconjugated to APC (eBioscience \#17-1402-80), $\alpha$-smooth muscle actin preconjugated to Cy3 (Sigma \#C6198-.2ML). Results were replicated using at least 3 separate experiments. hASCs and mASCs were isolated as described above.

Ocular Injections - Mice were anesthetized with ketamine/xylazine injected intraperitoneally or with inhaled isoflurane. If palpebral fissures were not yet open, they were carefully cut with iris scissors, followed by local application of proparacaine. Prior to injection, hASCs, mASCs, or hBMSCs were stained with 1,1'-Dioctadecyl-3,3,3',3'Tetramethylindocarbocyanine Perchlorate (DiI - Invitrogen D282), using a standard labeling technique for tracking of adult mesenchymal stem cells. ${ }^{153-158} \mathrm{hASCs}$, mASCs, or hBMSCs were suspended in 0.5 to $1.5 \mathrm{uL}$ of PBS were injected into the vitreous of the study eye with a 33 gauge Hamilton needle through the pars plana. An equal volume of PBS was in most experiments injected into the contralateral eye to serve as a paired control. For palpebral fissures cut with iris scissors, a small amount of methylcyanoacrylate was used to re-seal the lids. All injected ASCs were passage 4 to passage 6 at the time of injection. BMSCs were passage 3 at the time of injection. 
Oxygen Induced Retinopathy (OIR) - All procedures performed with mice conformed to the guidelines within the ARVO Statement for the Use of Animals in Ophthalmology and Vision Research and were approved by the University of Virginia's Animal Care and Use Committee. NOD SCID mice (Charles River) were immersed in 94\% oxygen from postnatal day 7 (P7) to day 12 (Biospherix A30274-P, P-110-E702), as 75\% oxygen did not produce substantial central avascular area in NOD SCID pups. The mice were checked through the clear plastic door twice daily for the duration of the oxygen treatment. Retinas were harvested as described below and retinal wholemounts prepared. Areas of capillary pruning (major vessels remain in tact) were traced manually by blinded individuals and quantified in ImageJ. For the OIR recovery model, following OIR 10,000 hASC cells in $1.5 \mu \mathrm{L}$ of PBS were injected into the vitreous of the post-natal day 12 (P12) eye, with equal volume of PBS alone in the contralateral control eye. As a cell type control for the OIR recovery model, two litters ( $\mathrm{n}=10$ P12 pups) of NOD SCID mice were used with either $10,000 \mathrm{hBMSC}$ or $10,000 \mathrm{hASC}$ cells in $1.5 \mu \mathrm{L}$ of PBS injected into the vitreous of the post-natal day 12 (P12) eye, with equal volume of PBS alone in the contralateral control eye. To account for litter variability, half the mice in these litters received hBMSCs ( $\mathrm{n}=5$ eyes of 5 P12 pups) in the study eye, while the other half received hASCs ( $n=5$ eyes of 5 P12 pups) in the study eye. Use of two NOD SCID litters controlled for known litter and littermate variability. All eyes were harvested and examined for areas of capillary pruning at P14. For the OIR protection model, $600 \mathrm{hASC}$ cells suspended in $0.5 \mu \mathrm{L}$ of PBS were injected at P2 into the study eye and $0.5 \mu \mathrm{L}$ of PBS alone in the contralateral control eye. Eyes were harvested and examined for areas of capillary pruning at P12 following OIR. For the rhTGF- $\beta 1$ OIR protection model, 
1000 hASC cells suspended in $0.5 \mu \mathrm{L}$ of PBS were injected at P6 into the study eye and $0.5 \mu \mathrm{L}$ of PBS alone in the contralateral control eye. Eyes were harvested and examined for areas of capillary pruning at P12 following OIR.

Akimba Model of Diabetic Retinopathy - Kimba and Akita mice were obtained from Elizabeth Rakoczy, $\mathrm{PhD}$, and crossed as previously described to establish a breeding colony for further ASC studies. ${ }^{159}$ Intraocular injections for the Akimba vascular protection model were performed at P9 with mASCs (Eton Bioscience, passage 3) cultured as described (Cell Harvest, Ocular Injections). Specifically 1,000 mASC cells in $0.5 \mu \mathrm{L}$ of PBS were injected into the vitreous of the post-natal day 9 (P9) eye, with equal volume of PBS alone in the contralateral eye. 2 months after injection, fluorescein angiography was performed with by injecting intraperitoneal $0.1 \mathrm{ml}$ of $10 \%$ fluorescein reconstituted in PBS into mice anesthetized with Ketamine/Xylazine. A Cantor Nissel contact lens was applied to the cornea and the retinal vasculature imaged on a Heidelberg Spectralis retinal imager as previously described. Following angiography, retinas were harvested and retinal wholemounts prepared as described below in the Retinal Wholemounts section of Methods. As with OIR experiments, areas of capillary pruning (major vessels remain in tact) were traced manually by blinded individuals and quantified in ImageJ. In a second experiment we examined the potential for homologous incorporation of mASCs at late time points. For this latter experiment, we harvested mASCs from mice of the same C57BL/6 background as the Akimba mice in which they were subsequently injected (as described above in Cell Harvest section of Methods). Specifically $1,000 \mathrm{mASC}$ cells in $0.5 \mu \mathrm{L}$ of PBS were injected into the vitreous of the 4 
week old Akimba eye, with equal volume of PBS alone in the contralateral eye. Retinas were harvested at 2 months of age and wholemounts prepared as described below in the Retinal Wholemounts section of Methods. Retinal vessels were isolectin stained, and imaged for incorporation of DiI labeled mASCs into the retina and association with the retinal microvasculature.

For experiments with older Akimba mice to evaluate impact of diabetic status of mASC donor, male four week old Akimba mice were anesthetized with ketamine/xylazine injected intraperitoneally and proparacaine applied topically to the eyes just prior to injection. mASCs were injected through the pars plana into the vitreous using a 33-gauge Hamilton syringe. A total of 12 Akimba mice were injected in this manner with mASCs in one eye and a contralateral PBS control injection in the other eye. In six of these mice, healthy mASCs were used, and in the other six diabetic mASCs were used.

Retinal Wholemounts - Mice were sacrificed by overdose of ketamine/xylazine injected intraperitoneally and then perfused for 5 minutes with $4 \%$ paraformaldehyde by insertion of a needle into the left ventricle of the heart, attached to a perfusion pump, following cutting of the inferior vena cava. Eyes were then enucleated and immersed in $4 \%$ paraformaldehyde for 10 minutes, without any perforation of eye, before being transferred to PBS at room temperature for 10 minutes. Cornea, extraocular muscles, optic nerve, iris, sclera, retinal pigment epithelium, lens, and hyaloid vasculature were then carefully removed in that order. Four relaxing cuts were made to enable flatmounting on a gelatin-coated slide. After permeabilization with $1 \mathrm{mg} / \mathrm{mL}$ digitonin 
(MP Biomedicals 0215948050) for 1 hour, retinas were stained with mouse monoclonal SMA-FITC (Sigma-Aldrich F3022; 1:250), isolectin IB4-647 (Invitrogen I32450; 1:200), isolectin IB4-488 (Invitrogen I21411; 1:200), anti-NG2 chondroitin sulfate proteoglycan (Millipore AB5320; 1:100), goat anti-rabbit IgG, and/or Cy2-conjugated (Millipore AP132J; 1:250). Slides were mounted with fluorogel with TRIS buffer (Electron Microscopy Sciences 17985-10).

Retinal Vascular Imaging and Quantification - Flat mounted retinas were imaged using a Leica TCS SP2 confocal with DMIRE2 inverted microscope and a Zeiss LSM 510 confocal microscope. 10x images were montaged using i2kAlignRetina (Dual Align, LLC) and the MosaicJ plugin in Fiji Software version of ImageJ.

For calculations of vascular length density in Akimba mice, 10x, 20x, and 60x image stacks were taken on a confocal laser scanning microscope. 10x stacks were flattened and tiled into whole-retina montages using ImageJ. Vessel length of whole retinas was calculated digitally by skeletonization in ImageJ and subsequent pixel count of the skeletonized vasculature in MATLAB. Briefly, skeletonized images were binary, so each black pixel was counted as vessel, and each white pixel was counted as non-vessel area. Vascular density is equal to the ratio of vessel length to whole retina area.

For ASC integration in Akimba mice, labeled mASCs were counted in three representative 20x image stacks per retina by blinded observers. Each field of view was taken at the same distance from the optic nerve. 
Angiogenesis Secretome - Conditioned media samples were obtained from 3 populations each of healthy and diabetic mASCs, taken from wild-type and Akimba mice of the same age, respectively. All cells were simultaneously passaged to P4, counted, plated with fresh media, and allowed to incubate at $37^{\circ} \mathrm{C}$ for 24 hours before collection of conditioned media. These samples were run on a Mouse Proteome Profiler Angiogenesis Array (R\&D Systems ARY015), which tested for 53 angiogenic factors. X-ray film captured chemiluminescence from each dot, which was proportional to the amount of factor bound. Relative expression levels were obtained from densitometry analysis (ImageJ) of x-ray film spots. Finally, angiogenic factor levels were normalized to positive control and cell count.

Cell Proliferation \& Apoptosis Assays - mASCs from three 9 week old healthy and three 9 week old diabetic Akimba animals were plated on glass coverslips in 12-well dishes at a density of 4000 cells $/ \mathrm{cm}^{2}$ and allowed to adhere for 24 hours (Cold Spring Harbor proceedings). Three coverslips were cultured for each animal. To measure cell proliferation in each population of mASCs, mASCs were incubated with 5-ethynyl-2'deoxyuridine (EdU) for 12 hours and subsequently stained following the manufacturer's instructions. To measure apoptosis, the terminal deoxynucleotidyl transferase dUTP nick end labeling (TUNEL) method was used. Fluorescence intensity was measured for each coverslip using confocal microscopy, taking image stacks with 3um spacing and measuring total fluorescence intensity for each coverslip in ImageJ. 
Measurements of oxygen consumption and mitochondrial function - Oxygen consumption rate (OCR) was measured using a Seahorse XF-24 Flux Analyzer (Seahorse Biosciences, Billerica, MA), as previously described ${ }^{160}$ mASCs were seeded in a Seahorse 24-well tissue culture plate at a density of 3.0x104 cells/well in normal growth media for 24 hours prior to the assay. On the day of the assay the media was changed to unbuffered DMEM and equilibrated at $37^{\circ} \mathrm{C}$. Oligomycin $(2 \mu \mathrm{M})$, FCCP $(1 \mu \mathrm{M})$, and Rotenone and Antimycin $\mathrm{A}(1 \mu \mathrm{M}$ and $10 \mu \mathrm{M})$ were injected sequentially during the assay as indicated. Each OCR measurement represents the average of a 3 minute reading every $10 \mathrm{~min}$, with $3 \mathrm{~min}$ of mixing and $4 \mathrm{~min}$ of wait time per cycle. 3-4 wells were used for each experimental group.

Statistics - Unless otherwise stated, comparisons were made using median values and significance tested with nonparametric Wilcoxan Matched Pairs and Mann-Whitney tests due to non-Gaussian dissimilar variance. Statistics were calculated on GraphPad Prism version 6.00 for Macintosh, GraphPad Software, La Jolla California USA, www.graphpad.com. Error bars represent standard deviation. Statistical significance is denoted in all figures indicated by asterisks with * for $\mathrm{p} \leq 0.05$, and $* *$ for $\leq 0.01$, and $* * *$ for $\leq 0.001$.

For in vivo Akimba experiments that studied the effect of diabetic status of donor stem cells, data was analyzed for numerical differences using paired t-tests comparing left and right eyes for 6 healthy and 6 diabetic animals. All in vitro mASC experiments were performed with 3 healthy and 3 diabetic animals, and significance was determined using 
a student's t-test. Statistical tests including t-tests, paired t-tests, Wilcoxon Signed Rank tests, and ANOVAs were performed in SigmaStat (Systat Software Inc, San Jose, CA). Statistical significance was determined using a maximum p-value of 0.05 or smaller if indicated. 


\section{Chapter 3}

Pericytes derived from adipose-derived stem cells protect against retinal vasculopathy. 


\section{The following chapter is adapted from the published manuscript:}

\section{Mendel, T.A., et al., Pericytes derived from adipose-derived stem cells protect against} retinal vasculopathy. PLoS One, 2013. 8(5): p. e65691.

Background: Retinal vasculopathies, including DR, threaten the vision of over 100 million people. Retinal pericytes are critical for microvascular control, supporting retinal endothelial cells via direct contact and paracrine mechanisms. With pericyte death or loss, endothelial dysfunction ensues, resulting in hypoxic insult, pathologic angiogenesis, and ultimately blindness. ASCs differentiate into pericytes, suggesting they may be useful as a protective and regenerative cellular therapy for retinal vascular disease. In this study, we examine the ability of ASCs to differentiate into pericytes that can stabilize retinal vessels in multiple pre-clinical models of retinal vasculopathy.

Methodology/Principal Findings: We found that ASCs express pericyte-specific markers in vitro. When injected intravitreally into the murine eye subjected to oxygen-induced retinopathy (OIR), ASCs were capable of migrating to and integrating with the retinal vasculature. Integrated ASCs maintained marker expression and pericyte-like morphology in vivo for at least 2 months. ASCs injected after OIR vessel destabilization and ablation enhanced vessel regrowth (16\% reduction in avascular area). ASCs injected intravitreally before OIR vessel destabilization prevented retinal capillary dropout (53\% reduction). Treatment of ASCs with transforming growth factor beta 1 (TGF- $\beta 1$ ) enhanced hASC pericyte function, in a manner similar to native retinal pericytes, with 
increased marker expression of smooth muscle actin, cellular contractility, endothelial stabilization, and microvascular protection in OIR. Finally, injected ASCs prevented capillary loss in the diabetic retinopathic Akimba mouse (79\% reduction 2 months after injection).

Conclusions/Significance: ASC-derived pericytes can integrate with retinal vasculature, adopting both pericyte morphology and marker expression, and provide functional vascular protection in multiple murine models of retinal vasculopathy. The pericyte phenotype demonstrated by ASCs is enhanced with TGF- $\beta 1$ treatment, as seen with native retinal pericytes. ASCs may represent an innovative cellular therapy for protection against and repair of DR and other retinal vascular diseases.

\section{Introduction}

Aberrant retinal angiogenesis and vasculopathies, including retinopathy of prematurity (ROP), exudative AMD, and DR, are among the leading causes of irreversible vision loss throughout the world. ${ }^{161}$ DR alone afflicts an estimated 101 million people worldwide, with a prevalence of 155 million expected by $2030 .^{5}$ While the pathogenesis and timing that underlie each condition differ, each involves destabilization of the retinal microvasculature.

Retinal pericytes, the cells that ensheath the retinal microvasculature, play a key role in the stabilization of endothelial cells, protecting them from hypoxic insults and angiogenic stimuli. ${ }^{26}$ They are likely to be amongst the first cellular responders to diabetes-induced 
complications, a direct consequence of chronic diabetic inflammation. ${ }^{21,65}$ Inadequate pericyte coverage of microvasculature has also been implicated in the pathogenesis of ROP. ${ }^{162,}{ }^{163}$ Rich in actin, ${ }^{148}$ contractile pericytes are considered critical for microvascular control throughout the human body, supporting endothelial cells via contact-dependent ${ }^{22}$ and soluble mediator-driven mechanisms. ${ }^{23,}{ }^{24}$ Following pericyte death or loss, endothelial dysfunction results in downstream hypoxic insult, VEGF, macular edema, pathologic angiogenesis, and ultimately blindness. ${ }^{14}$

Previous work has elegantly demonstrated that intravitreally injected BMSCs can help ameliorate and repair retinopathic insults. However, the BMSC mechanism of action appears to be primarily through their incorporation into the retina as endothelial cells, microglia, and photoreceptors. ${ }^{11,138,139,141,164}$ Although pericytes can be derived from $\mathrm{BMSCs}^{165}$, this does not appear to be a predominant differentiation pathway for these cells injected into the eye. ${ }^{138,162}$

ASCs are an alternative type of adult mesenchymal stem cells that are readily isolated from subcutaneous fat. ASCs contain a vascular progenitor subpopulation that is easily expanded for use in regenerative medicine. ${ }^{166}$ Importantly, these cells are postulated to have a direct role in providing microvascular support and appear to differentiate readily as pericytes. ${ }^{166,167}$ These attributes of ASCs suggest they could be useful for treatment of retinal vascular disease. 
To examine their potential therapeutic application in retinal vasculopathy, we sought to determine whether ASCs, once injected intravitreally, are able to migrate to and integrate with the retinal microvasculature. We also assessed to what extent ASCs could replicate characteristics of endogenous retinal pericytes in in vitro assays of retinal pericyte function. We hypothesized that, as pericyte progenitors, ASCs could enable microvascular stabilization and offer protection against retinal vascular insults, including DR.

\section{Results}

\section{Retinal incorporation of intravitreally injected hASCs}

We initially sought to determine if ASCs could be efficiently delivered to the retina through intravitreal pars plana injection, and once there, whether they would successfully integrate with the retinal vasculature. We injected hASCs intravitreally, similar to previously published BMSC retinal incorporation experiments. ${ }^{11}$ In particular, our goal was to assess the ability of intravitreally delivered ASCs to assume abluminal locations around retinal capillaries; a defining characteristic of pericytes.

In the OIR model, the central retinal microvasculature is ablated during a hyperoxic insult that takes place from $\mathrm{P} 7$ to $\mathrm{P} 12,{ }^{14}$ while the major vessels remain. Revascularization of the central retina, including recruitment of native retinal pericytes, occurs once mice are returned to room air at P12. ${ }^{168}$ hASCs suitable for injection were derived from human lipoaspirates that were serially passaged in culture, due to the known enrichment of a pericyte-like phenotype at later passages. ${ }^{169}$ Before injection, hASCs were labeled with 
DiI, as used by others for tracking adult mesenchymal stem cells in vivo. ${ }^{153-158}$ Initial injections with 10,000 DiI-labeled hASCs suspended in sterile PBS were performed through the pars-plana at post-natal day 12 (P12) after mice had first been exposed to OIR. $^{138,170-173}$

hASCs were observed in abundance alongside central retinal microvasculature 10 days after injection (Figure 3A). 8 weeks after injection, $308 \mathrm{hASCs}$, or 3.08\% (2.08-4.07 95\% CI) of the 10,000 injected cells, remained engrafted, which is comparable to stem cell engraftment efficiencies observed in other model systems. ${ }^{174} \quad 85.6 \%(82.8-88.7 \% 95 \%$ CI) of engrafted hASCs were found in physical contact with retinal microvessels, many adopting pericyte-like abluminal locations and phenotypic wrapping around vessels (Figure 3B, C). While our studies to date do not conclusively rule out some proliferation of injected ASCs after injection into the eye, the numbers of cells observed two months after injection were not substantially more than the number of cells in eyes harvested one week after injection.

\section{Verification of hASC-derived pericyte marker expression in vitro and in vivo}

While a functional pericyte phenotype for hASCs is suggested by their morphology and perivascular location, we sought to further explore hASC expression of characteristic pericyte markers. Alpha smooth muscle actin (SMA), nerve/glial antigen 2 (NG2), and platelet derived growth factor receptor beta (PDGFR $\beta$ ) frequently designate a pericyte phenotype, although specific isoprotein expression is dependent upon microvascular context in vivo. ${ }^{39,40}$ We found that hASCs express abundant steady state protein levels 
characteristic of native microvascular pericytes, including SMA, NG2, and PDGFR $\beta$ as measured by both antibody staining and flow cytometry, with $91.2 \%$ of cells showing coexpression of both SMA and PDGFR- $\beta$ (Figure 3 D-J). Additionally, hASCs injected intravitreally into NOD SCID mice following OIR induction also continue to express SMA and NG2, when harvested six to eight weeks post-injection (Figure $3 \mathrm{~K}-\mathrm{L}$ ). Both our in vivo and in vitro studies indicate that serially passaged hASCs can differentiate into retinal pericytes in response to microenvironmental cues.

Importantly, no ocular tumor formation was observed and no metastatic lesions in the lung or liver were found at these time points, consistent with prior reports on in vivo hASC use. ${ }^{175}$ Sagittal sections of hASC injected eyes stained with either oil red O or Alcian Blue did not reveal any off target differentiation of hASCs into adipose or chondrocyte lineages (data not shown). Similarly, antibody staining with F4/80, a microglial and macrophage marker, did not show any definitive differentiation into these cell types. Interestingly we saw no significant cell trafficking to deeper layers of the retina on sagittal section or $3 \mathrm{D}$ confocal reconstruction of the retinal vasculature. Subretinal hASCs were sometimes seen near the site of injection, often associated with a localized retinal detachment, that suggest cell trafficking to these locations occurred at the time of injection. 
Figure 3. hASCs demonstrate pericyte-like morphology and phenotype markers in vitro and in vivo. A, DiI labeled (red) hASCs injected intravitreally at postnatal day 12 (P12) following oxygen induced retinopathy (OIR) home from the vitreous to murine retinal microvasculature (green) as seen following harvest at P22. B-C, DiI labeled hASCs (red) wrap around isolectin labeled retinal microvessels (blue) abluminally and target vascular junctions, both properties of terminally differentiated pericytes. D-I, Passage 5 hASCs exhibit in vitro expression of the characteristic pericyte markers smooth muscle actin (SMA, D-E), nerve/glial antigen 2 (NG2, F-G), and platelet derived growth factor receptor beta (PDGFR- $\beta, \mathbf{H}-\mathbf{I}$ ) by both immunohistochemical staining on cultured cells and by flow cytometry on cells harvested from these cultures. $\mathbf{J}, 91.2 \%$ of hASCs demonstrated colabeling of SMA and PDGFR- $\beta$ compared to unstained controls. K-L, DiI labeled hASCs injected intravitreally into NOD SCID mice at P12, after OIR hyperoxia, maintain intimate association with the retinal microvasculature 6-8 weeks later and demonstrate persistent SMA (K), NG2 (L) (white arrows), with SMA extending into the cellular extension wrapping around the capillary. On average $308 \mathrm{hASCs}$, or $3.08 \%$ of the 10,000 injected cells, remained engrafted, with $85.6 \%$ of engrafted hASCs found in physical contact with retinal microvessels Note native retinal pericytes are also labeled with NG2 (L) but lacking DiI staining (white arrowheads). In contrast, no native retinal pericytes are seen labeled with SMA $(\mathrm{K})$ given that this is a tertiary branch of the retinal vasculature, and native pericyte SMA expression is typically seen only on primary and secondary vessels. Scale bars: $\mathbf{A}=200 \mu \mathrm{m} ; \mathbf{B}=20 \mu \mathrm{m}, \mathbf{C}=10 \mu \mathrm{m}$. Scale bars: $\mathbf{D}, \mathbf{F}$, $\mathbf{H}=100 \mu \mathrm{m} ; \mathbf{K}=10 \mu \mathrm{m}, \mathbf{L}=20 \mu \mathrm{m}$. 
Figure 3.

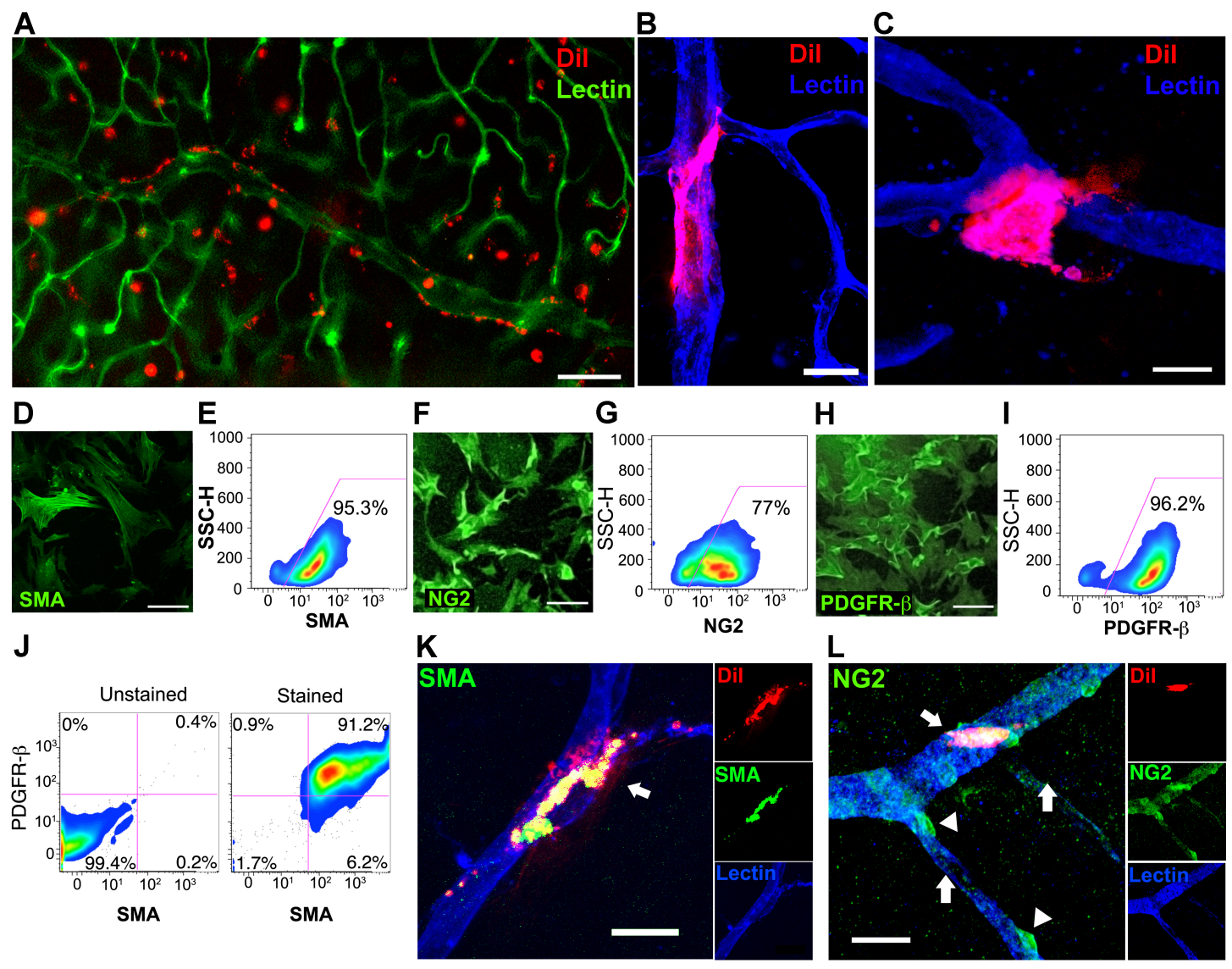


hASCs accelerate recovery from oxygen induced retinopathy

Having demonstrated that hASCs could home to and integrate with retinal vasculature with stable expression of pericyte markers, we next assessed whether these injected hASCs would functionally affect revascularization of the central retina following OIR injury. As before, eyes were injected with hASCs at P12 following OIR and then harvested at P14, which in NOD-SCID mice is the midpoint of post-OIR revascularization. Contralateral eyes were injected with an equal volume of PBS vehicle, serving as a commonly employed carrier control, ${ }^{138,}, 176-179$ and allowing paired comparison of eyes. NOD-SCID mice were chosen to avoid the potential immune rejection of our xenografted hASCs that might confound our analysis of revascularization. Flat-mounted retina demonstrated a $16.4 \%$ reduction in avascular area $(\mathrm{n}=17, \mathrm{p}=0.03)$, indicating greater central retinal revascularization compared to contralateral control retinas injected with PBS (Figure 4 A-C). No appreciable pre-retinal neovascularization was observed at any time point in either control or hASC injected eyes, likely due to our use of immunocomprimised mice, since inflammatory stimuli have been shown to be a large component of the aberrant neovascular response. ${ }^{180}$

As an additional cell type control, two NOD SCID litters ( $\mathrm{n}=10$ pups total) were injected with either 10,000 hASCs ( $\mathrm{n}=5$ eyes of 5 pups) or 10,000 human bone marrow derived stem cells (hBMSCs) ( $\mathrm{n}=5$ eyes of 5 pups) in the study eye at P12, along with and equal volume of PBS in the contralateral control eye ( $\mathrm{n}=10$ eyes of 10 pups). Unsorted hBMSCs were chosen as a negative control cell since sorted lineage negative murine BMSCs are another mesenchymal stem cell previously shown to influence retinal 
Figure 4. Human adipose-derived stem cells (hASCs) stabilize oxygen-induced retinopathy (OIR). A-C, Eyes of NOD SCID mice, injected intravitreally with hASCs at P12 following OIR, and then harvested at P14, demonstrate improved revascularization of central retina as compared to contralateral PBS injected (blue) carrier controls $(16.4 \%$ reduction, $\mathrm{n}=17, \mathrm{p}=0.03)$. $\mathbf{D}-\mathbf{F}$, NOD SCID eyes injected with intravitreal hASCs at $\mathrm{P} 2$, prior to OIR, exhibited dramatically less central vascular ablation at P12 than contralateral PBS injected carrier controls (blue) $(52.9 \%$ reduction, $\mathrm{n}=6, \mathrm{p}=0.03)$. Lines in $\mathbf{C}$ and $\mathbf{F}$ connect data points for hASC injected and contralateral PBS injected eyes in the same mouse. 
Figure 4.
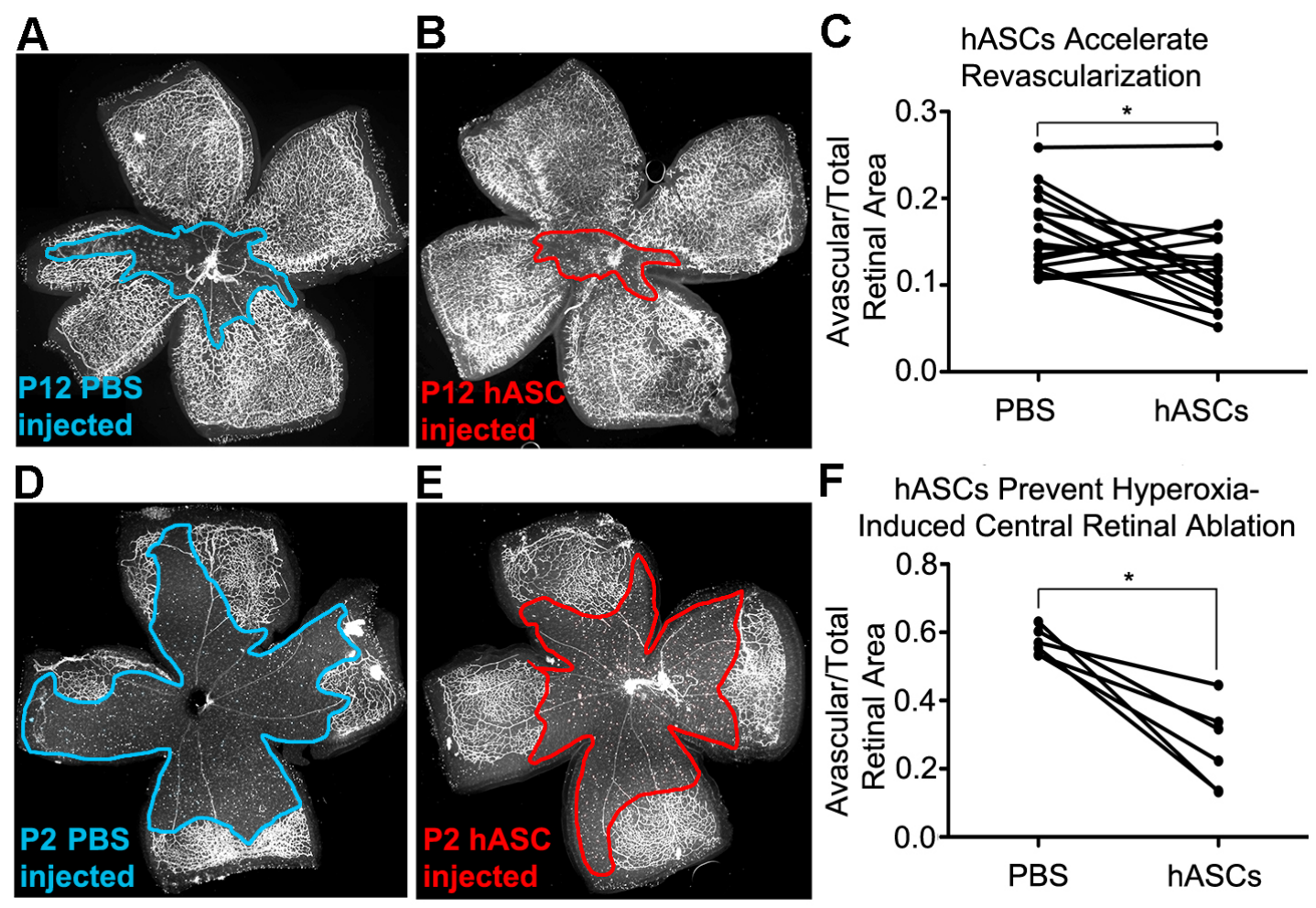

F hASCs Prevent HyperoxiaInduced Central Retinal Ablation

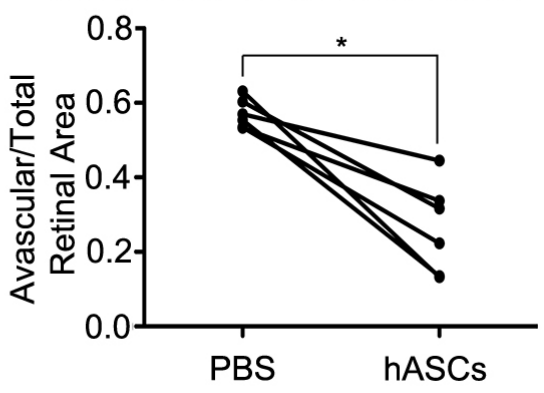


vasculature. ${ }^{11}$ We again confirmed at P14 that hASCs accelerate revascularization of the central retina by $16.4 \%$ compared to contralateral PBS injected control eyes $(n=5$ pups, $\mathrm{p}=0.03)$. However, hBMSCs had no statistically significant effect on the rate of revascularization compared to contralateral PBS injected control eyes $(n=5$ pups, $p=$ 0.29) (Figure 5).

\section{hASCs protect against oxygen induced retinopathy}

We next determined whether injected hASCs could protect central retinal microvessels against destabilization and ablation seen during OIR. Eyes were injected at P2 with 600 DiI labeled hASCs suspended in 0.5 $\mu \mathrm{l}$ PBS due to the smaller ocular volume at P2, with contralateral eyes receiving equal volumes of PBS as a vehicle control. Notably, injections with hASCs at P2 do not appear to appreciably affect normal retinal vascularization thru P7, just prior to OIR (Figure 6). Injected mice underwent OIR from P7 to P12 per standard protocol ${ }^{168}$. Retinal wholemounts at P12 demonstrated a profound $52.9 \%$ reduction of avascular area $(n=6, p=0.03)$ in hASC-treated eyes as compared to contralateral PBS injected controls (Figure 4 D-F).

This result suggests that injected hASCs may assist in stabilizing retinal microvasculature that is otherwise acutely unstable. Although the mechanism underlying this protection is not yet clear, in hASC injected eyes we find injected hASCs efficiently integrate into the retinal microvasculature after P8 and demonstrate a 57\% increase $(\mathrm{n}=16$ and $12, \mathrm{p}=$ 0.031) in vascular length density in retinal sub-fields containing labeled cells as compared to sub-fields without cells. This finding is consistent with prior studies 
Figure 5. hBMSCs fail to accelerate hypoxic revascularization. Compared to contralateral PBS injected controls (A), eyes injected with unsorted hBMSCs (B) at P12 and harvested at P14 displayed no statistical difference (C). However, when compared to PBS contralateral controls (D), eyes injected with hASCs demonstrated a statistically significant decrease in central retinal capillary dropout $(\mathbf{F}), 16.4 \%$ reduction, $\mathrm{p}=0.03, \mathrm{n}$ $=5)$. 
Figure 5.
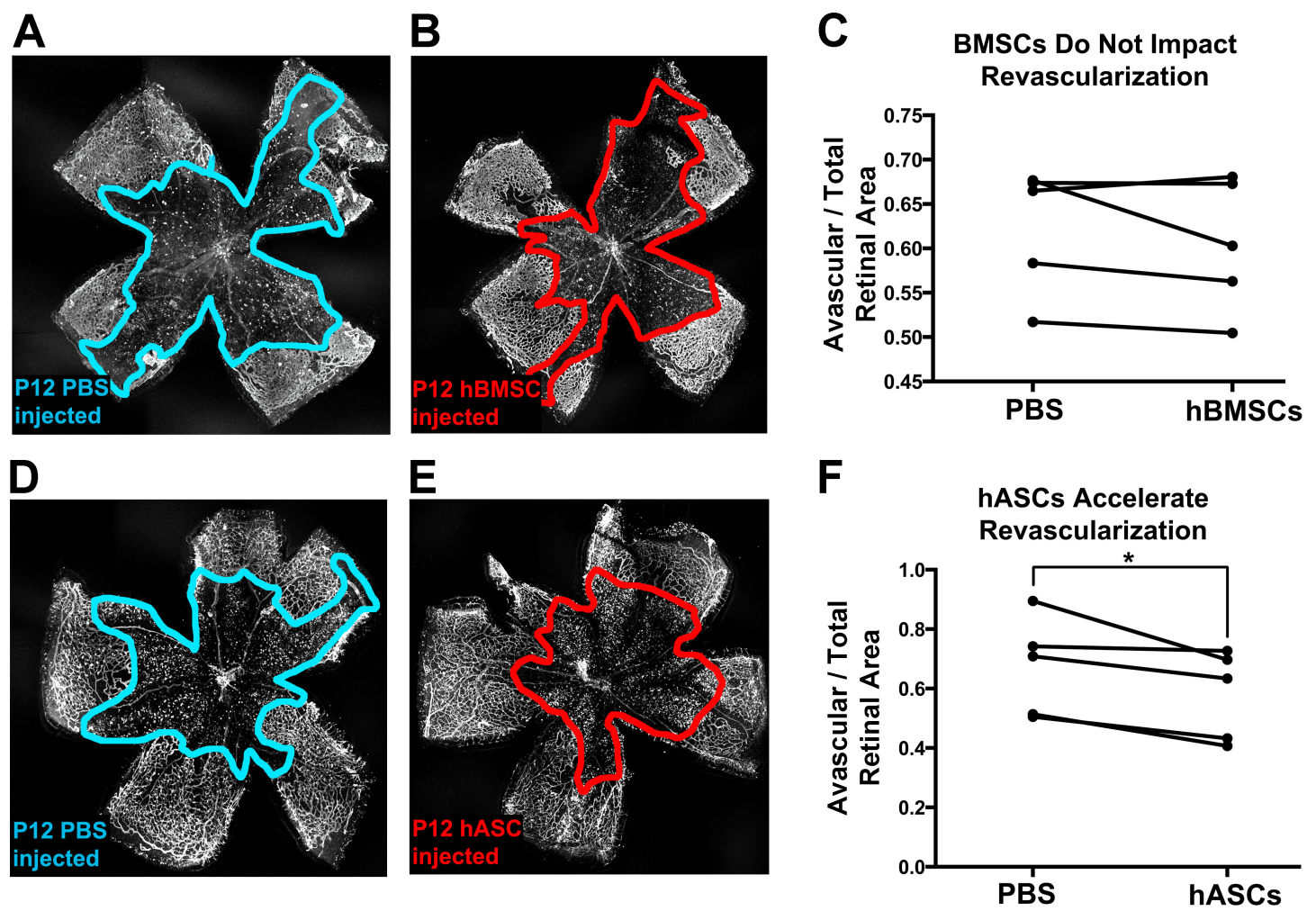
Figure 6. P2 hASC injections do not impact retinal vascularizaiton prior to hyperoxia. Compared to contralateral PBS injected controls (A), eyes injected with hASCs (B) at P2 and harvested at P7 without exposure to hyperoxia displayed no obvious differences in vascular coverage, density, or morphology. 
Figure 6.

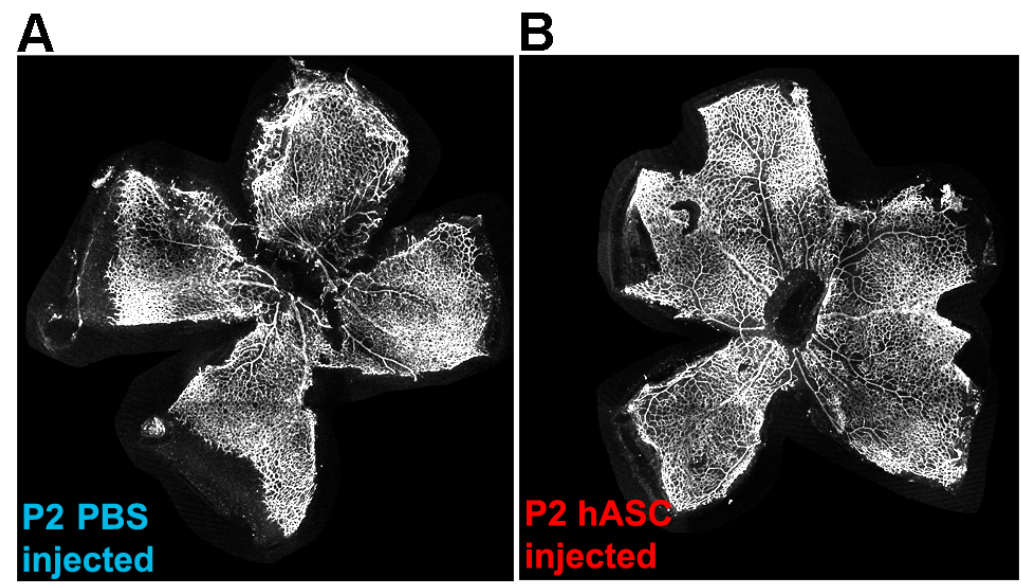


demonstrating decreased vessel susceptibility to OIR corresponding to increased desmin ensheathment ratio, which serves as a surrogate for pericyte coverage. ${ }^{162,163}$

However, this explanation seems insufficient to fully account for the observed results. Few cells are seen integrated with the retinal microvasculature at $\mathrm{P} 7$, prior to OIR, with less than $5 \%$ of total injected cells found associated with the microvasculature by P12, following OIR. Given that ASCs are known to secrete a large repertoire of trophic factors and that the majority of injected cells remain in the vitreous upon dissection, its seems likely that hASCs mediate protection of retinal microvessels at least in part via paracrine signaling as mechanisms.

hASCs respond to pre-treatment with TGF- $\beta 1$ in a manner analogous to endogenous retinal pericytes

TGF- $\beta 1$ has been previously demonstrated to have a direct effect on retinal pericytes and influence their potential interactions with endothelial cells. Its defined roles include helping maintain retinal vascular barrier function, ${ }^{181}$ increasing expression of smooth muscle actin, ${ }^{61}$ and enhancing pericyte contraction, ${ }^{62}$ which have been suggested to help stabilize endothelial cells. ${ }^{182,}{ }^{183}$ We wished to evaluate to what extent hASC-pericytes might also be influenced by TGF- $\beta 1$ pre-treatment, if these treatment effects were analogous those observed with retinal pericytes, and if TGF- $\beta 1$ might enhance hASC functionality within in vitro and in vivo assays of pericyte function and vascular stabilization. We first performed a hASC and bovine retinal endothelial cell (BRECs) coculture assay previously described for evaluating retinal pericytes. ${ }^{151}$ Using co-culture 
assays, we tested whether pre-conditioning the hASC and/or retinal pericytes with TGF$\beta 1$ would enhance these cells' ability to inhibit BREC cell cycle entry in a contactdependent manner. After $24-48 \mathrm{~h}$ of pre-conditioning hASC or pericytes with TGF- $\beta 1$, we found that BRECs contacting the TGF- $\beta 1$ pre-treated hASCs are $14.4 \%$ less likely to be found in mitosis, as compared to co-cultures where endothelial cells contacted untreated hASCs $(\mathrm{p}<0.01)$ This result is comparable to the $18.8 \%$ decrease in endothelial S-phase entry in cells contacting pericytes $(\mathrm{p}<0.05)$ (Figure 7A, B). BRECs in monoculture demonstrate a $23.1 \%$ decrease $(\mathrm{p}<0.01)$ in mitotic activity after constant exposure to TGF- $\beta 1$ (Figure 7A), requiring that hASC and pericyte cell cultures preconditioned with TGF- $\beta 1$ be washed with PBS prior to the addition of BRECs to the cocultures.

Furthermore, hASCs pre-treated with TGF- $\beta 1$ demonstrated a 2.6 fold enhancement of contractility $(\mathrm{n}=32,40, \mathrm{p}=0.0413)$ over untreated hASCs, as measured by the cells' ability to deform underlying silicone substratum (Figure 7C, D). This is analogous to results obtained when comparing TGF- $\beta 1$ and non-TGF- $\beta 1$ treated endogenous retinal pericytes $^{62}$. TGF- $\beta 1$ pre-treatment increased the fraction of hASCs highly expressing SMA by $15.3 \%$ without altering control $\beta$-actin levels (Figure $7 \mathrm{E}, \mathrm{F}$ ), which may in part account for their enhanced contractility.

Having demonstrated in vitro effects of TGF- $\beta 1$ pre-treatment on hASCs, we next sought to determine whether this would functionally improve their performance in protecting retinal vasculature from the effects of OIR. P6 NOD SCID pups were intravitreally 
Figure 7. hASC-pericytes respond to TGF- $\beta 1$ treatment in a manner analogous to native retinal pericytes. A, B. TGF- $\beta 1$ treatment of endothelial monoculture and preconditioning of hASC/pericyte co-cultures (right panels) are compared to control serum conditions (left panels). Endothelial cells demonstrate a $23.1 \%$ decrease in S-phase nuclei, or mitotic entry (pink nuclei), when treated with TGF- $\beta 1$ alone $(p<0.001)$. Further, endothelial cells in direct contact with hASC and pericytes (labeled green with SMA antibodies) demonstrate a $14.4 \%$ and $18.8 \%$ decrease respectively in cell cycle entry when hASC/pericytes are pre-treated with TGF- $\beta 1(\mathrm{p}<0.01,0.05$ respectively). $\mathbf{C}$, D, TGF- $\beta 1$ pre-treatment significantly strengthens pericyte-like contractile phenotype and hASC ability to deform underlying silicone substrates (white arrowheads) by 2.6 fold, a response analogous to that seen with bovine retinal pericytes ${ }^{62}(n=32$ and 40 , respectively, $p=0.0413)$. E, F, 48-hour pre-treatment of cultured hASCs with TGF- $\beta 1$ increases the percentage of hASCs highly expressing SMA by $15.3 \%$, without altering $\beta$ actin expression. G - I, Eyes intravitreally injected with TGF- $\beta 1$ treated hASCs at postnatal day $6(\mathrm{P} 6)$, demonstrated an $11.0 \%(\mathrm{n}=22, \mathrm{p}=0.01)$ median reduction in retinal avascular area upon removal from hyperoxia at $\mathrm{P} 12$, as compared to contralateral control eyes injected with untreated hASCs. Scale bars: A, C $=100 \mu \mathrm{m}$. 


\section{Figure 7.}

A
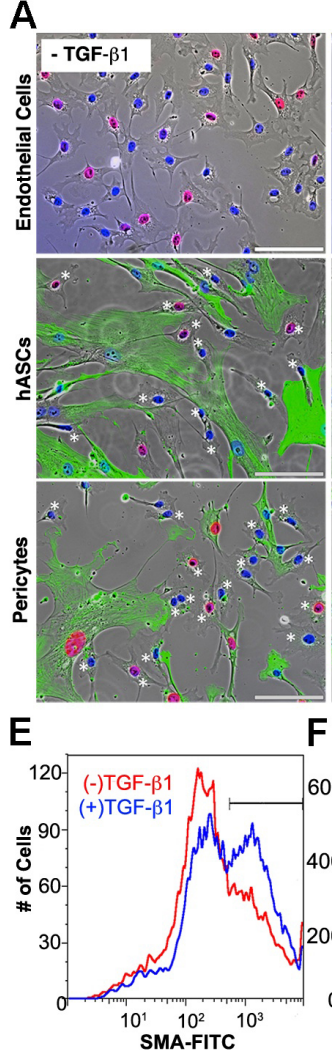

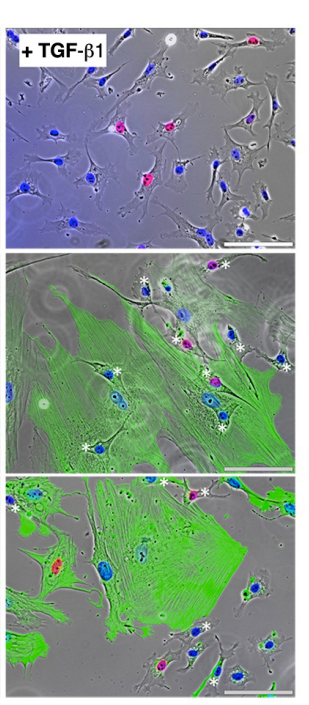

F

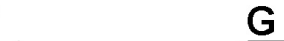

G
B
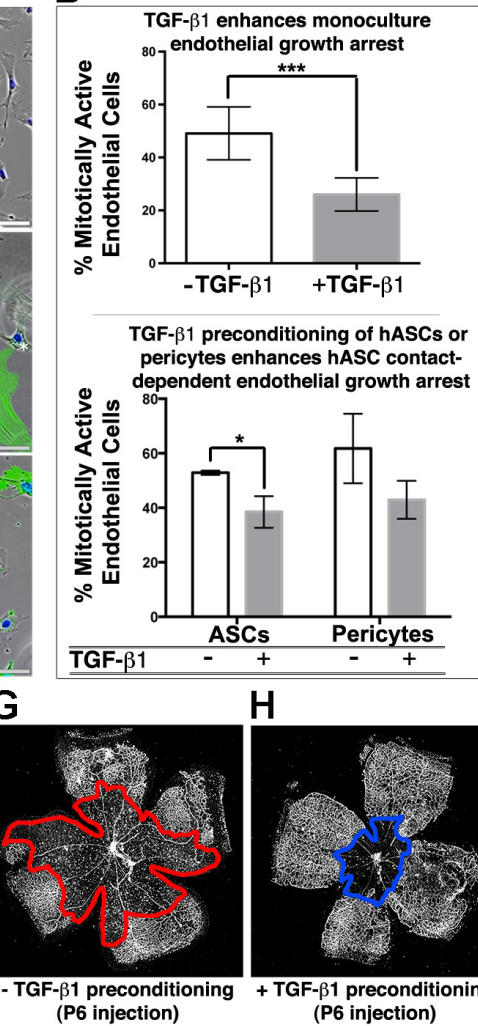

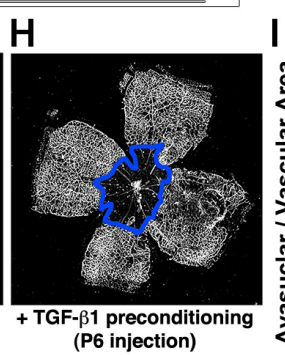

C

Contracting hASC, wrinking underlying silicone wafer

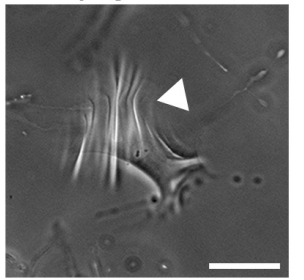

D TGF- $\beta 1$ enhances hASC contractility
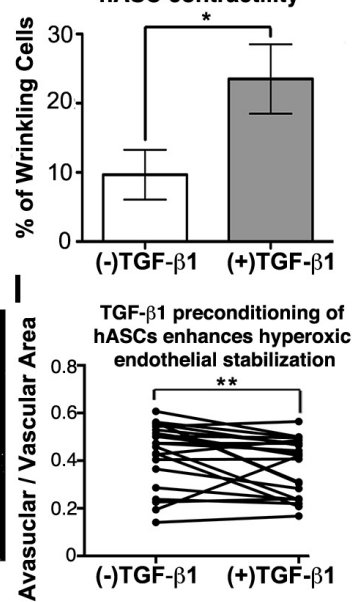

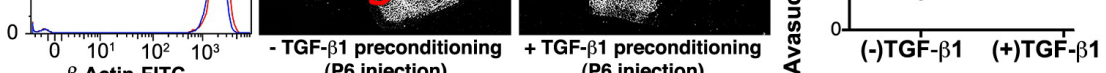


injected with either untreated or TGF- $\beta 1$ pre-treated hASCs ( 1,000 cells in $0.5 \mu 1 \mathrm{PBS})$. When harvested at P12 after hyperoxia, eyes injected with TGF- $\beta 1$ pre-treated hASCs demonstrated an $11.0 \%$ reduction in avascular area $(n=22, p=0.01)$, compared to the contralateral eyes injected with untreated hASCs (Figure 7G - I). This result suggests that TGF- $\beta 1$ pre-treatment enhances hASC stabilization of retinal vessels in vivo.

The mechanism for TGF- $\beta 1$ functional improvement of vessel stabilization remains unclear. The most straightforward explanation is that TGF- $\beta 1$ pre-treatment enhances the pericyte functionality of our hASC-pericytes in a manner analogous to TGF- $\beta 1$ effects on endogenous retinal pericytes. An alternative possibility, but one less directly supported by these results, is that our heterogeneous hASCs contain a subpopulation of pericyte precursor cells, which can be selected or functionally conditioned for endothelial protection and microvascular stabilization with TGF- $\beta 1$.

\section{ASCs prevent retinal capillary dropout in Akimba model of DR}

Having established that a functional retinal pericyte phenotype could be derived from hASCs, we next sought to examine their potential application for treatment of DR. The recently published Akimba model features large-scale retinal capillary dropout, vessel constriction, edema, fibrosis, and bleeding in an immunocompetent diabetic mouse ${ }^{159}$; findings that are more characteristic of severe forms of human disease than other available models. Briefly, diabetic Ins $2^{\text {Akita }}$ mice were crossed with Kimba mice that feature rhodopsin promoter driven human VEGF165 expression. The resultant Akimba pups demonstrated characteristic early onset hyperglycemia, followed by substantial 
weight loss and retinopathy, exhibiting profound retinal capillary dropout by 2 months of age. Because Akimba mice are fully immunocompetent, we used allogeneic murine adipose-derived stem cells (mASCs) derived from the same background strain.

We first verified that mASCs, isolated from the epididymal fat pad and cultured in the same conditions as hASCs, displayed phenotypic markers for pericytes. As expected mASCs were found to express abundant steady state protein levels characteristic of native microvascular pericytes, including SMA and PDGFR $\beta$ as measured by both antibody staining and flow cytometry (Figure 8A-C). Once injected in vivo we found mASCs would readily integrate and associate with the retinal microvasculature of the Akimba mouse whether injected at earlier timepoints (P9) prior to the onset of vessel loss, or at later timepoints (4 weeks) when vessel loss has already begun (Figure 8L).

We next tested the hypothesis that mASCs can prevent diabetic retinal microvascular dropout, by injecting DiI-labeled, TGF- $\beta 1$ - pre-conditioned, mASCs into the vitreous of P9 Akimba pup eyes. As before, PBS was injected as a carrier control in the contralateral eye. Two months post-injection, after verifying the diabetic status of each mouse, retinas were harvested and retinal microvessels stained with lectin as before. Over the course of two months, no teratoma formation was observed in any of the 18 dissected eyes. Wholemount analysis of retinal vessels revealed a $79 \%$ reduction in the area of capillary dropout in retinas treated with mASCs compared to contralateral PBS injected controls (n $=9, \mathrm{p}=0.01)($ Figure $8 \mathrm{D}-\mathrm{F})$. Complimentary analysis of total vessel area showed a $16 \%$ reduction in absolute loss of retinal vasculature in mASC injected compared to 
Figure 8. TGF- $\beta 1$ treated mASCs prevent long-term retinal capillary dropout in diabetic retinopathic Akimba mice. A, B, Passage 4 mouse adipose-derived stem cells (mASCs) were found to express SMA (80.3\%), PDGFR- $\beta(14.9 \%)$, or both $(13 \%)$ compared to unstained controls. C, mASCs also express SMA in a typical pattern in vitro, similar to hASCs. D-M, TGF- $\beta 1$ treated mASCs were injected at postnatal day 9 (P9) in Akimba mice, with PBS carrier control injected in the contralateral eye. Compared to eyes injected with PBS contralateral carrier control (D), circumscribed area of retinal capillary loss in 8 week old Akimba mice was substantially decreased in eyes injected with mASCs $(\mathbf{E})$, resulting in a $79 \%$ reduction of capillary dropout area $(\mathbf{F}, \mathrm{n}=$ $9, \mathrm{p}=0.01)$. Similarly, PBS injected eyes $(\mathbf{G})$ demonstrated a lower vascular area / total retinal area ratio than contralateral mASC injected eyes $(\mathbf{H})$, resulting in a $18 \%$ increase in vascular / total area $(\mathbf{I}, \mathrm{n}=9, \mathrm{p}=0.05)$. Preservation of retinal capillaries is revealed at higher magnification by both lectin stained retinal whole mounts $(\mathbf{J}, \mathbf{K})$ and in vivo fluorescein angiography $(\mathbf{L}, \mathbf{M})$. Note that $\mathbf{J}-\mathbf{M}$ were taken from the same mouse. $\mathbf{N}$, After injection with DiI labeled mASCs at 5 weeks of age, subsequent harvest at 9 weeks revealed substantial integration of mASCs into an Akimba retina. O, Di-I labeled mASC wrapping around Akimba retinal microvessel. $\mathrm{XZ}$ and $\mathrm{YZ}$ planes are also displayed. Scale bars: $\mathbf{J}, \mathbf{K}=150 \mu \mathrm{m}, \mathbf{N}=100 \mu \mathrm{m}, \mathbf{O}=25 \mu \mathrm{m}$. 
Figure 8.
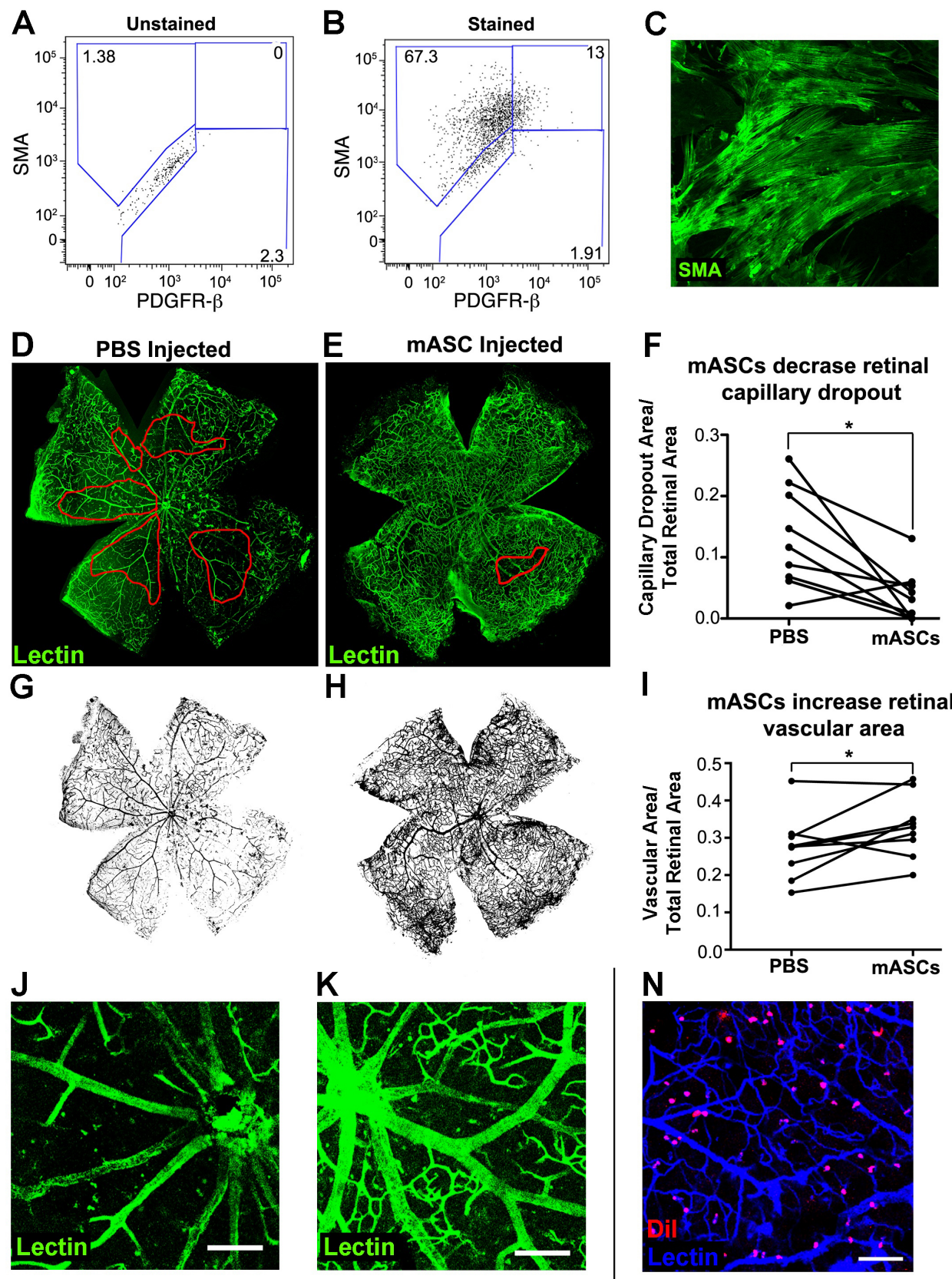

I mASCs increase retinal vascular area
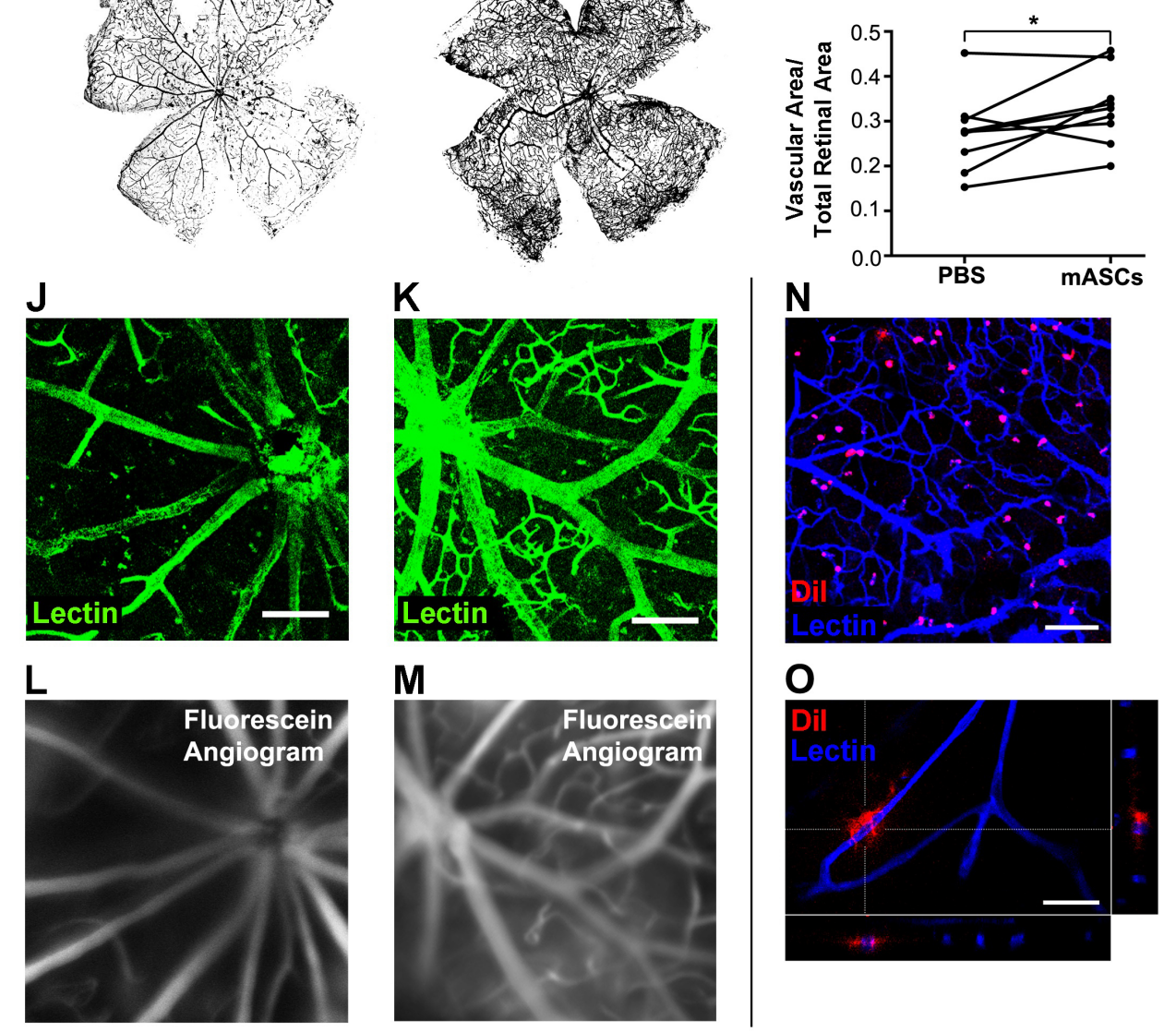
contralateral PBS control injected eyes $(n=9, p=0.01)$ (Figure 8G-I). Despite this dramatic reduction in vascular dropout, we interestingly found no significant reduction in the number of microaneurysms in mASC injected compared to PBS injected eyes $(n=9$, $\mathrm{p}=0.43$ ), although given the low frequency of microaneurysms in both cell injected and control eyes, greater numbers of animals may be needed to demonstrate a significant difference.

Prior to retinal harvest mice were also imaged in vivo with fluorescein angiography using customized Cantor Nissel contact lenses and a Heidelberg Spectralis Retinal Imager (Fig. 8L,M). Importanly, we find that protected retinal microvessels in the mASC injected eyes remain functional, as assessed by comparing the microvasculature as revealed by topical wholemount lectin staining (Fig. 8J,K) with the corresponding fluorescein angiography (Fig 8L,M). Taken together, these results suggest that mASCs display a complimentary pericyte phenotype to hASCs and show a similar capacity to functionally protect retinal microvessels from loss in the setting of DR.

\section{Discussion}

We have demonstrated the ability of ASCs to differentiate into pericytes, as determined by pericyte-specific marker expression, in vitro confirmation of perciyte function, and response to TGF- $\beta 1$ treatment that is analogous to that of endogenous retinal pericytes. When injected intravitreally, ASCs enhance retinal microvascular stabilization in three independent pre-clinical murine models of retinopathic vasculopathy. Specifically, ASCderived pericytes: 1) when injected prior to OIR, protect the retinal vasculature against 
central vascular dropout 2) when injected post-OIR insult, accelerate vascular regrowth and recovery of the central retinal vasculature, ${ }^{168}$ and 3) when injected at early postnatal time points, protect against capillary dropout in the Akimba murine model of DR. ${ }^{159} E x$ vivo treatment of ASC-derived pericyte progenitors with TGF- $\beta 1$ recapitulates the response of endogenous retinal pericytes to TGF- $\beta 1$, with enhanced pericyte marker expression, improved performance in in vitro functional assays and enhanced in vivo protection of the retinal microvasculature.

There has been increasing recognition of the role that dysregulation between pericytes and endothelial cells plays in the susceptibility of the retinal vasculature to development of angiogenesis and vasculopathies such as DR, age-related macular degeneration, and ROP. ${ }^{61,163} \mathrm{DR}$, a disease that proceeds over many years from initial pericyte dysfunction to microvascular degeneration, may be particularly well suited for cell-based therapies. However, in the absence of a readily available supply of human retinal pericytes for transplantation, identifying a plentiful, surgically accessible, and potentially autologous alternative could offer great therapeutic potential.

Our findings demonstrate that ASCs can differentiate into pericytes and, when exogenously injected, will incorporate within the retinal microcirculation with maintained pericyte marker expression; recapitulating results using these cells in other non-ocular model systems. ${ }^{169}$ Our studies also help establish that injection of an exogenous pericyte progenitor population can functionally protect retinal microvessels against profound capillary dropout in a novel pre-clinical model of retinal vasculopathy. Given that ASCs 
are perivascularly located and thought to function in adipose vascular support, ${ }^{123}$ it is perhaps not surprising that they would be able to incorporate and affect the retinal vasculature in similar manner, though our studies are importantly the first direct demonstration of this.

Further work is clearly needed to illuminate the dynamic control of retinal vessel formation and degeneration in retinal vasculopathies, such as DR and ROP, especially as it pertains to the observed functional effects of injected ASCs. Exogenous insulin-like growth factor-1, along with other paracrine signals, has been shown to modify retinal vascular stabilization in OIR. ${ }^{184}$ ASCs readily secrete insulin-like growth factor-1, more so than other types of human mesenchymal stem cells, ${ }^{118}$ and might be one method by which ASCs exert their influence on retinal vessels. Functional stabilization of retinal vasculature by ASCs, even in areas of the retina where no direct incorporation of ASC progenitors on retinal vessels is observed, lends support to the idea that ASCs exert their effects, at least in part, by conditioning the retinal microenvironment. If verified, this mechanism of action would bode well for future translational application. It would suggest that encapsulated cells injected into the vitreous might be sufficient to stabilize retinal vessels, without requiring direct vascular integration. ${ }^{174,185}$

Additionally and importantly, recent work from our group has revealed that pericyte dysfunction, rather than pericyte loss, may be 'rate-limiting' in determining whether retinal endothelial growth and microvascular proliferative disorders ensue as outcomes or complications accompanying conditions such as diabetes. ${ }^{151,}{ }^{152}$ In light of these findings, 
we intend to explore further the extent to which injected ASCs may help to maintain normal function of the native pericyte population in the face of toxic environments, such as chronic hyperglycemia. Given ASC's ability to survive the relatively greater hypoxic conditions of adipose tissue as compared to the eye, they may be particularly well suited to respond to such insults.

Despite the remaining work required to translate ASC stem cell therapy to the clinic, our results suggest that stem cell based strategies for retinal vasculopathies may one day allow a shift in focus from late destructive laser treatment of hypoxic retina to earlier interventions aimed at stabilizing existing retinal microvasculature. Our present findings suggest this may be accomplished using ASCs through both direct contact with retinal microvessels, as well as more general paracrine conditioning of the retinal microenvironment, both of which can prevent vessel loss and retinal hypoxia from occurring in the first place. The consistent and robust microvascular stabilizing properties of ASC-derived pericytes offer hope that such a regenerative treatment for retinal vasculopathies, including DR, may be attainable. 


\section{Chapter 4}

\section{Adipose-derived stem cells from diabetic sources}

show impaired vasoprotection in the treatment of diabetic retinopathy. 
The following chapter is adapted from the manuscript in preparation:

Cronk, S.M., Mendel T.A., Hoehn K.L., et al. Adipose-derived stem cells from diabetic

sources show impaired vasoprotection in the treatment of diabetic retinopathy.

\begin{abstract}
DR is a debilitating disease that leads to progressive retinal vascular pathologies and ultimately to vision loss, which current treatments are unable to reverse. We have recently shown that intra-vitreal injection of ASCs stabilize retinal microvasculature and encourage regeneration of damaged capillary beds in several mouse models of retinal vasculopathy. ASCs are advantageous because of their relative ease of harvest from accessible fat depots, as well as their potential for autologous or allogeneic treatment. Understanding the status of ASCs harvested from diabetic patients is of critical importance for moving forward with autologous therapies. Using the hyperglycemic Akimba mouse model of DR, we probed the differences in treatment efficacy and function of mASCs derived from healthy wildtype vs. diabetic Akimba mice. Akimba mice received intra-vitreal injections of DiI-labeled mASCs, and retinas were imaged four weeks later by confocal microscopy in order to quantify cell location and incorporation, as well as vascular density. mASCs from healthy, non-diabetic mice were more effective than diabetic mASCs in protecting the diabetic retina from vascular dropout. Additionally, a greater number of healthy mASCs were found incorporated into the retina than were diabetic mASCs. mASC viability was assessed using TUNEL and EdU incorporation assays, which revealed that healthy mASCs proliferate more rapidly
\end{abstract}


and undergo less apoptosis than diabetic mASCs. Finally, when compared to diabetic mASCs, healthy mASCs secreted more angiogenisis-promoting factors, such as IGFBP2/3 and MCP, as determined by high-throughput ELISA. Our findings suggest that injected ASCs derived from diabetic mice have a decreased ability to affect the retinal vasculature likely due to decreased cell viability and secretion of angiogenic factors, and support the utility of an allogeneic approach in the clinical arena.

\section{Introduction}

The therapeutic potential of ASCs has been demonstrated with success in several applications, including myocardial infarction, diabetic wound healing, and neurodegenerative disorders. ${ }^{186-188}$ We have recently shown that intra-vitreal injection of ASCs stabilizes retinal microvasculature and encourages regeneration of damaged capillary beds in several mouse models of retinal vasculopathy. ${ }^{41}$ ASCs are desirable because of their relative ease of harvest from accessible fat depots, as well as their potential for allogeneic or even autologous treatment. ${ }^{166}$ However, few studies have examined whether ASCs obtained from diabetic patients are negatively impacted by the disease, pertaining to their role in regenerative medicine. ${ }^{189}$ To date, no studies have assessed the functional impact of diabetes on ASCs for the treatment of DR.

Studies comparing the efficacy of ASCs from diabetic and non-diabetic sources have focused on their application in diabetic ulcers ${ }^{190}$ and hindlimb ischemia. ${ }^{191}$ Both of these studies found ASCs derived from diabetic mice to be impaired in their treatment efficacy relative to their non-diabetic counterparts. Stem cells from different tissues, such as bone 
marrow-derived stem cells (BMSCs), have been shown functional impairment in cells derived from diabetic mice in the treatment of cardiovascular disease. ${ }^{188}$

Diabetes profoundly impacts the microvasculature in nearly every tissue. In the retina, DR results in retinal capillary dropout, vessel leakage, and pathological neovascularization, leading to severe and irreversible vision loss. Current surgical and pharmacologic treatments are only effective at managing complications of DR, but do not repair existing retinal damage. ${ }^{192}$ Laser photocoagulation is the current treatment standard for proliferative DR, and operates on the principle of cauterizing hypoxic retinal tissue. $^{193}$ While effective at stemming the progression of retinopathy, this procedure damages peripheral and night vision, often requires repeated treatments, and only prevents visual deterioration in half of cases. ${ }^{14,192,193}$ Anti-VEGF therapy has been increasingly used alone or in combination with laser therapy, with improvements in vision loss due to diabetic macular edema. ${ }^{74,76,194}$ However, anti-VEGF therapy requires frequent and painful intra-vitreal injections for several years, and unfortunately does not reverse the underlying pathology. ${ }^{192}$ A lasting and non-destructive treatment for DR is clearly needed.

Using the Akimba mouse model of DR, we have probed the differences in treatment efficacy and function of mASCs derived from healthy vs. diabetic mice. The Akimba is a cross between the hyperglycemic Akita mouse, which carries a dominant negative mutation in its insulin 2 gene, and the Kimba mouse, which overexpresses human VEGF in retinal photoreceptor cells. ${ }^{195}$ The combination of these modifications creates a mouse 
whose retina exhibits hallmarks of proliferative DR in humans with capillary dropout, retinal edema, and aberrant neovascularization. ${ }^{159}$ In this study, we demonstrate that mASCs from healthy, non-diabetic mice are more effective than diabetic mASCs from Akimba mice in re-vascularizing the diabetic retina. To provide a mechanism for this observed difference in regenerative ability, a functional analysis of healthy and diabetic mASC was carried out. Several pro-angiogenic factors, including some known to effect retinal angiogenesis, ${ }^{196,}{ }^{197}$ were secreted at significantly higher levels in healthy versus diabetic mASCs. Furthermore, diabetic mASCs exhibited lower rates of proliferation and greater rates of apoptosis than healthy mASCs. These results indicate that diabetic ASCs are functionally impaired in treating murine models of DR, and do not support the use of autologous ASCs from diabetic patients.

\section{Results}

\section{Regenerative Potential}

Using the Akimba murine model of DR, we tested whether hyperglycemia alters mASCs ability to protect the diseased microvasculature in the Akimba retina. The Akimba retina demonstrates several hallmarks of proliferative DR in humans, including retinal thinning and severe vascular pathology such as capillary dropout, nonperfusion, retinal neovascularization, retinal edema, and microaneurysms. ${ }^{198}$ mASCs used for treatment were harvested from either 9 week old hyperglycemic Akimba mice or wild-type mice both on a C57BL/6J background. Each mouse received injected $\mathrm{mASCs}$ in one eye (either healthy or diabetic) and a contralateral PBS vehicle control. Confocal images of 
isolectin-stained retinas and DiI-labeled injected mASCs are shown in Figure 9A and C. The greater loss of capillaries in diabetic mASC-treated retinas compared to healthy mASC-treated retinas is visually apparent. To quantify this difference in treatment outcome, vascular density was calculated digitally by the ratio of total vessel length to total retinal area. The change in vascular density of mASC-injected eyes minus that of control eyes is shown graphically (Figure 9). To correct for variability in disease severity between individual mice, all analysis on vascular density was performed by comparing the mASC-treated retina to the control PBS-injected retina in the same mouse. Eyes treated with healthy mASCs showed a significant increase in vascular density relative to contralateral controls (Figure 9A, B). A majority of eyes treated with diabetic mASCs, on the other hand, had a lower vascular density compared to contralateral controls (Figure 9C, D). When considering the overall change of vascular density, diabetic mASC-treated eyes displayed both increases and decreases in vascular density with no meaningful trend. These data indicate that diabetic mASCs are not as effective as healthy mASCs in promoting protection against vascular dropout in the Akimba retina.

\section{Perivascular Incorporation}

Observing reduced vessel density and qualitatively impaired healing due to diabetic mASCs compared to healthy mASCs may be due in part to the ability of transplanted cells to incorporate into host retinal vasculature. DiI-labeled mASCs were counted from representative 20x confocal image stacks. Each counted cell was sorted as either perivascular or non-perivascular for eyes treated with healthy and diabetic mASCs (Figure 10). An equal number of both types of cells were injected, but a greater number 
Figure 9. Treatment with healthy and diabetic mASCs have differential effects on the retinal microvasculature. 5-week old Akimba mice received intraocular injections of "healthy" or "diabetic" passage-4, DiI-labeled mASCs in the right eye and contralateral phosphate-buffered saline control injections in the left eye. 10x confocal microscopy images with mASCs in red and lectin-stained vessels in blue of healthy celltreated $(\mathrm{A})$ and diabetic cell-treated $(\mathrm{C})$ retinas. Differences in vascular densities for each mouse between cell-treated retinas and contralateral PBS controls showed a significant increase in healthy cell-treated (B), and no change in diabetic cell-treated (D), $n=6, p<$ 0.05 , paired t-test. 
Figure 9.
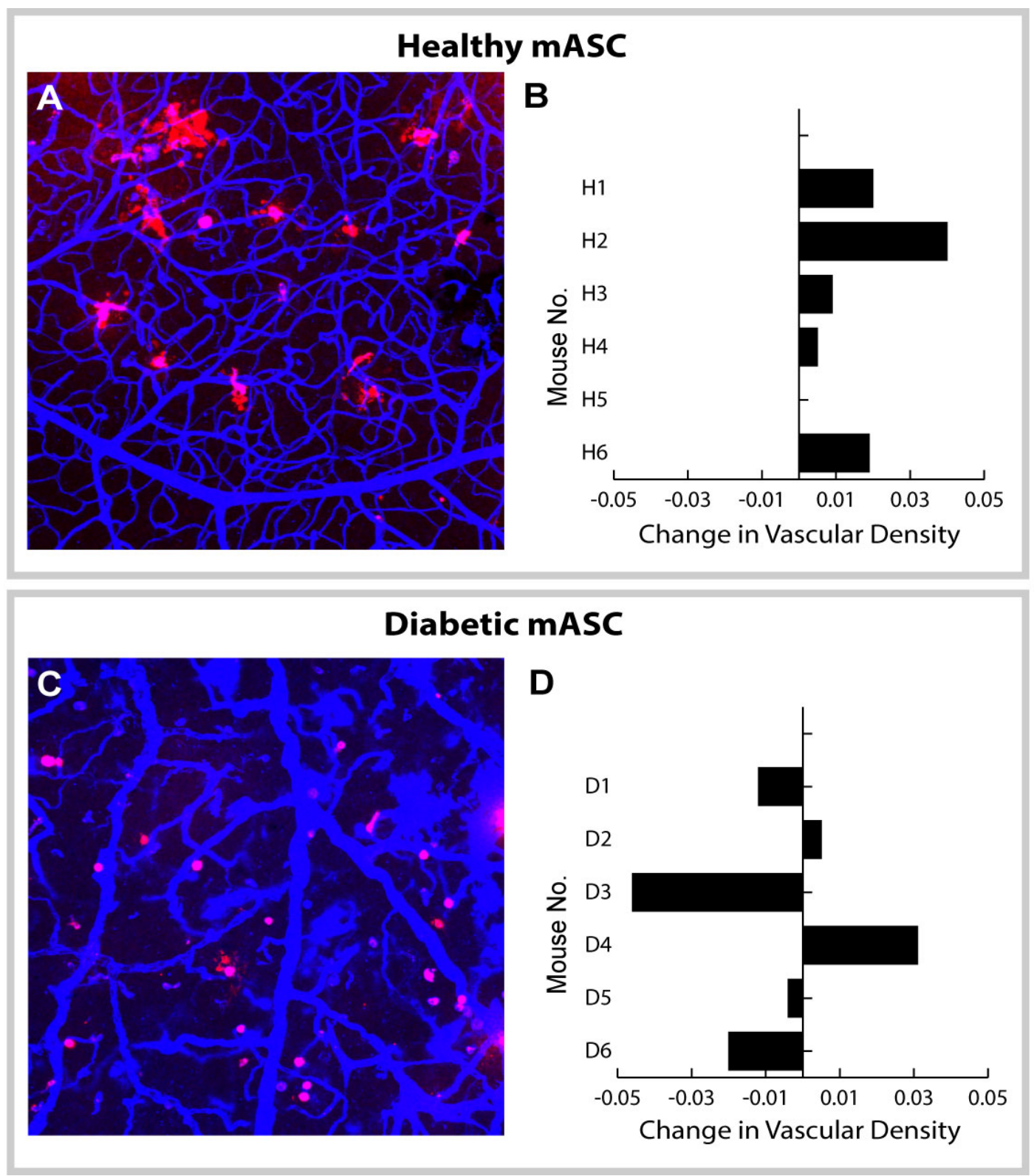
Figure 10. Healthy mASCs incorporate in the retina in greater numbers and assume perivascular positions more often than diabetic mASCs. Cells occupying perivascular and non-perivascular positions counted in representative $20 \mathrm{x}$ confocal image stacks. The average ratio of perivascular cells to total cells in each field is shown for both healthy and diabetic cells. $\mathrm{n}=16$ (healthy), $\mathrm{n}=19$ (diabetic), ${ }^{*} \mathrm{p}<0.05$, Wilcoxon Signed Rank test. 
Figure 10.

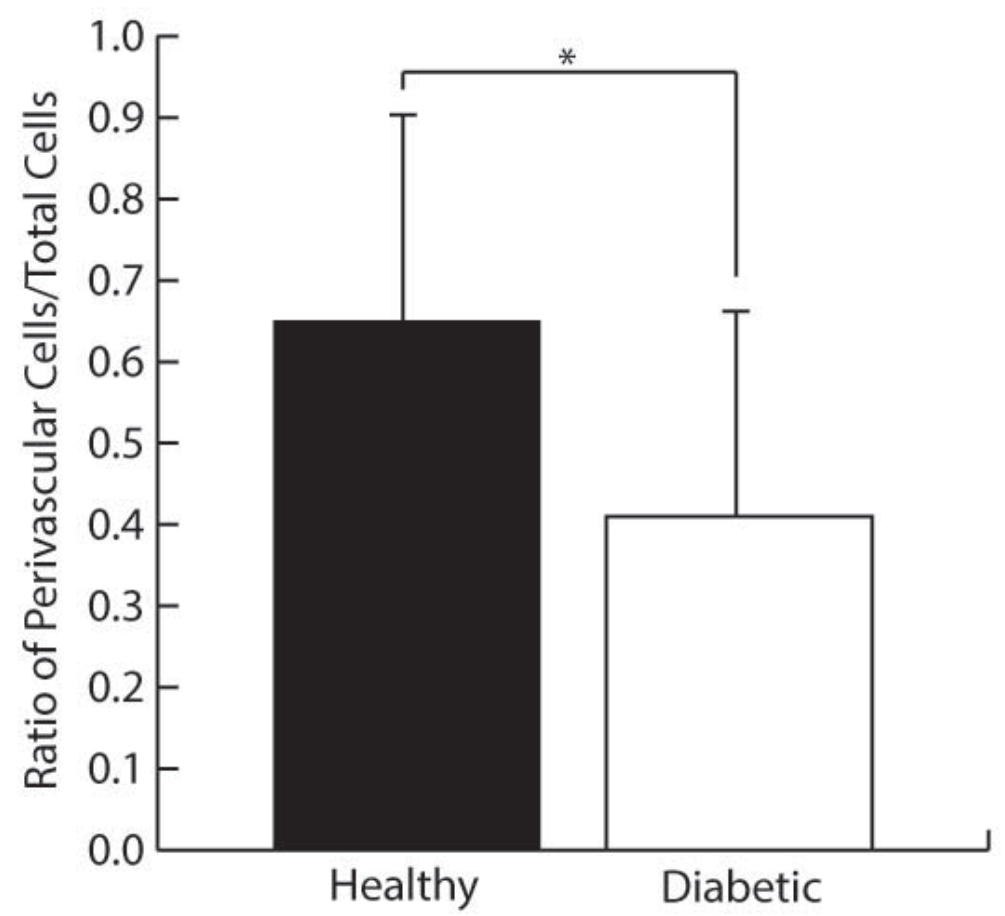


of total mASCs incorporated into the retina for healthy mASCs than diabetic mASCs. Furthermore, healthy mASCs were found in perivascular positions more often than nonperivascular positions. Diabetic mASCs were found in relatively equal abundance both in perivascular and non-perivascular positions.

\section{mASC Viability and Apoptosis Analysis}

Relative rates of proliferation and apoptosis between healthy and diabetic mASCs were quantified in-vitro with cultured mASCs. Proliferation frequencies were measured using an EdU-incorporation assay. We found that diabetic mASC proliferation activity was only $77 \%( \pm 5 \%)$ that of healthy mASCs (Figure $11 \mathrm{~A})$. Diabetic mASC apoptosis activity was increased to $121 \%( \pm 3 \%)$ that of healthy mASCs as determined by a TUNEL assay (Figure11B).

\section{mASC Cellular Bioenergetics}

An analysis of the two mASC populations' bioenergetic profiles was then performed using the Seahorse XF Bioanalyzer to determine whether differences in cellular metabolism may account for their differing treatment efficacy and function in vivo. Specifically, we assayed mitochondrial bioenergetics in whole cells by measuring oxygen consumption over time following the sequential addition of the ATP synthase inhibitor oligomycin, the mitochondrial uncoupler FCCP, and the complexes I and III inhibitors rotenone and Antimycin A. ${ }^{160}$ These data revealed that diabetic and non-diabetic mASCs had comparable rates of basal cellular respiration, ATP-dependent respiration, spare 
Figure 11. Healthy mASCs exhibit higher rates of proliferation and lower rates of apoptosis than diabetic mASCs. (A) Relative number of cells in S phase determined by EdU incorporation assay. (B) Cells undergoing apoptosis determined by TUNEL assay. mASCs from 3 healthy and 3 diabetic animals were used for each condition, with three cell plates per animal. Values were normalized to the healthy value in each case. ${ }^{*} \mathrm{p}<$ 0.001 , t-test. 
Figure 11.
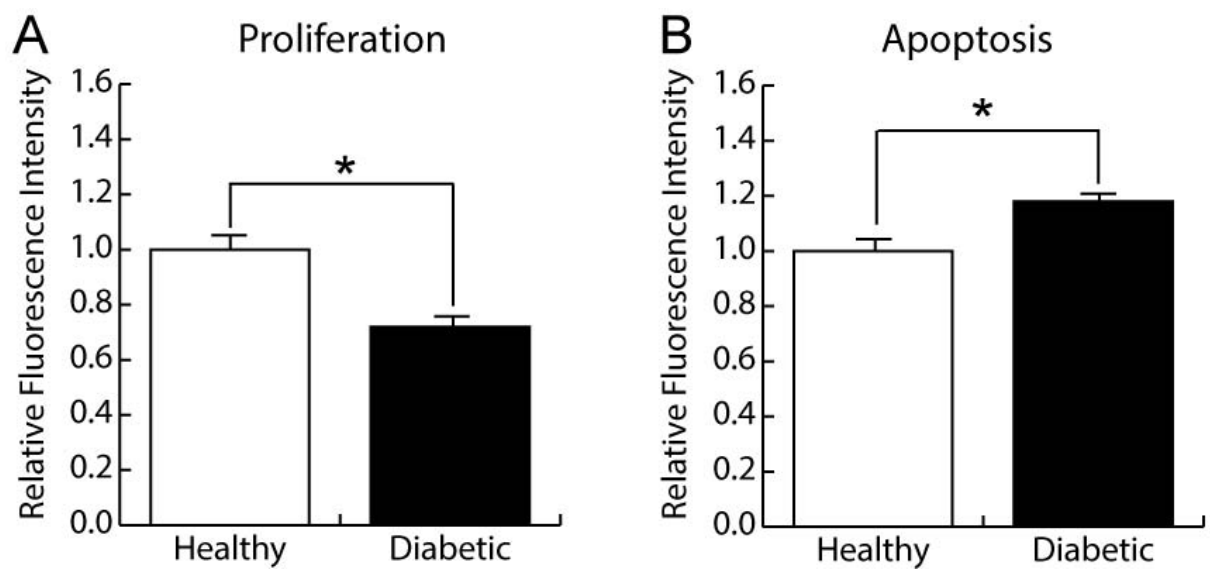
respiratory capacity, uncoupled respiration, and non-mitochondrial respiration (Figure 12).

\section{Angiogenesis Factor Secretome}

To investigate a possible paracrine signaling basis for the differences in the potential of healthy and diabetic mASCs to protect against vascular dropout, levels of secreted angiogenic factors were measured via high-throughput ELISA. Conditioned media samples were collected from three populations each of healthy and diabetic mASCs. Each sample was run on a separate array under identical conditions, which enabled us to calculate a relative abundance of each angiogenesis factor by comparing arrays after normalizing to a positive control. Since healthy mASCs were found to proliferate faster than diabetic mASCs in culture, angiogenesis factor levels were also normalized to cell number as counted immediately prior to collection of conditioned media. We found 5 angiogenic factors that were secreted at significantly higher levels by healthy mASCs than by diabetic mASCs, namely IGFBP-2, IGFBP-3, MCP-1, osteopontin, and SDF-1 (Figure 13). The remaining factors of the 11 analyzed were secreted at similar levels by healthy and diabetic mASCs, and none were secreted at higher levels by diabetic mASCs.

\section{Discussion}

ASC therapy holds promise for many debilitating and increasingly common microvascular disorders due to their regenerative potential. This potential has been attributed to the ability of ASCs and other stem cell types to release angiogenic cytokines and to differentiate into different cell types. ${ }^{199,200}$ Furthermore, isolation of ASCs has 
Figure 12. Healthy and diabetic mASCs show no difference in metabolic activity. Healthy and diabetic mASCs were isolated from three diabetic mice and three healthy mice, passaged to P4, and subjected to mitochondrial stress tests on the Seahorse XF Bioanalyzer. Individual profiles (A) and combined profiles (B) show no difference in baseline cellular respiration, spare respiratory capacity, ATP-linked respiration, uncoupled respiration, or non-mitochondrial respiration. 
Figure 12.

A

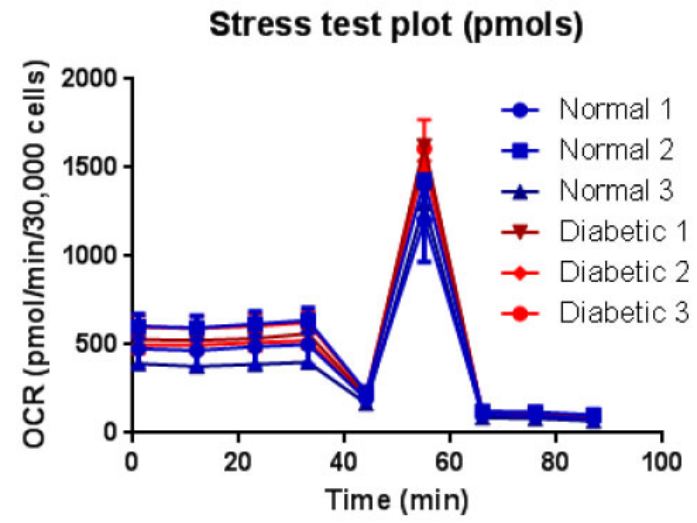

B

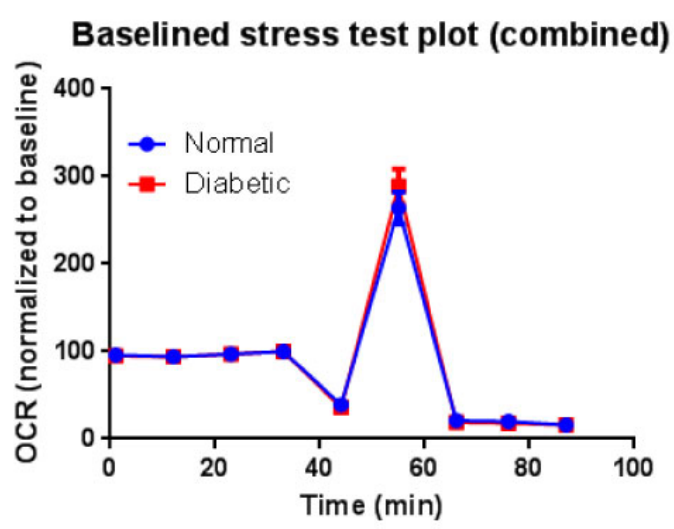


Figure 13. Diabetic mASCs secrete decreased levels of angiogenic factors. Relative expression levels of secreted angiogenesis factor of healthy versus diabetic mASCs were taken using high-throughput ELISA arrays. mASCs were isolated from "healthy" wildtype and "diabetic" Akimba mice and maintained to passage 4. Samples consisted of conditioned media obtained by incubating cells immediately after passage in fresh media, and collecting media after 24 hours. $\mathrm{n}=3,{ }^{*} \mathrm{p}<0.05,{ }^{*} \mathrm{p}<0.01$, t-test 
Figure 13

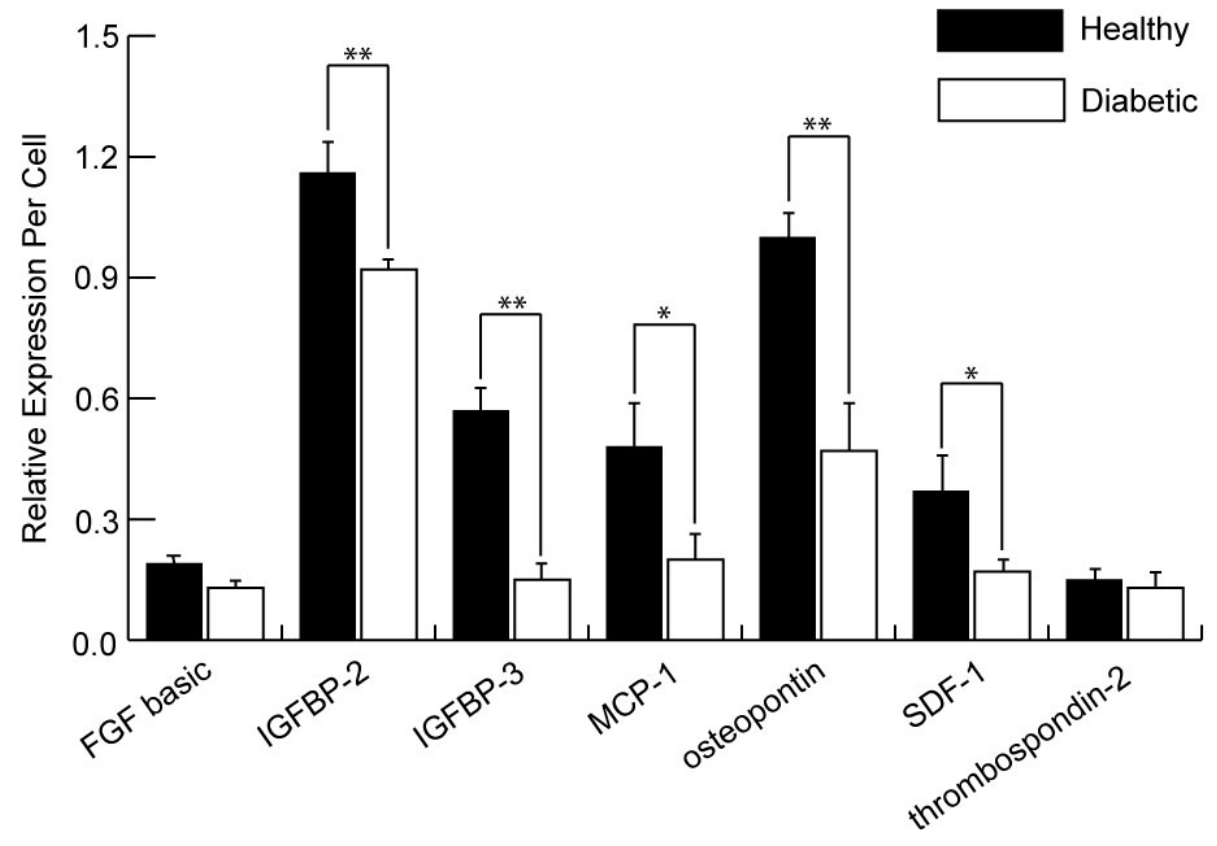


several advantages over other cell types due to the relative abundance of adipose tissue and relatively painless extraction procedure ${ }^{38}$ The fact that ASCs can be rapidly isolated at high enough quantities for treatment without culture and expansion holds great implications for autologous treatment options. Thus, it is important to assess whether or to what extent ASCs isolated from a diabetic source have compromised treatment efficacy and function.

In this study, we first demonstrated that mASCs from diabetic sources are not as effective as those from healthy sources in protecting against vascular dropout in DR. In addition to highlighting the effect of diabetes on mASCs treatment efficacy in vivo, this experiment corroborated our group's previous findings that healthy ASCs regenerate damaged retinal microvasculature. In contrast to the current study, these previous results were obtained using the oxygen-induced retinopathy model in immunosuppressed mice, and with ASCs isolated from only non-diabetic human adipose tissue. ${ }^{41}$ In an effort to explain the observed decreased treatment efficacy when using ASCs from diabetic sources, we carried out an analysis of mASC incorporation in vivo, and an in vitro functional analysis. We found that a higher ratio of healthy mASCs incorporated into the retina than diabetic mASCs. mASCs from diabetic sources were additionally found to undergo proliferation less frequently and apoptosis more frequently, in accordance with other functional studies using diabetic mASCs. ${ }^{190}$ Finally, mASCs from diabetic sources secreted lower levels of angiogenesis-promoting factors. 
The observed differences in mASCs isolated from healthy and diabetic sources have implications for the use and study of stem cells beyond the model disease in this study. Based on the fact that diabetic mASCs are impaired in their regenerative ability to the point that their use did not elicit a predictable and positive response in vivo, an autologous approach to ASC therapy in diabetic patients cannot be recommended without considering and possibly correcting for these differences. Furthermore, the greater levels of angiogenesis factor secretion in healthy mASCs and concomitant increase in microvascular regeneration supports the notion that ASCs act on surrounding tissues through paracrine activity. Several studies have found that the regenerative effects of mesenchymal stem cells are at least in part due to the release of paracrine factors. ${ }^{201-203} \mathrm{~A}$ comparison of diabetic and healthy embryonic stem cell function using a hindlimb ischemia model also determined that the loss of function and treatment efficacy was due to lower angiogenic factor secretion by diabetic ESCs. ${ }^{204}$ It is interesting to note that while diabetic mASCs showed decreased secretion of these factors as well as functional impairment, the impairment was not universally seen in all aspects of cell function. Specifically, metabolic capacity and mitochondrial function were identical in healthy and diabetic cells, suggesting diabetes-associated hyperglycemia had no lasting effect on these functions (Figure 12). While others have reported significant hyperglycemiainduced changes in metabolism in other cell types such as bovine retinal pericytes, ${ }^{205,206}$ these studies were all performed using high-glucose media. The fact that we saw no metabolic differences after culturing cells to $\mathrm{P} 4$ indicates that these differences were likely transient, in contrast to angiogenesis factor secretion, which was persistent. Possible mechanisms for this relative persistence might be epigenetic modifications in 
response to hyperglycemia, which are selective for cell-cycle and growth factor regulation. ${ }^{207,208}$

Pericytes belong to the vascular smooth muscle cell lineage, and are known to communicate with endothelial cells through direct cell-cell contact, and regulate blood flow through contraction and relaxation. ${ }^{209}$ ASCs have been found to have many similarities with pericytes, such as expressing surface markers, taking up a perivascular location, and stabilizing endothelial networks. ${ }^{123}$ An absence of pericytes, such as in the pathogenesis of DR, leads to dysfunction of endothelial cell junctions and abnormal vessel morphology. ${ }^{210}$

As a potential therapy for DR, it is important to know how ASCs behave in the retina. Examining the number and placement of mASCs found in retinas from our study with the Akimba mouse can provide valuable insight into this. MSCs are thought to be closely connected with perivascular cells, and ASCs have been shown to originate from perivascular MSCs which reside in great numbers in adipose tissue. ${ }^{22}$ This would suggest that ASCs might exert their vascular-stabilizing effects by taking up perivascular positions. The fact that there are significantly more heathy mASCs than diabetic mASCs residing in the retina after four weeks is likely due to a combination of several factors such as increased rates of apoptosis as well as increased migration capabilities of diabetic mASCs as demonstrated by others. ${ }^{188,190}$ 
In summary, we have shown that ASCs taken from diabetic sources impairs their ability to regenerate the microvasculature in DR, and that use of autologously-derived ASCs from diabetic patients would not be effective. Furthermore, hyperglycemia causes distinct changes in ASC function, but only to certain aspects related to cell cycle and growth factor regulation. Finally, our results support the notion that ASCs promote vascular regeneration through paracrine activity rather than direct cell-cell contact. To improve ASC therapy for DR as well as other diabetic complications, it is critical to better understand their mechanism of action in vivo. Future work may focus on describing the means by which ASCs migrate towards and incorporate into the retina and their activity in vivo, as well as the mode of diabetes-induced changes in ASC function. 


\section{Chapter 5}

Discussion and Future Directions 


\section{Discussion}

DR features a particular attribute that suggests it may be unusually well suited for stem cell therapy; pericyte dysfunction occurs prior to clinical progression of disease. A chronic inflammatory disease, DR provides us a cellular understanding that uniquely assists its study and potential for translational therapy. Further, the current therapeutic options for DR, while major advances in their own right that have prolonged the vision of millions of patients, fail to address the known cellular pathophysiologic progression. The disease appears ripe for a paradigm shift in treatment that more elegantly utilizes our increasing molecular and cellular understanding of DR.

Upon those observations we laid our studies, endeavoring to adapt ASCs for therapeutic use, capitalizing on their ability to express pericyte markers and adopt a pericyte location after homing to microvessels. Like many in the field at the time, we conceptualized harvested ASCs as therapeutic solely through their ability to replace lost or dysfunctional cells. We hypothesized that ASCs could simply replace retinal pericytes and act fully in their capacity only by investing in the basement membrane of capillary endothelial cells.

Our OIR experiments did reveal, in fact, that transplanted human ASCs could integrate into the NOD SCID murine retinal microvasculature and display pericyte expression markers, location, and morphology. But early in our studies, we came to appreciate the profound impact of intravitreally injected ASCs on developing retinal microvasculature, 
sometimes exerted over very short time frames without sufficient ASC retinal integration to account singularly for their effect.

When conducting the experiments that featured ASC injections after hyperoxia, at the onset of retinal microvascular regeneration at P12, we were confronted with an unexpected hurdle. We had not anticipated that immunocompromised NOD SCID mice would demonstrate substantially less central retinal vascular ablation upon removal from hyperoxia than immunocompetent C57 mice, with only C57 data being previously reported. $^{168}$ Of note, the impact of the immune system on the process of hyperoxic vascular ablation is an interesting observation in its own right, and merits further study. In order to detect a signal difference between the PBS and cell injected eyes, we were forced to harvest the retinas at an earlier time point so as to prevent full revascularization of both the experimental and control groups. Instead of harvesting five days after stem cell injection, permitting the cells to condition the microenvironment from P12 to P17, as is standard procedure in OIR for C57s, we harvested at P14 for our NOD SCID pups, allowing only 48 hours of stem cell residence time in the vitreous. We hypothesized that the very small time frame would render any signal difference undetectable, but we proceeded anyway. To our surprise, the injected ASCs still produced a $16 \%$ treatment effect. In longer studies of multiple weeks' residence time, transplanted ASCs integrated into the retina, wrapped around microvessles and demonstrated pericyte markers, as would be classically expected. However, ASCs clearly influenced the retinal microvasculature in a paracrine fashion without integration and with very little time for said interaction. 
Concurrently, other groups published some of the first papers exploring solely the paracrine potential of ASCs in other model systems. ${ }^{211,212}$ These reports and our own in vivo data prompted us to consider possible treatment impact of ASCs delivered earlier in the OIR protocol, before vascular ablation, so that the ASCs and their secretome could be present at the time of initial hyperoxic vascular regression. While not a chronic diabetic inflammatory model, we were translationally curious about the prospect of stem cell transplantation prior to vascular insult. Impressively, ASCs produced a substantial 53\% treatment effect, which was reproducible over each specimen tested and in multiple trials. It became clear that, now under both hyperoxic and hypoxic conditions, ASCs were orchestrating a microvascular response, rather than acting singularly as integrative pericytes. The Akimba experiments further validated the microvascular impact of implanted ASCs, both as paracrine and integrative cells. Importantly, the Akimba results were produced in a diabetic immunocompetent mice, more akin to a potential therapeutic situation for actual adult diabetic patients than the previous experiments with xenografts into immunocompromised neonatal mice.

Returning to our original hypothesis, we had posited that ASCs differentiate into and then act as pericytes in a sequence of events to stabilize the retinal microvasculature. Concurrent with our in vivo studies, other groups published on the relationship between pericytes and MSCs, describing in detail their phenotypic and functional overlap. ${ }^{24,42} \mathrm{~A}$ more complete picture - one of more plasticity between pericytes and MSCs - began to emerge that incorporated the paracrine functions of MSCs, particularly their trophic 
capacity, which had been previously known but unconnected to pericyte biology schematically. We began to understand that pericytes could act as stem cells, referred to as MSC/pericytes for the remainder of this thesis, influencing the inflammatory environment as well as integrating into the retinal microvasculature as traditionally understood.

Moreover, the paracrine secretome of MSC/pericytes was suspected to be deficient in diabetic hosts, ${ }^{189}$ lending itself to a mechanism by which diabetes could impact the function of $\mathrm{MSC} /$ pericytes. In that light, our laboratory established a series of experiments - led by Stephen Cronk - to illuminate further the role that murine ASCs played in the Akimba rescue we had previously demonstrated, and whether or not diabetic status of the donor cells impacted those data. As expected, diabetic ASCs were not as proficient at rescuing pathologic Akimba microvasculature, perhaps suffering from an altered paracrine secretome. As our original hypothesis claimed that ASCs could act as pericytes to stabilize retinal microvasculature, and we now understood that occurred both by integration and paracrine secretion, these results served to reinforce the support for our original hypothesis; that ASCs could function as pericytes to stabilize the retinal microvasculature.

\section{Future Directions}

Stem cells hold much promise for the future of medical therapy. That promise has resulted worldwide interest in their function and potential therapeutic application. As 
enormous funding and investigator effort has been dedicated towards that promise, the number of stem cell publications has risen quickly in the past two decades. The prospect of curing - or even preventing - degenerative diseases for which medicine has no sufficient cure is a potent motivating force. That motivation has kept many investigators up late in the laboratory, myself included.

Yet despite the ample resources, intense translational efforts, and growing knowledge base about stem cells, there still remain no "home run" cures in the field of regenerative medicine. We have not successfully implanted differentiated dopaminergic neurons in the substantia nigra to cure Parkinson's disease. We have not replaced dying motor neurons to cure those suffering from amyotrophic lateral sclerosis. We have not generated functional $\beta$ islet cells from autologous stem cells and successfully transplanted them to cure patients with type 1 diabetes. We have not generated new lung or cardiac tissue that has repaired patient vital organs. We have not generated new retinal tissue capable of restoring a blind patient's vision in full. In recent years, we have taken strides towards these goals in the laboratory, but the dream of personalized regenerative medicine envisioned by many some decades ago remains vaguely out of reach. There have been some modest successes, including seeding donor tissues or biomaterial scaffolds with stem cells prior to implantation. But these limited successes fall short of the full restoration to function envisioned for stem cell regenerative therapy. Deeper understanding is needed to accelerate translation to therapy and advance our scientific understanding. 
Challenges confronting regenerative therapy, or even the study of MSC/pericyte basic science underpinnings, include:

1. Confusion about identity of MSCs with other cell types, most notably pericytes.

2. Obscurity surrounding the intracellular control mechanisms that MSCs utilize to differentiate and proliferate.

3. Confusion regarding MSC response to their environment over time, including paracrine activity.

To accelerate progress towards clinical translation, it seems reasonable to select an organ system and disease that offer unique advantages for the study of stem cells. As evidenced by the number of stem cell trials to date, discussed earlier, the eye is a privileged site in which to pursue stem cell study. A literal window to the central nervous system and fine retinal microvascular network, the eye provides a unique platform for stem cell research and therapy. The medical and surgical access afforded at the eye is nearly unmatched, permitting repetitive doses if necessary both investigationally and therapeutically. The eye is enclosed, the vitreous serving as an in vivo Matrigel of sorts in which to assay both implanted cells and their secretomes. Although not known at the start of these studies, the eye's ability to assay the paracrine functionality of stem cell transplant therapy is particularly advantageous. That the visual system is also gifted with multiple readouts of functionality, from vascular response to neural firing to visual acuity, confers to it a unique set of advantages over other systems for the study of stem cell basic science and clinical translation. Capitalizing on those unique attributes of the visual system, ongoing 
and future studies in our laboratory endeavor to illuminate more measured control of MSC/pericytes, both transplanted and endogenous.

Obviously, an ideal therapy for DR wouldn't be ocular at all, but would rather be a regenerative cure for diabetes itself, restoring proper endocrine function, insulin signaling, and glycemic control. However, stem cell advances may be more easily attainable in the experimental platform of the eye. It is true that ASCs injected into the vitreous can integrate into the retina during inflammation, display pericyte markers, adopt pericyte morphology and location, and stabilize the retinal microvasculature. But translation of stem cell therapy to treat DR will require a more nuanced understanding of stem cell control and function.

Adapting the three general challenges to MSC/pericyte research, outlined above, to the specific challenge of a DR regenerative cure, we are confronted with the following set of questions:

1. What is the functional overlap of MSCs with pericytes in the retina, before disease and during retinopathic progression?

2. How, molecularly, does diabetes impair the intracellular mechanisms that $\mathrm{MSC} /$ pericytes use to regulate their differentiation, migration, and proliferation?

3. How does chronic diabetic inflammation functionally impair MSC/pericyte ability to respond to the inflammatory environment over time? 
To address the first question, which is essential for subsequent work to continue in an informed way, experiments should be designed that capitalize on the in vivo visualization of the retina. The importance of in vivo observation to the study of MSC/pericytes cannot be understated. As these cells work in concert with other retinal and immune cells, removal of them from their in vivo environment for assay on tissue culture plastic can be problematic without elegant and direct in vivo validation. Especially considering that tissue culture itself is reported to alter the marker expression and possibly differentiation capabilities of MSC/pericytes, in vivo correlation is necessary to advance the field both scientifically and translationally.

Our laboratory already possesses a strain of mice, generously procured by Dr. Gary Owens' laboratory, which express eYFP in all cells that currently - or previously express smooth muscle myosin heavy chain. These mice can be applied to elegant in vivo experiments in which their retinas can be imaged in vivo to capture time-lapse data in response to inflammation, such as that produced by laser photocoagulation. While a different source of inflammation and more acute, the inflammation produced is easily reproducible. Breeding these eYFP mice with mice that feature other markers of cellular identity, such as the NG2-dsRed mice, might be especially informative.

Perhaps the most useful mouse genotype, based upon what is known now and discussed earlier, would be a combination of the NG2-dsRed mouse that faithfully demonstrates location of pericytes, with a mouse that features coexpression of a different color fluorophore with a more active MSC marker, such as CD34. In that way, using the in 
vivo visualization capabilities of the eye, we may be able to observe directly the activation, migration, and proliferation of $\mathrm{MSC} /$ pericytes in response to injury. Importantly, those studies would cut through the haze that clouds our current view of MSC/pericytes as their biological identity - in real time - would be laid bare in their native microenvironment without in vitro culture artifacts. That combination color mouse could be further bread with the diabetic Akita mouse or made diabetic by streptozocin induction to study the long-term effects of chronic diabetic inflammation in the retina. Further, MSC/pericytes harvested from those mice could be sorted by FACS for purification and further study, a link necessary to tie in vitro findings of cellular control and paracrine modulation more strongly to the in vivo data. Those in vitro studies should include follow up on the paracrine secretome data presented in this thesis, so as to focus our understanding on key signals responsible for endothelial influence. The role of IGF-1 in particular is intriguing, as it is produced in abundance by $\mathrm{ASCs}^{213}$ and has been implicated in the pathophysiology of ROP. ${ }^{214}$

Considering the later two questions regarding the impact of diabetes on intracellular stem cell control and extracellular response, respectively, one reasonable synthetic hypothesis might address these questions. If MSC/pericytes prove to be central orchestrating cells that respond to injury and inflammation, exerting their anti-inflammatory, anti-apoptotic, angiogenic, and pro-differentiation influence on the surrounding tissues, then DR must develop only after those central orchestrating MSC/pericytes are either dead or ineffective. How, specifically, MSC/pericytes become impotent 
remains elusive. The theories that surround this question generally fall into two mechanistic linkages:

1. Diabetes degrades pericytes directly, rendering them ineffective.

2. Diabetes degrades pericytes indirectly; the severity and extended time course of chronic diabetes eventually exhausts their natural wound-healing ability.

Considering the original Cogan papers detailing pericyte pathology preceding DR, even prior to generation of "capillary ghosts," it is not unreasonable to suggest that hyperglycemia impacts pericytes irrespective of its effects on endothelial cells. ${ }^{64,65}$ Like endothelial cells, pericytes are also prone to chronic hyperglycemia-induced oxidative damage. ${ }^{215}$ Our own data suggest that murine ASCs, when harvested from diabetic mice but maintained in the same normoglycemic media alongside "healthy" murine ASCs, still demonstrate impaired endothelial stabilization capacity and altered secretomes. In fact, our data shows that while diabetic ASCs can function normally metabolically, their secretome remains altered, perhaps reflecting a diabetic cellular memory of sorts. The concept of hyperglycemic memory is not new. Microvascular alterations induced by 2.5 years of hyperglycemia in dogs are maintained - most strikingly in the retina -2.5 years following a return to normoglycemia. ${ }^{16,216}$ Epigenetic modifications of MSC/pericytes subjected to chronic hyperglycemia would serve as one mechanism to imprint the cells with a cellular memory. 
Contributing to the hypothesis that diabetes' direct impairment of MSC/pericytes, some intriguing work in the central nervous system might explain one mechanism by which retinal MSC/pericytes lose their "stemness," effectively ceasing to become potent stem cells. A member of the University's faculty, Dr. Sarah E. Siegrist, has discovered that neuronal stem cells require constitutive insulin signaling to maintain their "stemness."217 These studies investigated the role of foxo and reaper, two genes required in drosophila for neuroblast transition to quiescence at the conclusion of central nervous system embryogenesis. Here data suggests that a decrease in insulin signaling causes an increase in nuclear Foxo protein localization, which effectively halts the asymmetric cell division required to produce daughter cells that maintain the stem cell niche for their mother neuroblast. Thus, when insulin is removed, the stem cells lose their "stemness" and terminally differentiate, effectively exhausting their abilities as stem cells. It may very well be that MSCs in the retina require insulin signaling to remain potent stem cells. Perhaps the signaling culprit of diabetes is not only hyperglycemia, but also chronic hypoinsulinemia, representing a failure to maintain the requisite stem cell nice in the retina. Observationally, the implications of this data align closely with the clinical time course often seen in type 2 diabetic patients, in which retinopathy worsens after decades when the pancreas halts insulin production.

Or perhaps a more indirect mechanism links diabetes to $\mathrm{MSC} /$ pericyte decline. The coordinated stem cell repair mechanism in the retina may only be equipped to confront inflammation of a given severity for so long before acquiescing to the fibrotic response that is common in chronic inflammatory situations throughout the human body. 
Inflammation that is sufficiently severe, such as a third degree burn, typically results in a fibrotic response. Additionally, chronic inflammation produces fibrosis in nearly every organ system of the body, including calluses in the skin from persistant irritation, granulomas in the lungs from difficult-to-clear mycobacteria, and end-stage renal or hepatic failure from drug chronic drug toxicity. The retina is no exception, producing epiretinal membranes in response to decades of microvascular dysfunction and resultant retinal hypoxia. Supplementing the acute studies of MSC/pericyte response to acute injury with chronic studies of diabetes' impact on retinal MSC/pericytes could be fruitful, with specific attention paid to the intermediate contribution of sorbitol, AGEs, and reactive oxidative species. Correlating MSC/pericyte density with those intermediate products as well as microvascular phenotype over time would be informative.

Of course, as is often the case in biology, the mechanistic link between diabetes and retinal MSC/pericyte dysfunction could be a combination of both direct and indirect insult. Whether by direct or indirect means - or a combination - we do know that the retinal MSC/pericytes become dysfunctional over time. We must, therefore, track down the molecular progression that occurs within MSC/pericytes over time when exposed to hyperglycemic inflammation. The role of non-coding RNAs is particularly enticing, given their previous demonstrable ability to influence stem cell differentiation epigenetically, ${ }^{218}$ alter angiogenesis, ${ }^{219}$ and respond to diabetes. ${ }^{220}$ 


\section{Concluding Remarks}

Upon further consideration, it is not surprising that DR indeed often takes multiple decades to develop, given the very high densities of MSC/pericytes found within the retinal microvasculature. That dense coverage may serve not only to help seal the blood retina barrier, but also to endow the retina with unusually ample resources to hold inflammation at bay, perhaps due to the importance of the visual system to the Darwininan fitness of an organism. But Darwin has not been afforded the opportunity to hone our cellular armory against chronic inflammation whilst we consume a Western diet rich in diabetogenic carbohydrates and refined sugars. The retina was not designed to endure chronic diabetic microvascular damage at all, let alone multiple decades of it.

Since Cogan's original papers, ophthalmologists have understood the importance of retinal pericyte dysfunction to the progression of DR. But pericyte dropout in the later decades of life from chronic hyperglycemia is not merely the loss of one particular cell type. Rather, pericyte dropout represents a stem cell failure. It is inconceivable that no microvascular stem cells exist in the retina, actively maintaining its microvascular architecture and perfusion. The retina, a highly metabolically active tissue that is constantly bombarded by ultraviolet radiation, might in fact require more aggressive regenerative capacity than other tissues, especially as it is so very necessary for the function of an organism. Consequently, DR is efficiently devastating, robbing the retina of its requisite microvascular regenerative capacity. It is incumbent upon us to ascertain 
precisely how the microvascular regeneration machinery of the retina fails over time, threatening the vision of so many millions of patients. 
Chapter 6

Literature Cited 
1. Danaei, G., et al., National, regional, and global trends in fasting plasma glucose and diabetes prevalence since 1980: systematic analysis of health examination surveys and epidemiological studies with 370 country-years and 2.7 million participants. Lancet, 2011. 378(9785): p. 31-40.

2. Ashcroft, F.M. and P. Rorsman, Diabetes mellitus and the beta cell: the last ten years. Cell, 2012. 148(6): p. 1160-71.

3. Wild, S., et al., Global prevalence of diabetes: estimates for the year 2000 and projections for 2030. Diabetes Care, 2004. 27(5): p. 1047-53.

4. Al-Rubeaan, K., Type 2 diabetes mellitus red zone. International Journal of Diabetes Mellitus, 2010. 2(1): p. 1-2.

5. Wong, T., Yau J, Rogers S, Kawasaki R, Lamoureux EL, Meta-Eye Group, Kowalski J, Global Prevalence of Diabetic Retinopathy: Pooled Data from Population Studies from the United States, Australia, Europe and Asia, in Association for Research in Vision and Ophthalmology Annual Meeting. 2011: Ft. Lauderdale, FL, USA.

6. Cheung, N., P. Mitchell, and T.Y. Wong, Diabetic retinopathy. Lancet, 2010. 376(9735): p. 124-36.

7. Saaddine, J.B., et al., Projection of diabetic retinopathy and other major eye diseases among people with diabetes mellitus: United States, 2005-2050. Archives of Ophthalmology, 2008. 126(12): p. 1740-7.

8. Antonetti, D.A., et al., Diabetic retinopathy: seeing beyond glucose-induced microvascular disease. Diabetes, 2006. 55(9): p. 2401-11.

9. Nathan, D.M., et al., Modern-day clinical course of type 1 diabetes mellitus after 30 years' duration: the diabetes control and complications trial/epidemiology of diabetes interventions and complications and Pittsburgh epidemiology of diabetes complications experience (1983-2005). Arch Intern Med, 2009. 169(14): p. 1307-16.

10. Dorrell, M.I., E. Aguilar, and M. Friedlander, Retinal vascular development is mediated by endothelial filopodia, a preexisting astrocytic template and specific R-cadherin adhesion. Invest Ophthalmol Vis Sci, 2002. 43(11): p. 3500-10.

11. Otani, A., et al., Bone marrow-derived stem cells target retinal astrocytes and can promote or inhibit retinal angiogenesis. Nat Med, 2002. 8(9): p. 1004-10.

12. Smith, L.E.H., Pathogenesis of retinopathy of prematurity. Growth Hormone \& Igf Research, 2004. 14 Suppl A: p. S140-4.

13. Aiello, L.M., Perspectives on diabetic retinopathy. Am J Ophthalmol, 2003. 136(1): p. 122-35.

14. Hammes, H.P., et al., Pericytes and the pathogenesis of diabetic retinopathy. Diabetes, 2002. 51(10): p. 3107-12.

15. Mizutani, M., T.S. Kern, and M. Lorenzi, Accelerated death of retinal microvascular cells in human and experimental diabetic retinopathy. J Clin Invest, 1996. 97(12): p. 2883-90.

16. Brownlee, M., Biochemistry and molecular cell biology of diabetic complications. Nature, 2001. 414(6865): p. 813-20. 
17. Stitt, A.W., et al., Advanced glycation end products (AGEs) co-localize with AGE receptors in the retinal vasculature of diabetic and of AGE-infused rats. Am J Pathol, 1997. 150(2): p. 523-31.

18. Lander, H.M., et al., Activation of the receptor for advanced glycation end products triggers a p21(ras)-dependent mitogen-activated protein kinase pathway regulated by oxidant stress. J Biol Chem, 1997. 272(28): p. 17810-4.

19. Williamson, J.R., et al., Hyperglycemic pseudohypoxia and diabetic complications. Diabetes, 1993. 42(6): p. 801-13.

20. Kolm-Litty, V., et al., High glucose-induced transforming growth factor beta1 production is mediated by the hexosamine pathway in porcine glomerular mesangial cells. J Clin Invest, 1998. 101(1): p. 160-9.

21. Romeo, G., et al., Activation of nuclear factor-kappaB induced by diabetes and high glucose regulates a proapoptotic program in retinal pericytes. Diabetes, 2002. 51(7): p. 2241-8.

22. Armulik, A., et al., Pericytes regulate the blood-brain barrier. Nature, 2010. 468(7323): p. 557-61.

23. Jechlinger, M., et al., Autocrine PDGFR signaling promotes mammary cancer metastasis. J Clin Invest, 2006. 116(6): p. 1561-70.

24. Chen, C.W., et al., Perivascular multi-lineage progenitor cells in human organs: regenerative units, cytokine sources or both? Cytokine Growth Factor Rev, 2009. 20(5-6): p. 429-34.

25. Klaassen, I., C.J. Van Noorden, and R.O. Schlingemann, Molecular basis of the inner blood-retinal barrier and its breakdown in diabetic macular edema and other pathological conditions. Progress in Retinal \& Eye Research, 2013. 34: p. 19-48.

26. Perdiguero, E.G., et al., Alteration of developmental and pathological retinal angiogenesis in angptl4-deficient mice. J Biol Chem, 2011. 286(42): p. 3684151.

27. Daneman, R., et al., Pericytes are required for blood-brain barrier integrity during embryogenesis. Nature, 2010. 468(7323): p. 562-6.

28. Armulik, A., G. Genove, and C. Betsholtz, Pericytes: developmental, physiological, and pathological perspectives, problems, and promises. Dev Cell, 2011. 21(2): p. 193-215.

29. Rouget, C., Memoire sur le developpement, la structures et les proprietes des capillaires sanguins et lymphatiques. Archs Physiol Norm Pathol, 1873. 5: p. 603-633.

30. Eberth, C.J., Handbuch der Lehre von der Gewegen des Menschen und der Tiere. 1871. 1.

31. Zimmermann, K., Der feinere bau der blutcapillares. Anat. Entwicklungsgesch, 1923. 68: p. 3-109.

32. Sims, D.E., The pericyte--a review. Tissue Cell, 1986. 18(2): p. 153-74.

33. Armulik, A., A. Abramsson, and C. Betsholtz, Endothelial/pericyte interactions. Circ Res, 2005. 97(6): p. 512-23.

34. Gaengel, K., et al., Endothelial-mural cell signaling in vascular development and angiogenesis. Arterioscler Thromb Vasc Biol, 2009. 29(5): p. 630-8. 
35. Stratman, A.N., et al., Pericyte recruitment during vasculogenic tube assembly stimulates endothelial basement membrane matrix formation. Blood, 2009. 114(24): p. 5091-101.

36. Stratman, A.N., et al., Endothelial-derived PDGF-BB and HB-EGF coordinately regulate pericyte recruitment during vasculogenic tube assembly and stabilization. Blood, 2010. 116(22): p. 4720-30.

37. Larson, D.M., M.P. Carson, and C.C. Haudenschild, Junctional transfer of small molecules in cultured bovine brain microvascular endothelial cells and pericytes. Microvasc Res, 1987. 34(2): p. 184-99.

38. Diaz-Flores, L., et al., Pericytes. Morphofunction, interactions and pathology in a quiescent and activated mesenchymal cell niche. Histol Histopathol, 2009. 24(7): p. 909-69.

39. Guillemin, G.J. and B.J. Brew, Microglia, macrophages, perivascular macrophages, and pericytes: a review of function and identification. J Leukoc Biol, 2004. 75(3): p. 388-97.

40. Hamzah, J., et al., Vascular normalization in Rgs5-deficient tumours promotes immune destruction. Nature, 2008. 453(7193): p. 410-4.

41. Mendel, T.A., et al., Pericytes derived from adipose-derived stem cells protect against retinal vasculopathy. PLoS One, 2013. 8(5): p. e65691.

42. Crisan, M., et al., Perivascular multipotent progenitor cells in human organs. Ann N Y Acad Sci, 2008. 1176: p. 118-23.

43. Mathiisen, T.M., et al., The perivascular astroglial sheath provides a complete covering of the brain microvessels: an electron microscopic 3D reconstruction. Glia, 2010. 58(9): p. 1094-103.

44. Shepro, D. and N.M. Morel, Pericyte physiology. FASEB J, 1993. 7(11): p. 10318.

45. Tilton, R.G., C. Kilo, and J.R. Williamson, Pericyte-endothelial relationships in cardiac and skeletal muscle capillaries. Microvasc Res, 1979. 18(3): p. 325-35.

46. Clark, E.R. and E.L. Clark, A. The development of adventitial (Rouget) cells on the blood capillaries of amphibian larvae. American Journal of Anatomy, 1925. 35(2): p. 239-264.

47. Drake, C.J., J.E. Hungerford, and C.D. Little, Morphogenesis of the first blood vessels. Ann N Y Acad Sci, 1998. 857: p. 155-79.

48. Majesky, M.W., Developmental basis of vascular smooth muscle diversity. Arterioscler Thromb Vasc Biol, 2007. 27(6): p. 1248-58.

49. Majesky, M.W., et al., Vascular smooth muscle progenitor cells: building and repairing blood vessels. Circ Res, 2011. 108(3): p. 365-77.

50. Bergwerff, M., et al., Neural crest cell contribution to the developing circulatory system: implications for vascular morphology? Circ Res, 1998. 82(2): p. 22131.

51. Etchevers, H.C., et al., The cephalic neural crest provides pericytes and smooth muscle cells to all blood vessels of the face and forebrain. Development, 2001. 128(7): p. 1059-68. 
52. Asahina, K., et al., Septum transversum-derived mesothelium gives rise to hepatic stellate cells and perivascular mesenchymal cells in developing mouse liver. Hepatology, 2011. 53(3): p. 983-95.

53. Que, J., et al., Mesothelium contributes to vascular smooth muscle and mesenchyme during lung development. Proc Natl Acad Sci U S A, 2008. 105(43): p. 16626-30.

54. Wilm, B., et al., The serosal mesothelium is a major source of smooth muscle cells of the gut vasculature. Development, 2005. 132(23): p. 5317-28.

55. Lindahl, P., et al., Paracrine PDGF-B/PDGF-Rbeta signaling controls mesangial cell development in kidney glomeruli. Development, 1998. 125(17): p. 331322.

56. Andrae, J., R. Gallini, and C. Betsholtz, Role of platelet-derived growth factors in physiology and medicine. Genes Dev, 2008. 22(10): p. 1276-312.

57. Lindahl, P., et al., Pericyte loss and microaneurysm formation in PDGF-Bdeficient mice. Science, 1997. 277(5323): p. 242-5.

58. Soriano, P., Abnormal kidney development and hematological disorders in PDGF beta-receptor mutant mice. Genes Dev, 1994. 8(16): p. 1888-96.

59. Goumans, M.J., et al., Activin receptor-like kinase (ALK)1 is an antagonistic mediator of lateral TGFbeta/ALK5 signaling. Mol Cell, 2003. 12(4): p. 817-28.

60. Oh, S.P., et al., Activin receptor-like kinase 1 modulates transforming growth factor-beta 1 signaling in the regulation of angiogenesis. Proc Natl Acad Sci U S A, 2000. 97(6): p. 2626-31.

61. Papetti, M., et al., FGF-2 antagonizes the TGF-beta1-mediated induction of pericyte alpha-smooth muscle actin expression: a role for myf-5 and Smadmediated signaling pathways. Invest Ophthalmol Vis Sci, 2003. 44(11): p. 4994-5005.

62. Sieczkiewicz, G.J. and I.M. Herman, TGF-beta 1 signaling controls retinal pericyte contractile protein expression. Microvasc Res, 2003. 66(3): p. 190-6.

63. Dulmovits, B.M. and I.M. Herman, Microvascular remodeling and wound healing: a role for pericytes. Int J Biochem Cell Biol, 2012. 44(11): p. 1800-12.

64. Cogan, D.G. and T. Kuwabara, CAPILLARY SHUNTS IN THE PATHOGENESIS OF DIABETIC RETINOPATHY. Diabetes, 1963. 12: p. 293-300.

65. Cogan, D.G., D. Toussaint, and T. Kuwabara, Retinal vascular patterns. IV. Diabetic retinopathy. Archives of Ophthalmology, 1961. 66: p. 366-78.

66. Kuwabara, T. and D.G. Cogan, Retinal vascular patterns. VI. Mural cells of the retinal capillaries. Arch Ophthalmol, 1963. 69: p. 492-502.

67. Kuwabara, T. and D.G. Cogan, GLYCOGEN IN THE RETINA. Ann Histochim, 1963. 8: p. 223-8.

68. Simpson, D.A., et al., Expression of the VEGF gene family during retinal vasoobliteration and hypoxia. Biochem Biophys Res Commun, 1999. 262(2): p. 333-40.

69. Rodrigues, M., et al., VEGF secreted by hypoxic Muller cells induces MMP-2 expression and activity in endothelial cells to promote retinal neovascularization in proliferative diabetic retinopathy. Diabetes, 2013. 62(11): p. 3863-73. 
70. Aiello, L.P., et al., Vascular endothelial growth factor in ocular fluid of patients with diabetic retinopathy and other retinal disorders. N Engl J Med, 1994. 331(22): p. 1480-7.

71. Focal photocoagulation treatment of diabetic macular edema. Relationship of treatment effect to fluorescein angiographic and other retinal characteristics at baseline: ETDRS report no. 19. Early Treatment Diabetic Retinopathy Study Research Group. Arch Ophthalmol, 1995. 113(9): p. 1144-55.

72. Photocoagulation treatment of proliferative diabetic retinopathy. Clinical application of Diabetic Retinopathy Study (DRS) findings, DRS Report Number 8. The Diabetic Retinopathy Study Research Group. Ophthalmology, 1981. 88(7): p. 583-600.

73. Mohamed, Q., M.C. Gillies, and T.Y. Wong, Management of diabetic retinopathy: a systematic review. JAMA, 2007. 298(8): p. 902-16.

74. Ranibizumab and Bevacizumab for Neovascular Age-Related Macular Degeneration. New England Journal of Medicine, 2011. 364(20): p. 18971908.

75. Rosenfeld, P.J., et al., Ranibizumab for neovascular age-related macular degeneration.[see comment]. New England Journal of Medicine, 2006. 355(14): p. 1419-31.

76. Brown, D.M., et al., Ranibizumab versus verteporfin for neovascular agerelated macular degeneration.[see comment]. New England Journal of Medicine, 2006. 355(14): p. 1432-44.

77. Tolentino, M., Systemic and ocular safety of intravitreal anti-VEGF therapies for ocular neovascular disease. Survey of Ophthalmology, 2011. 56(2): p. 95113.

78. Storkebaum, E., D. Lambrechts, and P. Carmeliet, VEGF: once regarded as a specific angiogenic factor, now implicated in neuroprotection. Bioessays, 2004. 26(9): p. 943-54.

79. Lee, S., et al., Autocrine VEGF signaling is required for vascular homeostasis. Cell, 2007. 130(4): p. 691-703.

80. Kamba, T., et al., VEGF-dependent plasticity of fenestrated capillaries in the normal adult microvasculature. Am J Physiol Heart Circ Physiol, 2006. 290(2): p. H560-76.

81. Baffert, F., et al., Cellular changes in normal blood capillaries undergoing regression after inhibition of VEGF signaling. Am J Physiol Heart Circ Physiol, 2006. 290(2): p. H547-59.

82. Curtis, L.H., et al., Risks of mortality, myocardial infarction, bleeding, and stroke associated with therapies for age-related macular degeneration. Arch Ophthalmol, 2010. 128(10): p. 1273-9.

83. Jager, R.D., W.F. Mieler, and J.W. Miller, Age-related macular degeneration. N Engl J Med, 2008. 358(24): p. 2606-17.

84. Whoriskey, P. and D. Keating, An effective eye drug is available for $\$ 50$. But many doctors chose a $\$ 2000$ alternative., in The Washington Post. 2013: Washington, DC. 
85. Ciulla, T.A., A.G. Amador, and B. Zinman, Diabetic retinopathy and diabetic macular edema: pathophysiology, screening, and novel therapies. Diabetes Care, 2003. 26(9): p. 2653-64.

86. Aiello, L.P., Angiogenic pathways in diabetic retinopathy. N Engl J Med, 2005. 353(8): p. 839-41.

87. Friedenstein, A.J., R.K. Chailakhjan, and K.S. Lalykina, The development of fibroblast colonies in monolayer cultures of guinea-pig bone marrow and spleen cells. Cell Tissue Kinet, 1970. 3(4): p. 393-403.

88. da Silva Meirelles, L., A.I. Caplan, and N.B. Nardi, In search of the in vivo identity of mesenchymal stem cells. Stem Cells, 2008. 26(9): p. 2287-99.

89. Phinney, D.G., Building a consensus regarding the nature and origin of mesenchymal stem cells. J Cell Biochem Suppl, 2002. 38: p. 7-12.

90. Kolf, C.M., E. Cho, and R.S. Tuan, Mesenchymal stromal cells. Biology of adult mesenchymal stem cells: regulation of niche, self-renewal and differentiation. Arthritis Res Ther, 2007. 9(1): p. 204.

91. Dominici, M., et al., Minimal criteria for defining multipotent mesenchymal stromal cells. The International Society for Cellular Therapy position statement. Cytotherapy, 2006. 8(4): p. 315-7.

92. Gimble, J. and F. Guilak, Adipose-derived adult stem cells: isolation, characterization, and differentiation potential. Cytotherapy, 2003. 5(5): p. 362-9.

93. Gimble, J.M., A.J. Katz, and B.A. Bunnell, Adipose-derived stem cells for regenerative medicine. Circ Res, 2007. 100(9): p. 1249-60.

94. Helder, M.N., et al., Stem cells from adipose tissue allow challenging new concepts for regenerative medicine. Tissue Eng, 2007. 13(8): p. 1799-808.

95. Schaffler, A. and C. Buchler, Concise review: adipose tissue-derived stromal cells--basic and clinical implications for novel cell-based therapies. Stem Cells, 2007. 25(4): p. 818-27.

96. Lin, G., et al., Defining stem and progenitor cells within adipose tissue. Stem Cells Dev, 2008. 17(6): p. 1053-63.

97. Takahashi, K. and S. Yamanaka, Induction of pluripotent stem cells from mouse embryonic and adult fibroblast cultures by defined factors. Cell, 2006. 126(4): p. 663-76.

98. Housman, T.S., et al., The safety of liposuction: results of a national survey. Dermatol Surg, 2002. 28(11): p. 971-8.

99. Strem, B.M., et al., Multipotential differentiation of adipose tissue-derived stem cells. Keio J Med, 2005. 54(3): p. 132-41.

100. Wagner, W., et al., Aging and Replicative Senescence Have Related Effects on Human Stem and Progenitor Cells. PLoS One, 2009. 4(6): p. e5846.

101. Murphy, M.B., K. Moncivais, and A.I. Caplan, Mesenchymal stem cells: environmentally responsive therapeutics for regenerative medicine. Exp Mol Med, 2013. 45(45): p. e54.

102. Caplan, A.I. and D. Correa, The MSC: an injury drugstore. Cell Stem Cell, 2011. 9(1): p. 11-5. 
103. Singer, N.G. and A.I. Caplan, Mesenchymal stem cells: mechanisms of inflammation. Annu Rev Pathol, 2011. 6: p. 457-78.

104. Groh, M.E., et al., Human mesenchymal stem cells require monocyte-mediated activation to suppress alloreactive T cells. Exp Hematol, 2005. 33(8): p. 92834.

105. Lanz, T.V., et al., Mouse mesenchymal stem cells suppress antigen-specific TH cell immunity independent of indoleamine 2,3-dioxygenase 1 (IDO1). Stem Cells Dev, 2010. 19(5): p. 657-68.

106. Karlsson, H., et al., Mesenchymal stem cells exert differential effects on alloantigen and virus-specific T-cell responses. Blood, 2008. 112(3): p. 532-41.

107. Augello, A., et al., Bone marrow mesenchymal progenitor cells inhibit lymphocyte proliferation by activation of the programmed death 1 pathway. Eur J Immunol, 2005. 35(5): p. 1482-90.

108. Aggarwal, S. and M.F. Pittenger, Human mesenchymal stem cells modulate allogeneic immune cell responses. Blood, 2005. 105(4): p. 1815-22.

109. Parekkadan, B. and J.M. Milwid, Mesenchymal stem cells as therapeutics. Annu Rev Biomed Eng, 2010. 12: p. 87-117.

110. Tidball, J.G. and S.A. Villalta, Regulatory interactions between muscle and the immune system during muscle regeneration. Am J Physiol Regul Integr Comp Physiol, 2010. 298(5): p. R1173-87.

111. Ezquer, F., et al., The antidiabetic effect of mesenchymal stem cells is unrelated to their transdifferentiation potential but to their capability to restore Th1/Th2 balance and to modify the pancreatic microenvironment. Stem Cells, 2012. 30(8): p. 1664-74.

112. Mokarram, N., et al., Effect of modulating macrophage phenotype on peripheral nerve repair. Biomaterials, 2012.33(34): p. 8793-801.

113. Wang, Y., et al., Ex vivo programmed macrophages ameliorate experimental chronic inflammatory renal disease. Kidney Int, 2007. 72(3): p. 290-9.

114. Sica, A., et al., Macrophage polarization in tumour progression. Semin Cancer Biol, 2008. 18(5): p. 349-55.

115. Li, N., et al., Prosaposin in the secretome of marrow stroma-derived neural progenitor cells protects neural cells from apoptotic death. J Neurochem, 2010. 112(6): p. 1527-38.

116. Cselenyak, A., et al., Mesenchymal stem cells rescue cardiomyoblasts from cell death in an in vitro ischemia model via direct cell-to-cell connections. BMC Cell Biol, 2010. 11(29): p. 29.

117. Mitsiades, C.S., et al., Activation of NF-kappaB and upregulation of intracellular anti-apoptotic proteins via the IGF-1/Akt signaling in human multiple myeloma cells: therapeutic implications. Oncogene, 2002. 21(37): p. 5673-83.

118. Hsiao, S.T., et al., Comparative analysis of paracrine factor expression in human adult mesenchymal stem cells derived from bone marrow, adipose, and dermal tissue. Stem Cells Dev, 2012. 21(12): p. 2189-203.

119. Rehman, J., et al., Secretion of angiogenic and antiapoptotic factors by human adipose stromal cells. Circulation, 2004. 109(10): p. 1292-8. 
120. Sorrell, J.M., M.A. Baber, and A.I. Caplan, Influence of adult mesenchymal stem cells on in vitro vascular formation. Tissue Eng Part A, 2009. 15(7): p. 175161.

121. Hirschi, K.K. and P.A. D'Amore, Pericytes in the microvasculature. Cardiovasc Res, 1996. 32(4): p. 687-98.

122. Sacchetti, B., et al., Self-renewing osteoprogenitors in bone marrow sinusoids can organize a hematopoietic microenvironment. Cell, 2007. 131(2): p. 32436.

123. Traktuev, D.0., et al., A population of multipotent CD34-positive adipose stromal cells share pericyte and mesenchymal surface markers, reside in a periendothelial location, and stabilize endothelial networks. Circ Res, 2008. 102(1): p. 77-85.

124. Campanholle, G., et al., Cellular mechanisms of tissue fibrosis. 3. Novel mechanisms of kidney fibrosis. Am J Physiol Cell Physiol, 2013. 304(7): p. C591-603.

125. Chen, Y.T., et al., Platelet-derived growth factor receptor signaling activates pericyte-myofibroblast transition in obstructive and post-ischemic kidney fibrosis. Kidney Int, 2011. 80(11): p. 1170-81.

126. Stefanska, A., B. Peault, and J.J. Mullins, Renal pericytes: multifunctional cells of the kidneys. Pflugers Arch, 2013. 465(6): p. 767-73.

127. Braun, J., et al., Concerted regulation of CD34 and CD105 accompanies mesenchymal stromal cell derivation from human adventitial stromal cell. Stem Cells Dev, 2013. 22(5): p. 815-27.

128. Corselli, M., et al., The tunica adventitia of human arteries and veins as a source of mesenchymal stem cells. Stem Cells Dev, 2012. 21(8): p. 1299-308.

129. Suga, H., et al., Functional implications of CD34 expression in human adiposederived stem/progenitor cells. Stem Cells Dev, 2009. 18(8): p. 1201-10.

130. Zimmerlin, L., et al., Mesenchymal markers on human adipose stem/progenitor cells. Cytometry A, 2013. 83(1): p. 134-40.

131. Diaz-Romero, J., et al., Immunophenotypic analysis of human articular chondrocytes: changes in surface markers associated with cell expansion in monolayer culture. J Cell Physiol, 2005. 202(3): p. 731-42.

132. Barbero, A., et al., Plasticity of clonal populations of dedifferentiated adult human articular chondrocytes. Arthritis Rheum, 2003. 48(5): p. 1315-25.

133. Tallheden, T., et al., Phenotypic plasticity of human articular chondrocytes. J Bone Joint Surg Am, 2003. 85-A Suppl 2: p. 93-100.

134. "stem cells" AND eye. 2013; Available from: www.clinicaltrials.gov.

135. Huang, Y., V. Enzmann, and S.T. Ildstad, Stem cell-based therapeutic applications in retinal degenerative diseases. Stem Cell Rev, 2011. 7(2): p. 434-45.

136. Marchetti, V., et al., Stemming vision loss with stem cells. J Clin Invest, 2010. 120(9): p. 3012-21.

137. Otani, A., et al., Rescue of retinal degeneration by intravitreally injected adult bone marrow-derived lineage-negative hematopoietic stem cells. J Clin Invest, 2004. 114(6): p. 765-74. 
138. Ritter, M.R., et al., Myeloid progenitors differentiate into microglia and promote vascular repair in a model of ischemic retinopathy. J Clin Invest, 2006. 116(12): p. 3266-76.

139. Grant, M.B., et al., Adult hematopoietic stem cells provide functional hemangioblast activity during retinal neovascularization. Nat Med, 2002. 8(6): p. 607-12.

140. Chan-Ling, T., et al., Hematopoietic stem cells provide repair functions after laser-induced Bruch's membrane rupture model of choroidal neovascularization. Am J Pathol, 2006. 168(3): p. 1031-44.

141. Sengupta, N., et al., The role of adult bone marrow-derived stem cells in choroidal neovascularization. Invest Ophthalmol Vis Sci, 2003. 44(11): p. 4908-13.

142. Shaw, L.C., M.B. Neu, and M.B. Grant, Cell-based therapies for diabetic retinopathy. Curr Diab Rep, 2011. 11(4): p. 265-74.

143. Loomans, C.J., et al., Endothelial progenitor cell dysfunction: a novel concept in the pathogenesis of vascular complications of type 1 diabetes. Diabetes, 2004. 53(1): p. 195-9.

144. Caballero, S., et al., Ischemic vascular damage can be repaired by healthy, but not diabetic, endothelial progenitor cells. Diabetes, 2007. 56(4): p. 960-7.

145. Tepper, O.M., et al., Human endothelial progenitor cells from type II diabetics exhibit impaired proliferation, adhesion, and incorporation into vascular structures. Circulation, 2002. 106(22): p. 2781-6.

146. Fadini, G.P., et al., Circulating endothelial progenitor cells are reduced in peripheral vascular complications of type 2 diabetes mellitus. J Am Coll Cardiol, 2005. 45(9): p. 1449-57.

147. Katz, A.J., et al., Cell surface and transcriptional characterization of human adipose-derived adherent stromal (hADAS) cells. Stem Cells, 2005. 23(3): p. 412-23.

148. Herman, I.M. and P.A. D'Amore, Microvascular pericytes contain muscle and nonmuscle actins. J Cell Biol, 1985. 101(1): p. 43-52.

149. Healy, A.M. and I.M. Herman, Preparation of fluorescent basic fibroblast growth factor: localization in living retinal microvascular endothelial cells. Experimental Eye Research, 1992. 55(5): p. 663-9.

150. Newcomb, P.M. and I.M. Herman, Pericyte growth and contractile phenotype: modulation by endothelial-synthesized matrix and comparison with aortic smooth muscle. J Cell Physiol, 1993. 155(2): p. 385-93.

151. Kutcher, M.E., et al., Pericyte Rho GTPase mediates both pericyte contractile phenotype and capillary endothelial growth state. Am J Pathol, 2007. 171(2): p. 693-701.

152. Kotecki, M., et al., Calpain- and talin-dependent control of microvascular pericyte contractility and cellular stiffness. Microvasc Res, 2010. 80(3): p. 339-48.

153. Lu, F., et al., Improvement of the survival of human autologous fat transplantation by using VEGF-transfected adipose-derived stem cells. Plast Reconstr Surg, 2009. 124(5): p. 1437-46. 
154. Lu, F., et al., Improved viability of random pattern skin flaps through the use of adipose-derived stem cells. Plast Reconstr Surg, 2008. 121(1): p. 50-8.

155. Huang, S.D., et al., Transplantation of angiogenin-overexpressing mesenchymal stem cells synergistically augments cardiac function in a porcine model of chronic ischemia. J Thorac Cardiovasc Surg, 2006. 132(6): p. 1329-38.

156. Gruh, I., et al., No evidence of transdifferentiation of human endothelial progenitor cells into cardiomyocytes after coculture with neonatal rat cardiomyocytes. Circulation, 2006. 113(10): p. 1326-34.

157. Hauger, O., et al., MR evaluation of the glomerular homing of magnetically labeled mesenchymal stem cells in a rat model of nephropathy. Radiology, 2006. 238(1): p. 200-10.

158. Cetrulo, C.L., Jr., et al., Stem cells and distraction osteogenesis: endothelial progenitor cells home to the ischemic generate in activation and consolidation. Plast Reconstr Surg, 2005. 116(4): p. 1053-64; discussion 1065-7.

159. Rakoczy, E.P., et al., Characterization of a mouse model of hyperglycemia and retinal neovascularization. Am J Pathol, 2010. 177(5): p. 2659-70.

160. Kenwood, B.M., et al., Identification of a novel mitochondrial uncoupler that does not depolarize the plasma membrane. Molecular Metabolism, (0).

161. Mario, S.P. Global Data on Visual Impairments. 2010; Available from: http://www.who.int/blindness/GLOBALDATAFINALforweb.pdf.

162. Chan-Ling, T., et al., Desmin ensheathment ratio as an indicator of vessel stability: evidence in normal development and in retinopathy of prematurity. Am J Pathol, 2004. 165(4): p. 1301-13.

163. Hughes, S., et al., Changes in pericytes and smooth muscle cells in the kitten model of retinopathy of prematurity: implications for plus disease. Invest Ophthalmol Vis Sci, 2007. 48(3): p. 1368-79.

164. Kicic, A., et al., Differentiation of marrow stromal cells into photoreceptors in the rat eye. J Neurosci, 2003. 23(21): p. 7742-9.

165. Kielczewski, J.L., et al., Insulin-like growth factor binding protein-3 mediates vascular repair by enhancing nitric oxide generation. Circ Res, 2009. 105(9): p. 897-905.

166. Zuk, P.A., et al., Multilineage cells from human adipose tissue: implications for cell-based therapies. Tissue Eng, 2001. 7(2): p. 211-28.

167. Ding, L., et al., Endothelial and perivascular cells maintain haematopoietic stem cells. Nature, 2012. 481(7382): p. 457-62.

168. Smith, L.E., et al., Oxygen-induced retinopathy in the mouse. Invest Ophthalmol Vis Sci, 1994. 35(1): p. 101-11.

169. Amos, P.J., et al., IFATS Series: The Role of Human Adipose-Derived Stromal Cells in Inflammatory Microvascular Remodeling and Evidence of a Perivascular Phenotype. Stem Cells, 2008.

170. McVicar, C.M., et al., Intervention with an erythropoietin-derived peptide protects against neuroglial and vascular degeneration during diabetic retinopathy. Diabetes, 2011. 60(11): p. 2995-3005. 
171. Al-Shabrawey, M., et al., Increased expression and activity of 12-lipoxygenase in oxygen-induced ischemic retinopathy and proliferative diabetic retinopathy: implications in retinal neovascularization. Diabetes, 2011. 60(2): p. 614-24.

172. Stitt, A.W., et al., Impaired retinal angiogenesis in diabetes: role of advanced glycation end products and galectin-3. Diabetes, 2005. 54(3): p. 785-94.

173. Zhang, S.X., et al., Genetic difference in susceptibility to the blood-retina barrier breakdown in diabetes and oxygen-induced retinopathy. Am J Pathol, 2005. 166(1): p. 313-21.

174. Hou, D., et al., Radiolabeled cell distribution after intramyocardial, intracoronary, and interstitial retrograde coronary venous delivery: implications for current clinical trials. Circulation, 2005. 112(9 Suppl): p. I150-6.

175. MacIsaac, Z.M., et al., Long-term in-vivo tumorigenic assessment of human culture-expanded adipose stromal/stem cells. Exp Cell Res, 2012. 318(4): p. 416-23.

176. Chan, R.K., et al., Side population hematopoietic stem cells promote wound healing in diabetic mice. Plast Reconstr Surg, 2007. 120(2): p. 407-11; discussion 412-3.

177. Cheng, L.N., et al., Transplanted neural stem cells promote nerve regeneration in acute peripheral nerve traction injury: assessment using MRI. AJR Am J Roentgenol, 2011. 196(6): p. 1381-7.

178. Kendirci, M., et al., Transplantation of nonhematopoietic adult bone marrow stem/progenitor cells isolated by $p 75$ nerve growth factor receptor into the penis rescues erectile function in a rat model of cavernous nerve injury. J Urol, 2010. 184(4): p. 1560-6.

179. Aoki, H., et al., Transplantation of cells from eye-like structures differentiated from embryonic stem cells in vitro and in vivo regeneration of retinal ganglionlike cells. Graefes Arch Clin Exp Ophthalmol, 2008. 246(2): p. 255-65.

180. Zhang, B., Y. Hu, and J.X. Ma, Anti-inflammatory and antioxidant effects of SERPINA3K in the retina. Invest Ophthalmol Vis Sci, 2009. 50(8): p. 3943-52.

181. Walshe, T.E., et al., TGF-beta is required for vascular barrier function, endothelial survival and homeostasis of the adult microvasculature. PLoS One, 2009. 4(4): p. e5149.

182. Orlidge, A. and P.A. D'Amore, Inhibition of capillary endothelial cell growth by pericytes and smooth muscle cells. J Cell Biol, 1987. 105(3): p. 1455-62.

183. Sato, Y. and D.B. Rifkin, Inhibition of endothelial cell movement by pericytes and smooth muscle cells: activation of a latent transforming growth factorbeta 1-like molecule by plasmin during co-culture. J Cell Biol, 1989. 109(1): p. 309-15.

184. Heidary, G., D. Vanderveen, and L.E. Smith, Retinopathy of prematurity: current concepts in molecular pathogenesis. Semin Ophthalmol, 2009. 24(2): p. 77-81.

185. Zhang, H., et al., Adipocytes derived from human bone marrow mesenchymal stem cells exert inhibitory effects on osteoblastogenesis. Curr Mol Med, 2011. 11(6): p. 489-502. 
186. Leu, S., et al., Adipose-derived mesenchymal stem cells markedly attenuate brain infarct size and improve neurological function in rats. J Transl Med, 2010. 8(63): p. 63.

187. Zografou, A., et al., Autologous transplantation of adipose-derived stem cells enhances skin graft survival and wound healing in diabetic rats. Ann Plast Surg, 2013. 71(2): p. 225-32.

188. Fadini, G.P. and A. Avogaro, Diabetes impairs mobilization of stem cells for the treatment of cardiovascular disease: a meta-regression analysis. Int J Cardiol, 2013. 168(2): p. 892-7.

189. Keats, E.C. and Z.A. Khan, Vascular stem cells in diabetic complications: evidence for a role in the pathogenesis and the therapeutic promise. Cardiovasc Diabetol, 2012. 11(37): p. 37.

190. Cianfarani, F., et al., Diabetes impairs adipose tissue-derived stem cell function and efficiency in promoting wound healing. Wound Repair Regen, 2013. 21(4): p. 545-53.

191. Tamarat, R., et al., Impairment in ischemia-induced neovascularization in diabetes: bone marrow mononuclear cell dysfunction and therapeutic potential of placenta growth factor treatment. Am J Pathol, 2004. 164(2): p. 457-66.

192. Heng, L.Z., et al., Diabetic retinopathy: pathogenesis, clinical grading, management and future developments. Diabet Med, 2013. 30(6): p. 640-50.

193. Gardner, T.W., A.W. Eller, and T.R. Friberg, Reduction of severe macular edema in eyes with poor vision after panretinal photocoagulation for proliferative diabetic retinopathy. Graefes Arch Clin Exp Ophthalmol, 1991. 229(4): p. 3238.

194. Diago, T., et al., Ranibizumab combined with low-dose sorafenib for exudative age-related macular degeneration. Mayo Clinic Proceedings, 2008. 83(2): p. 231-4.

195. Han, Z., et al., Retinal angiogenesis in the Ins2(Akita) mouse model of diabetic retinopathy. Invest Ophthalmol Vis Sci, 2013. 54(1): p. 574-84.

196. Niu, J., et al., Prevention of actute allograft rejection in an orthotopic liver transplant model in rats by interleukin-10 engineered mesenchymal stem cells. Clin Exp Immunol, 2014. 15(10): p. 12283.

197. Jiang, W., et al., Intracarotid transplantation of autologous adipose-derived mesenchymal stem cells significantly improves neurological deficits in rats after MCAo. J Mater Sci Mater Med, 2014. 28: p. 28.

198. Elizabeth Rakoczy, P., et al., Mouse models of age-related macular degeneration. Experimental Eye Research, 2006. 82(5): p. 741-52.

199. Takakura, N., et al., A role for hematopoietic stem cells in promoting angiogenesis. Cell, 2000. 102(2): p. 199-209.

200. Ebrahimian, T.G., et al., Cell therapy based on adipose tissue-derived stromal cells promotes physiological and pathological wound healing. Arterioscler Thromb Vasc Biol, 2009. 29(4): p. 503-10.

201. Chen, L., et al., Paracrine factors of mesenchymal stem cells recruit macrophages and endothelial lineage cells and enhance wound healing. PLoS One, 2008. 3(4): p. e1886. 
202. Wu, Y., et al., Mesenchymal stem cells enhance wound healing through differentiation and angiogenesis. Stem Cells, 2007. 25(10): p. 2648-59.

203. Falanga, V., et al., Autologous bone marrow-derived cultured mesenchymal stem cells delivered in a fibrin spray accelerate healing in murine and human cutaneous wounds. Tissue Eng, 2007. 13(6): p. 1299-312.

204. Ho, J.C., et al., Reversal of endothelial progenitor cell dysfunction in patients with type 2 diabetes using a conditioned medium of human embryonic stem cell-derived endothelial cells. Diabetes Metab Res Rev, 2012. 28(5): p. 462-73.

205. Trudeau, K., A.J. Molina, and S. Roy, High glucose induces mitochondrial morphology and metabolic changes in retinal pericytes. Invest Ophthalmol Vis Sci, 2011. 52(12): p. 8657-64.

206. Kowluru, R.A., Q. Zhong, and M. Kanwar, Metabolic memory and diabetic retinopathy: role of inflammatory mediators in retinal pericytes. Experimental Eye Research, 2010. 90(5): p. 617-23.

207. Cooper, M.E. and A. El-Osta, Epigenetics: mechanisms and implications for diabetic complications. Circ Res, 2010. 107(12): p. 1403-13.

208. Ling, C. and L. Groop, Epigenetics: a molecular link between environmental factors and type 2 diabetes. Diabetes, 2009. 58(12): p. 2718-25.

209. Bell, R.D., et al., Pericytes control key neurovascular functions and neuronal phenotype in the adult brain and during brain aging. Neuron, 2010. 68(3): p. 409-27.

210. Hellstrom, M., et al., Lack of pericytes leads to endothelial hyperplasia and abnormal vascular morphogenesis. J Cell Biol, 2001. 153(3): p. 543-53.

211. Kim, W.S., B.S. Park, and J.H. Sung, The wound-healing and antioxidant effects of adipose-derived stem cells. Expert Opin Biol Ther, 2009. 9(7): p. 879-87.

212. Kilroy, G.E., et al., Cytokine profile of human adipose-derived stem cells: expression of angiogenic, hematopoietic, and pro-inflammatory factors. J Cell Physiol, 2007. 212(3): p. 702-9.

213. Razmkhah, M., et al., Expression profile of IL-8 and growth factors in breast cancer cells and adipose-derived stem cells (ASCs) isolated from breast carcinoma. Cell Immunol, 2010. 265(1): p. 80-5.

214. Ley, D., et al., Longitudinal infusion of a complex of insulin-like growth factor-I and IGF-binding protein-3 in five preterm infants: pharmacokinetics and shortterm safety. Pediatr Res, 2013. 73(1): p. 68-74.

215. Price, T.O., et al., Topiramate treatment protects blood-brain barrier pericytes from hyperglycemia-induced oxidative damage in diabetic mice. Endocrinology, 2012. 153(1): p. 362-72.

216. Engerman, R.L. and T.S. Kern, Progression of incipient diabetic retinopathy during good glycemic control. Diabetes, 1987. 36(7): p. 808-12.

217. Siegrist, S.E., et al., Inactivation of both Foxo and reaper promotes long-term adult neurogenesis in Drosophila. Curr Biol, 2010. 20(7): p. 643-8.

218. Katsushima, K. and Y. Kondo, Non-coding RNAs as epigenetic regulator of glioma stem-like cell differentiation. Front Genet, 2014. 5(14): p. 14.

219. Kane, N.M., et al., MicroRNAs as modulators of stem cells and angiogenesis. Stem Cells, 2014. 21(10). 
220. McClelland, A.D. and P. Kantharidis, microRNA in the development of diabetic complications. Clin Sci (Lond), 2014. 126(2): p. 95-110. 
Appendix A

\section{Pre-retinal Neovascular Quantification}

When investigating the OIR model, we interrogated multiple outputs of microvascular remodeling. In addition to measuring both the generation of central retinal avascular area and the standard revascularization within the plane of the retina, we also quantified preretinal neovascularization. Frustrated by variability reported in the literature by ocular sagittal cutting and random selection of slices for pre-retinal neovascular tuft quantification, we turned to a semi-automated method for quantifying the entire retinal area with the use of confocal microscopy and an ImageJ post-processing algorithm. Louis Smith directed me to Adreas Stahl, a former post-doc in her lab, who kindly shared his SWIFT_NV algorithm. For this procedure, C57 mice were run through 75\% oxygen from $\mathrm{P} 7$ to $\mathrm{P} 12$, harvesting at $\mathrm{P} 17$ as is the standard protocl for OIR. After flat mounting and lectin staining the retinas, a narrow pinhole of 1 Airy Unit was selected on the confocal microscope. Then the superficial vascular network was brought into the confocal focus plane. Fine focus was adjusted anteriorly, such that preretinal neovascularization was brought into focus with subsequent signal increase in the narrow axial resolution conferred by small pinhole. Montage images were collected and then subjected to semi-automated analysis by the SWIFT_NV algorithm, which applies a userdefined threshold to calculate the pixels of pre-retinal neovascularization per retina. In this way, combining the narrow confocal axial resolution centered on neovascularization 
with the automated ImageJ algorithm, the entire area of pre-retinal neovascularization was quantified and compared from eye to eye.

We anticipated that ASC injection into the vitreous at P12 would more readily stabilize the central avascular hypoxic retinal tissue than the contralateral PBS injected eyes, since revascularization in the plane of the retina was accelerated. Thus, we hypothesized that ASC injected eyes would demonstrate less P17 pre-retinal neovascularation than PBS injected controls, fitting with the translational picture that aims to reduce pre-retinal neovascularization. However, our results resoundingly demonstrated that ASC injected eyes displayed more pre-retinal neovascularization than contralateral PBS controls.

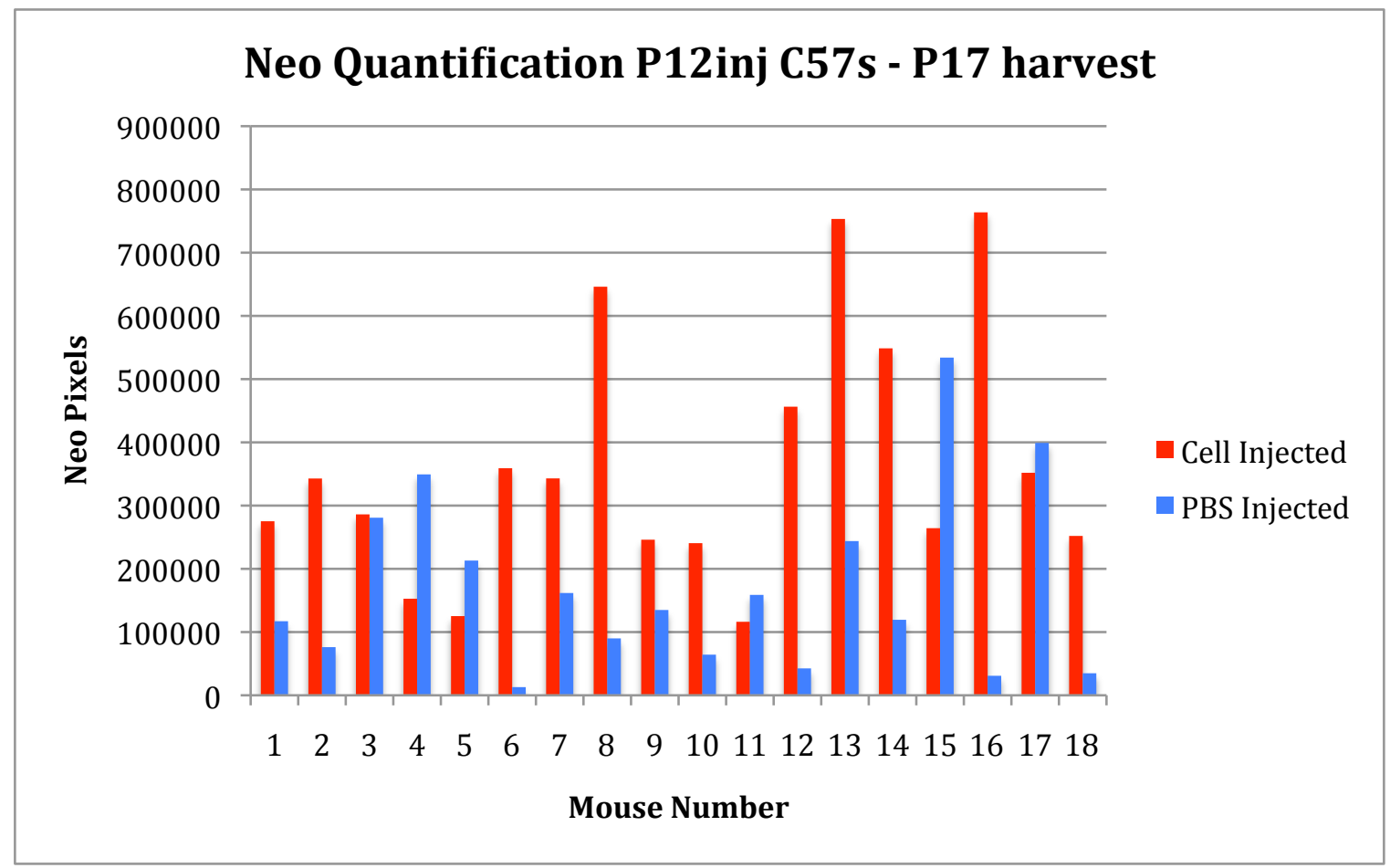

Comparing $\mathrm{L}$ and $\mathrm{R}$ eye of each mouse pup, the cell injected eye had 5.78 fold more neovascularization when compared to the contralateral control PBS eye on average. (2 tailed paired t-test $\mathrm{p}=0.01$ ). 
This result was certainly surprising, especially in it reproducibility. Only three mice out of 18 tested demonstrated less pre-retinal neovacularization in the ASC injected eyes compared to PBS injected controls. However, upon further consideration 